\title{
Geothermal Probabilistic Cost Study
}

Lowell H. Orren

G. Michael Ziman

Sue Campbell Jones

Tom K. Lee

Roger Noll

Louis Wilde

Venkatraman Sadanand

$$
\text { AI03-79ET } 37116
$$

August 1981

Prepared for

U.S. Department of Energy

Through an agreement with

National Aeronautics and Space Administration

by

Jet Propulsion Laboratory

California Institute of Technology

Pasadena, California 


\section{DISCLAIMER}

This report was prepared as an account of work sponsored by an agency of the United States Government. Neither the United States Government nor any agency Thereof, nor any of their employees, makes any warranty, express or implied, or assumes any legal liability or responsibility for the accuracy, completeness, or usefulness of any information, apparatus, product, or process disclosed, or represents that its use would not infringe privately owned rights. Reference herein to any specific commercial product, process, or service by trade name, trademark, manufacturer, or otherwise does not necessarily constitute or imply its endorsement, recommendation, or favoring by the United States Government or any agency thereof. The views and opinions of authors expressed herein do not necessarily state or reflect those of the United States Government or any agency thereof. 


\section{DISCLAIMER}

Portions of this document may be illegible in electronic image products. Images are produced from the best available original document. 
Prepared by the Jet Propulsion Laboratory, California Institute of Technology, for the U.S. Department of Energy through an agreement with the National Aeronautics and Space Administration.

This report was prepared as an account of work sponsored by the United States Government. Neither the United States nor the United States Department of Energy, nor any of their employees, nor any of their contractors, subcontractors, or their employees, makes any warranty, express or implied, or assumes any legal liability or responsibility for the accuracy, completeness or usefulness of any information, apparatus, product or process disclosed, or represents that its use would not infringe privately owned rights. 


\section{ACKNOWLEDGMENT}

Part One of this document was prepared by Lowell H. Orren, G. Michael Ziman, and Sue Campbe11 Jones of JPL. The Geothermal Probabilistic Cost Model was originally developed by Tom $\mathrm{K}$. Lee while he was at JPL and Katsuaki Teresawa of JPL. Part Two was prepared by Tom K. Lee of the University of California, San Diego, and Roger Noll, Venkatraman Sadanand, and Louis Wilde of California Institute of Technology.

Robert Lacy and James Nugent of San Diego Gas \& Electric, A. M. Cooper of Chevron, and William Livesay of Livesay Consultants were most generous with their time and provided valuable inputs.

Fred Abel managed this study for the U.S. Department of Energy. His insightful comments and suggestions improved the work in a number of ways. Inja Paik managed an earlier study for the U.S. Department of Energy in which the Geothermal Probabilistic Cost Study was originally developed.

The document was edited by Martha Martinez. The document was typed by Fran Mulvehill and Susan Elrod. 
CONTENTS

PAGE

PART ONE: INTRODUCTION

1. INTRODUCTION................................. 1-1

PART TWO: MODEL AND SITE STUDY

2. THE HEBER GEOTHERMAL RESERVOIR SITE STUDY............. 2-1

2.1 INTRODUCTION...............................

2.2 DATA DESCRIPTION.......................... 2-2

2.2.1 FINANCIAL VARIABLES.................. 2-3

2.2.2 TECHNICAL DESCRIPTION.................. 2-5

2.2.3 COST ACCOUNTS BY STAGE OF DEVELOPMENT......... 2-7

2.2.3.I DESCRIPTION OF COSTS IN

STAGE I: RESOURCE PROVING......... 2-7

2.2.3.2 DESCRIPTION OF COSTS IN

STAGE II: PERMIT PROCESS.......... 2-8

2.2.3.3 DESCRIPTION OF COSTS IN

STAGE III: DEVELOPING SITE RESOURCE... 2-8

2.2.3.4 DESCRIPTION OF COSTS IN

STAGE IV: OPERATING THE RESERVOIR.... 2-9

2.2.3.5 COSTS USED IN THE REFERENCE SCENARIO... 2-10

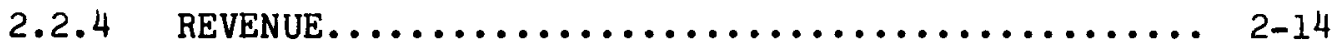

2.2.5 PROBABILISTIC ASSUMPTIONS............... 2-14

2.3 RESULTS OF THE BASE CASE.................... 2-18

2.3.1 PROFIT IN THE BASE CASE................ 2-18

2.3 .2 COST IN THE BASE CASE................. 2-18

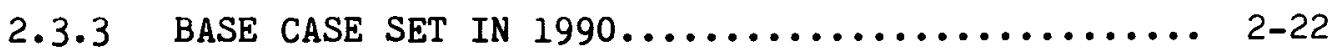

2.4 SENSITIVITY ANALYSIS OF THE BASE CASE............ 2-24 
2.4.1 SENSITIVITY TO ENERGY PRICE................ 2-24

2.4.2 SENSITIVITY TO DiSCOUNT RATE.............. 2-24

2.4.3 SENSITIVITY TO CAPACITY FACTOR............. 2-26

2.4.4 SENSITIVITY TO INVESTMENT TAX CREDIT.......... 2-26

2.4.5 SENSITIVITY TO ENERGY ESCALATION RATE......... 2-26

2.4.6 SENSITIVITY TO GENERAL INELATION RATE........ 2-26

2.4.7 SENSITIVITY TO WELL LIFE................. 2-27

2.4.8 SENSITIVITY TO CORRELATED EVENTS............ 2-27

3. THE GEOTHERMal PROBABILISTIC COST MODEL $\ldots \ldots \ldots \ldots \ldots \ldots \ldots \ldots, 3-1$

3.1 INTRODUCTION TO THE MODEL AND THE REFERENCE SCENARIO..... 3-1

3.2 REFERENCE SCENARIO FOR A GEOTHERMAL RESERVOIR......... $3-4$

3.2.1 STAGES OF GEOTHERMAL RESERVOIR DEVELOPMENT...... 3-8

3.2.1.1 STAGE I: PROVING THE RESOURCE....... 3-8

3.2.1.2 STAGE II: DEVELOPMENT PERMITS....... 3-12

3.2.1.3 STAGE III: RESERVOIR DEVELOPMENT..... 3-13

3.2.1.4 Stage IV: OPERATION............. 3-13

3.3 SOURCES OF UNCERTAINTY IN THE DEVELOPMENT

OF GEOTHERMAL RESOURCES $\ldots \ldots \ldots \ldots \ldots \ldots \ldots \ldots \ldots \ldots \ldots, 3-14$

3.3.1 WELLHEAD TEMPERATURE................... 3-17

3.3 .2 COST PER WELL AS A FUNCTION OF
WELL DEPTH AND ROCK TYPE................. $3-20$

3.3 .3 WELL FLOW RATES $. \ldots \ldots \ldots \ldots \ldots \ldots \ldots \ldots \ldots \ldots \ldots, 3-20$

3.3.4 OTHER SENSITIVE VARIABLES................ 3-25

3.4 GEOTHERMAL PROBABILISTIC COST MODEL.............. 3-27

3.4.1 INTRODUCTION TO PROBABILISTIC

3.4 .2 FORMAL MODEL........................ 3-33

3.4.2.1 THE METHODOLOGY: AN OVERVIEW........ 3-33

3.4.2.2 THE COMPUTER PROGRAM............. 3-35 
PART THREE: INSTITUTIONAL ASPECTS OF GEOTHERMAL DEVELOPMENT

4. LEASING, CONTRACTING, AND INSURANCE................ $4-1$

4.1 introduction............................. 4-1

4.2 LEASING............................... $4-3$

4.2.1 CHARACTERISTICS OF LEASING.............. 4-3

4.2.2 COMPETITIVE AND NONCOMPETITIVE FEDERAL
GEOTHERMAL RESOURCES LEASING PROCEDURES........ 4-8

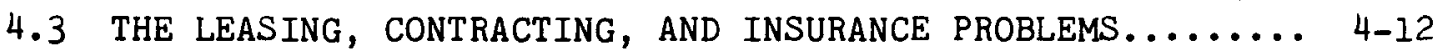

4.3.1 THE LEASING PROBLEM................... 4-12

4.3.1.1 REVENUES FROM LEASING OF FEDERALLY
OWNED GEOTHERMAL RESOURCE LANDS ...... 4-13

4.3.1.2 INFORMATION IN A PRE-LEASING
CONTEXT: THE NASH EQUILIBRIUM CASE.... 4-19

$\begin{array}{ll}4.3 .1 .3 & \text { INFORMATION IN A PRE-LEASING } \\ \text { CONTEXT: THE "STACKELBERG" CASE..... 4-24 }\end{array}$

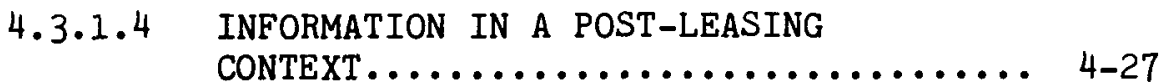

4.3.2 THE CONTRACTING PROBLEM................ 4-33

4.3 .3 THE INSURANCE PROBLEM................. 4-40

4.4. SUMMARY................................... $4-48$

APPENDICES

A. USERS GUIDE TO JPL GEOTHERMAL

PROBABILISTIC COST MODEL........................ A-I

B. CASH FLOW LEVELIZATION........................ B-I

C. A BRIEF SURVEY OF THE THEORY OF INSURANCE.............. c-1

\section{Figures}

2-1 Base Case Cumulative Distribution Function for Profit.......... 2-20

2-1 Correlated Events Cumulative Distribution Function for Profit..... 2-29

3-1 Expected Cost of a New Technology $\ldots \ldots \ldots \ldots \ldots \ldots \ldots \ldots \ldots \ldots \ldots \ldots . \ldots . \ldots$ 
3-2 Completion Time and Conditional Probability................. 3-5

3-3 Distribution of Geothermal Electric Costs.................. 3-7

3-4 Time-Lapse From Non-Competitive Lease.................... 3-10

3-5 Temperature/Depth Relations.......................... 3-18

3-6 Distribution of Temperature with Depth....................... 3-19

3-7 Effect of Depth on Drilling Cost...................... 3-21

3-8 Well Costs as a Function of Depth....................... 3-22

3-9 Effect of Depth on Production Rate...................... 3-23

3-10 Steam Production vs. Time........................... 3-24

3-11 Effect of Time of Start of Sales on Expected Present Worth........ 3-28

3-12a Negatively Correlated Events.......................... 3-31

$3-12 b$ Positively Correlated Events.......................... 3-31

3-13a Total Cost When Events Negatively Correlated.................. 3-32

3-13b Discrete Approximation of Continuous Events................ 3-32

3-14 Flow of Time-Dependent Cost Accounts in RCOST................ 3-42

4-1 Typical Bargaining Region........................... 4-37

4-2 Bargaining Region for Game......................... 4-38

Tables

2-1 Production Wells................................. 2-5

$2-2 \quad$ Injection Wells.................................... 2-6

2-3 Power Production and Consumption........................ 2-6

2-4a Costs Accounts: Stages I and II....................... 2-II

$2-4 b$ Costs Accounts: Stage III........................... 2-12

$2-4 c$ Cost Accounts: Stage IV............................ 2-13

2-5 Density Functions.................................. 2-15

2-6 Base Case Set Scenarios............................ 2-16

2-7 Probabilities in Base Case Set Scenarios.................. 2-17 
2-8 Profit in the Base Case Set.......................... 2-19

2-9 Cost in the Base Case Set........................... 2-21

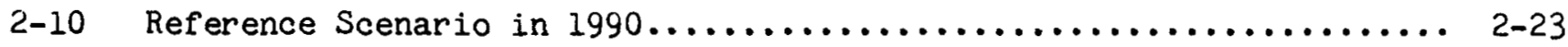

2-11 Present Value of Profits in 1990 Dollars................... 2-23

2-12 Sensitivity Results at Heber......................... 2-25

2-13 Flow Correlated to Stage I Probabilities.................... 2-27

3-1 Results of Sensitivity Analysis From Literature.............. 3-16

3-2 Capital Costs....................................... 3-26

3-3 Probability Limit for the Kolmogorov-Smirnov Theorem........... 3-47

4-1 Time to Obtain CPUC Certificate.......................... 4-16

$4-2$ Leasing Activities................................ 4-18

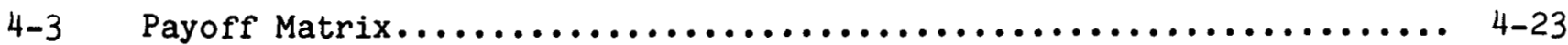

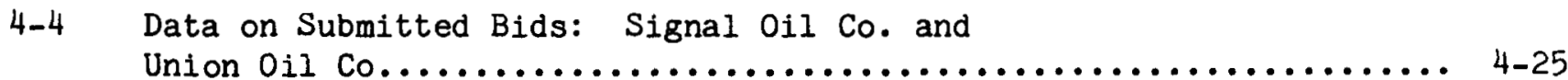

4-5 Data on Submitted Bids: Union Oil Co. and Phillips............ 4-25 
PART ONE

INTRODUCTION 
CHAPTER 1

INTRODUCTION

As its critics are quick to point out, geothermal energy does entail risk. There are risks resulting from unknowns in physical factors such as required well depth, fluid temperature, and flow rates, and there are risks resulting from unknowns in institutional factors such as length of permit procedures, negotiations for price between the energy producer and the energy user, and liability for faulty performance. To the investor these unknowns create uncertainty about the economic viability of the project.

In Part One of this study we present a tool to quantify the risks of geothermal projects, the Geothermal Probabilistic Cost Model (GPCM). The GPCM model is used to evaluate a geothermal reservoir for a binary-cycle electric plant at Heber, California. In Part Two we analyze three institutional aspects of the geothermal risk which can shift the risk among different agents. We examine the leasing of geothermal land, contracting between the producer and the user of the geothermal heat, and insurance against faulty performance.

\section{Part One}

The Heber Site Study is Chapter 2. The basic result is that under the assumptions and data used, a geothermal reservoir to supply heat for a 45-MW (net) binary-cycle plant at Heber, California, is an economically feasible project and would allow the reservoir developer to recover all his costs and earn a rate of return suitable for projects of this nature.

The GPCM is discussed in Chapter 3. The primary output of the GPCM is the distribution of key financial parameters such as profit, capital requirements, and cost. These distributions can be used to make a rational investment decision incorporating the investor's attitude toward risk. 
Two characteristics of the GPCM make it distinct from other probabilistic financial models. First, the GPCM does not merely solve for the mean and variance of the distributions of financial variables--it solves for the distributions themselves. This is important because many decision makers care about more than merely the first two moments of a distribution. Second, the GPCM can model cases where different uncertain events are not stochastically independent; that is, the GPCM does allow the outcome of an uncertain event to be infiuenced by the outcome of another uncertain event. Such correlations between different events is often reality, but cannot be modeled in the typical Monte-Carlo-type simulation model.

\section{Part Two}

Chapter 4 analyzes institutional questions in geothermal leasing, contracting between producer and user of geothermal resources, and insurance for geothermal. After an examination of current procedures of geothermal leasing, the paper examines the effect of information about the nature of the resource on bidding for leases. The contracting problem is examined in a game theory model which examines how contracting arrangements can create market structure barriers to the development of geothermal resources. The paper examines how insurance can spread the risk among different participants and examines the question of who should provide the insurance--government or private insurers. 
PART TWO

MODEL AND SITE STUDY 
CHAPTER 2

THE HEBER GEOTHERMAL RESERVOIR SITE STUDY

\section{$2.1 \quad$ INTRODUCTION}

The Geothermal Probabilistic Cost Model (GPCM) evaluated the economics of a geothermal reservoir at Heber, California, to provide geothermal fluid for a $45 \mathrm{MW}$ (net) binary-cycle electric generating plant. If such a commercial size binary facility could be successfully built at Heber, it would mean that many medium temperature geothermal sites could produce economical electricity. The proposed Heber Geothermal Project consists of the reservoir, binary-cycle plant, and a demonstration period.. The power plant and demonstration period would be a demonstration project to prove the binary technology, ${ }^{1}$ but the reservoir would be developed as a for-profit commercial venture. ${ }^{2}$ One conclusion of this study is that the reservoir portion of the Heber Geothermal Project seems to be economically viable, although the degree of profitability is sensitive to certain key parameters.

The Heber site was chosen for study using the GPCM model for two reasons: (1) the desire to study a binary site; and (2) extensive engineering evaluation has been done for the Heber Geothermal Project and much of the work has been made public. Although JPL contacted the major participants in the Heber Project, this study is based primarily on publicly available information.

1 The proposed participants in the funding of the generating plant are the U.S. Department of Energy, San Diego Gas and Electric Co., Imperial Irrigation District, Southern California Edison Co., California Department of Water Resources, Electric Power Research Institute, and others. The plant would be operated by SDG\&E.

2 The reservoir is a joint venture of Chevron Resources Co., Union Oil Co., and New Albion Resources (a subsidiary of SDG\&E). Chevron would develop and manage the reservoir. 
This study models the reservoir at Heber, but not the power plant. The difficulty with the power plant is that the relationship between costs and changes in physical parameters is not thoroughly understood. For the reservoir, the relationship between physical parameters such as well depth, flow rate, resource temperature, and cost is understood. ${ }^{3}$ with sufficient additional engineering relationships, or by ignoring physical uncertainties and considering only time uncertainties, the power plant could be modeled by the GPCM.

This study models a reservoir development at Heber with the same technical characteristics as the proposed reservoir development; however, the actual reservoir to be developed could have a slightly different development path and possibly different costs. The reasons for the difference are that the initial exploratory activities with the Heber Reservoir were in search of oil, not geothermal heat. Therefore, it seemed unwise to model this period based on what had occurred as the intent was not to find a geothermal reservoir. Thus, we have modeled the early developments on the Heber Reservoir based on a reasonable pattern of development for a geothermal reservoir beginning in 1980. Much of the pertinent data about the Heber Reservoir, particularly cost data, is proprietary and is not avallable to JPL. To the extent that our secondary source data differ from the true data, our predicted results for the reservoir may differ from the actual results of the project. 2.2 DATA DESCRIPTION

The data description is divided into five parts: financial variables, technical description, costs by stage of development, revenue, and probabilistic assumptions. Specific assumptions have been made and references are given. Unless otherwise stated, all dollar amounts are in 1980 dollars.

3 See discussion of OPT Functions in Section 3.4 .2 .2 of this report. 
The description of the Reference Scenario and other described inputs form what is termed the Base Case Set of Assumptions. The Base Case Set of Assumptions includes the Reference Scenario (which is supplied as input) and all other scenarios that are created by the model from perturbations in the Reference Scenario's stage times or physical parameter values. 4 Sensitivities to specific parameters in the Base Case are made in a later section.

\subsubsection{Financial Variables}

Energy Price - $17.5 \mathrm{mills} / \mathrm{kWh}$

- This is the price received by the reservoir for each $\mathrm{kWh}$ produced gross. The price used is the price which Cassel (Reference 1) claims is the competitive price for Heber. Based on 9 years required to develop the field before operation and the $10 \%$ escalation rate assumed below, this would grow to $41.3 \mathrm{mills} / \mathrm{kWh}$ for the first year of operation.

Energy Price Escalation - 10\%/yr

- It is assumed that the energy price will escalate along with fuel costs. DRI (Reference 2) forecasts residual fuel wholesale price escalation of $13.3 \%$ between 1980 and 1990 and $8.9 \%$ between 1990 and 2000 . The $10 \%$ rate selected is a compromise between these figures.

4 If any of the financial parameters, cost accounts, or probabilistic assumptions are changed by the user, a new set of assumptions, different from the Base Case Set, is created. Any such new case would again include a Reference Scenario, and the model would generate other scenarios as perturbations of this Reference Scenario. For a discussion of this aspect of the model, see Section 3.4.2. 
General Inflation - 9\%/yr

- All prices other than electricity will be assumed to grow at this rate. It is based on the DRI (Reference 2) forecast of the wholesale price index growing at $10.1 \%$ from 1980 to 1990 and $6.7 \%$ from 1990 to 2000.

Discount Rate - 15\%/yr

- The rate used is the required after tax rate of return on capital invested in projects of this risk class. The figure was obtained from the Atlantic Richfield Co. Royalty Rate - 10\% on Gross Revenue

- A common rate used for geothermal property. Federal Tax Rate - 46\%

- Standard corporate tax rate.

State Tax Rate - 9\%

- Corporate tax for California.

Local Tax Rate - $1 \%$

- Standard for California.

Investment Tax Credit - 10\%

- Geothermal would receive an additional credit of $15 \%$ for a total ITC of $25 \%$. However, this extra $15 \%$ is due to expire December 31,1985 , before the major capital expenditures for this site study would occur. (Reference 3)

Depletion Allowance - 15\%

- Although the present rate is $21 \%$, it will decline to $15 \%$ by 1984, which is before scheduled operation of the plant. 


\section{Depreciation Method - Sum of years digits \\ - This form of accelerated depreciation is used.}

\subsubsection{Technical Description}

The pertinent technical details about the reservoir are in Tables $2-1$, $2-2$, and 2-3.

\section{Table 2-1. Production Wells}

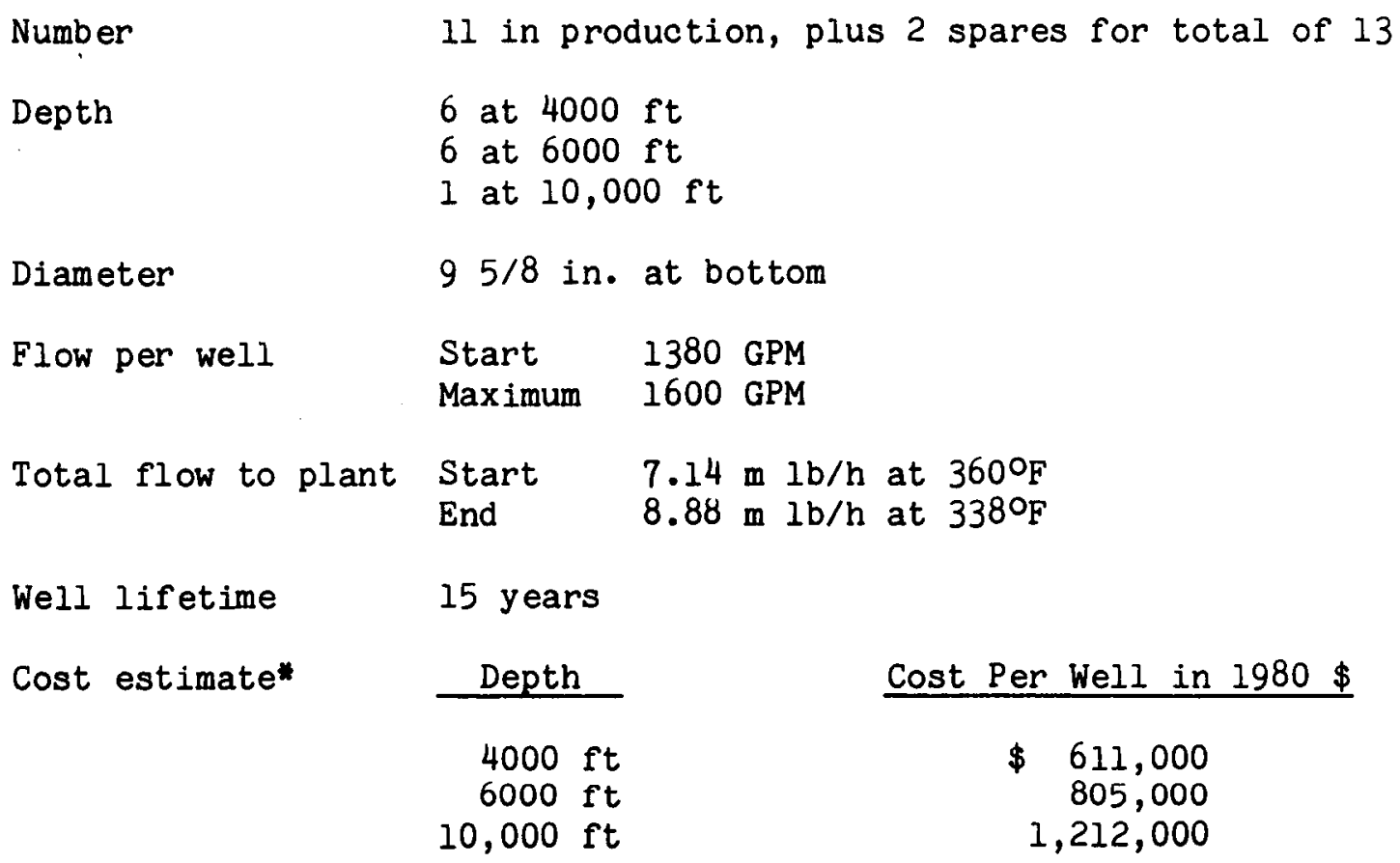

*This cost is an estimate for a trouble-free well, pumps not included. To this cost must be added a "dry hole/drilling problem" expense.

Source: Number, depth, diameter, flows, and well lifetime are from San Diego Gas \& Electric (Reference 6) and conversations with Chevron. Well cost estimates are from Livesay Consultants, modified by JPL. 


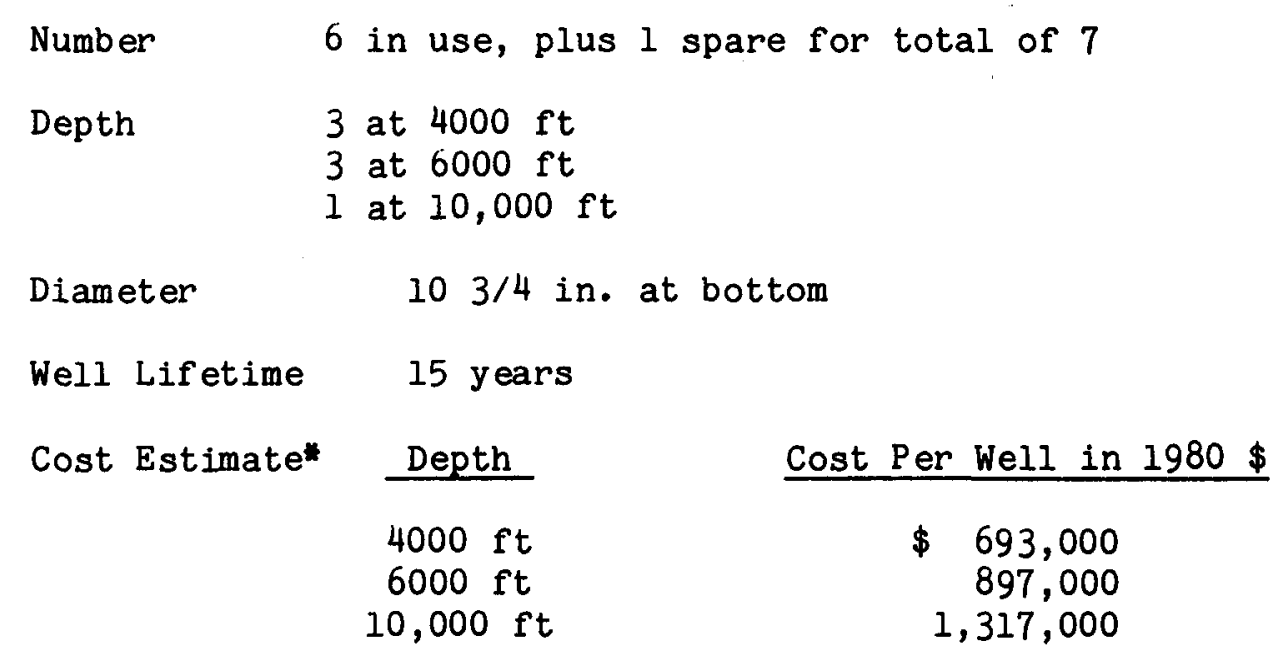

* Cost is an estimate for trouble-free well. To this cost must be added a "dry hole/drilling problem" expense.

Source: Number, depth and diameter are from conversations with Chevron. Well cost estimates are from Livesay Consultants, modified by JPL.

Table 2-3. Power Production and Consumption

$\begin{array}{lrr} & \text { Start } & \text { End } \\ \text { Gross Power Production (MW) } & 61.9 & 64.1 \\ \text { Auxiliary Power Consumption (MW) } & & \\ \text { Plant } & 14.6 & 15.3 \\ \text { Chevron Production Well Pumps } & 2.3 & 3.8 \\ \text { Total Auxiliary Consumption } & 16.9 & 19.1 \\ & & 45.0 \\ \text { Net Power Production (MW) } & 45.0 & 70 \% \\ \text { Capacity Factor } & 70 \% & \end{array}$

Source: San Diego Gas \& Electric (Reference 6). 


\subsubsection{Cost Accounts by Stage of Development}

The development of the geothermal reservoir is divided into four stages of development: resource proving, permit process, developing the resource, and operating the reservoir. ${ }^{5}$ In this section we describe the cost accounts in the stages for the Heber Site Study, and list the actual costs used in the Reference Scenario.

\subsubsection{Description of Costs in Stage I: Resource Proving}

Rent

This is the payment to the owners of the land. This payment is replaced by royalty payments when production starts in Stage IV.

Source: Estimate from SDG\&E

Exploration Permits

Cost of securing permits for surface exploration and exploratory drilling.

Source: Estimate from SDG\&E

Exploration and Well Logging

Expenses of surface exploration, drilling exploratory wells and well logging.

Source: Grieder (Reference 5)

G\&A

General and administrative expenses, including project management.

Source: Estimate from SDG\&E

Contingency

Additional allowance of $10 \%$ of all the above Stage I expenses for contingency.

This is more thoroughly discussed in Section 3.2.2. 
Lease Acquisition Cost

Payment to land owners to obtain lease.

Source: Estimate from SDG\&E

Surface Occupancy

Purchase of 5 acres for surface installation facilities such as pad for wells, pipes, roads, and required structures.

Source: Estimate from SDG\&E

\subsubsection{Description of Costs in Stage II: Permit Process}

Rent

See description in Stage I.

G\&A

See description in Stage I.

Regional Environmental Assessment

Preparation of required document on environmental assessment

before obtaining permit to develop the reservoir.

Source: Estimate from SDG\&E

Contingency

$10 \%$ of all the above.

\subsubsection{Description of Costs in Stage III: Developing the Resource}

Rent

See description in Stage I.

Development Well Cost

This is the expense of drilling all production and infection wells. This expense is divided into in $75 \%$ intangible drilling costs and $25 \%$ capitalized expense.

Source: Livesay Consultants 
Dry Hole and Drilling Problem

The development well costs are for trouble-free wells.

To account for expected trouble during drilling, $20 \%$ of the

development well cost is added. This expense is divided into

75\% intangible drilling costs and $25 \%$ capitalized expense.

Source: Livesay Consultants

Surface Installation

This is the expense of all facilities other than the wells. It

also includes down-hole pumps. This expense is divided into $50 \%$

intangible drilling costs and 50\% capitalized expense.

Source: Holt/Procon (Reference 7)

G\&A

As discussed in Stage I.

Contingency

10\% of surface installation, leasing, and G\&A.

2.2.3.4 Description of Costs in Stage IV: Operating the Reservoir

Redrilling of Wells

Depending on the lifetime assumption, all wells will be

redrilled. This expense will be made in the last year of

the lifetime of the well. The expense will be divided into

75\% intangible drilling costs and $25 \%$ capitalized expense.

Dry Hole and Drilling Problem

Same as described in Stage III.

Operation and Maintenance

This is the expense of G\&A, well maintenance, surface

maintenance, down-hole surveys, and miscellaneous supplies.

Source: Holt/Procon (Reference 7) 


\section{Electricity Expense for Pumping}

This is the cost of electricity to drive the down-hole pumps on the production wells. The power required increases from an initial 2.3 MW to an eventual 3.8 MW. We assume that power consumption increases linearly. The price of the electricity is based on the assumption that the reservoir buys electricity from the plant at cost, and $48 \%$ of the cost of electricity is geothermal heat. Thus, the price paid for electricity is $(1 / .48) \times$ (heat $\operatorname{mill}$ rate/ $\mathrm{kWh}$ ).

Source: SDG\&E (Reference 4)

\section{Contingency}

10\% of 0\&M expense.

\subsubsection{Costs used in the Reference Scenario}

The costs used in the Reference Scenario for the Heber Site Study are in Tables 2-4a, 2-4b, and 2-4c.

The set of distributions for the four uncertain variables generates

$$
\text { (3) } x(2) \times(1) \times(3) \times(3)=54 \text { scenarios. }
$$

These scenarios and their associated probabilities are shown in Tables 2-5 and $2-6$.

2.2.4 Revenue

Revenue to the reservoir will be based on the gross output of the generating plant during Stage IV. We assume that the effective operating capacity of the plant will be $70 \%$. Thus, for the first year of operation the plant will produce

$$
(.70)(8760 \text { hours })(61.9 \mathrm{MW})=3.80 \times 10^{8} \mathrm{kWh}
$$

The revenue during the first year will be this energy multiplied by the energy price. The energy price will escalate as described in Section 2.2.1. 
Table 2-4a

Cost Accounts: Stages I and II

(thous ands, 1980

\$)

\section{Stage I}

\begin{tabular}{|c|c|c|c|c|c|c|c|}
\hline Interva I & 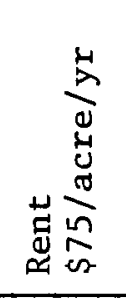 & 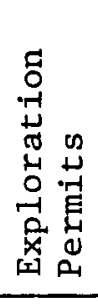 & 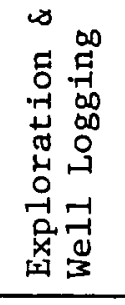 & 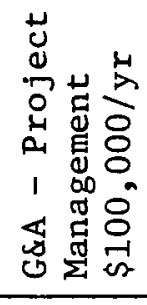 & 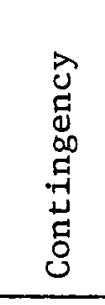 & 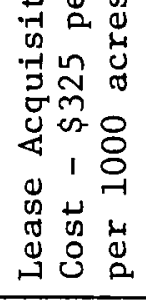 & 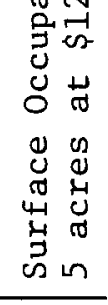 \\
\hline $\begin{array}{l}1 \\
2 \\
3 \\
4 \\
5 \\
6\end{array}$ & $\begin{array}{l}68.75 \\
68.75 \\
68.75 \\
68.75 \\
68.75 \\
68.75\end{array}$ & $\begin{array}{r}0 \\
25.0 \\
0 \\
0 \\
0 \\
0\end{array}$ & $\begin{array}{l}240.0 \\
240.0 \\
800.0 \\
800.0 \\
800.0 \\
800.0\end{array}$ & $\begin{array}{l}91.67 \\
91.67 \\
91.67 \\
91.67 \\
91.67 \\
91.67\end{array}$ & $\begin{array}{l}79.0 \\
43.0 \\
96.0 \\
96.0 \\
96.0 \\
96.0\end{array}$ & $\begin{array}{r}325.0 \\
0 \\
0 \\
0 \\
0 \\
0\end{array}$ & $\begin{array}{r}60.0 \\
0 \\
0 \\
0 \\
0 \\
0\end{array}$ \\
\hline
\end{tabular}

Accounting

Lifetime

$1 \mathrm{yr}$

$1 \mathrm{yr}$

$1 \mathrm{yr}$

$1 \mathrm{yr}$

$1 \mathrm{yr}$

$1 \mathrm{yr}$

$1 \mathrm{yr}$

Cost

Escalation

$9 \% \quad 9 \%$

$9 \% \quad 9 \% \quad 9 \%$

$9 \%$

$9 \%$

Interval

1

Accounting

Lifetime

Cost

Escalation
$1 \mathrm{yr}$

$1 \mathrm{yr}$

$9 \%$

$9 \%$

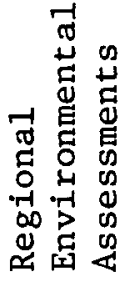

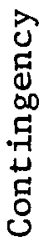

200.0

38.0

100.0

$1 \mathrm{yr}$

$1 \mathrm{yr}$

$9 \%$ 


\begin{tabular}{|c|c|c|c|c|c|c|c|c|c|c|}
\hline Interva I & 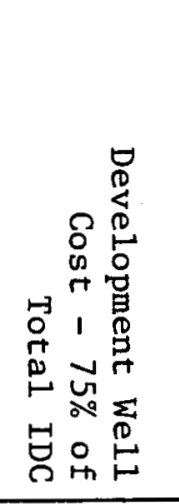 & 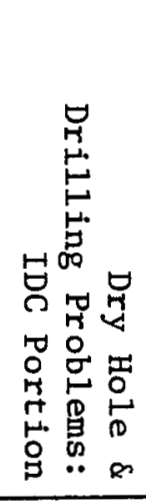 & 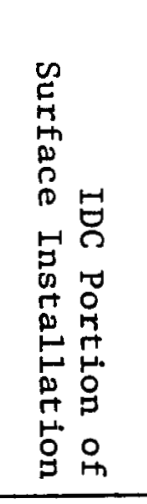 & 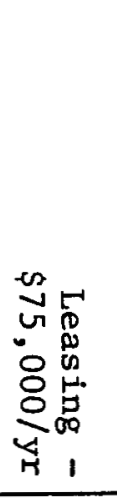 & 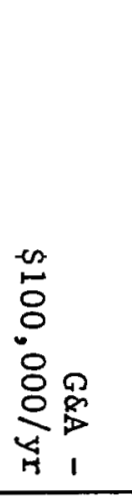 & 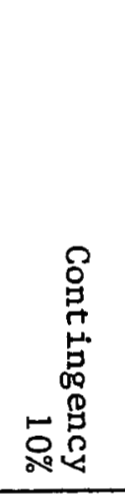 & 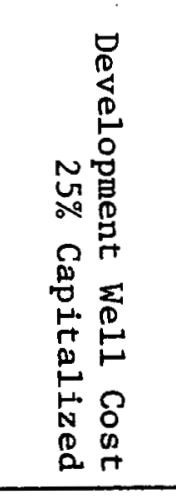 & 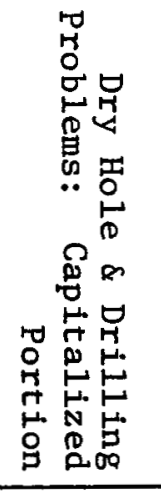 & 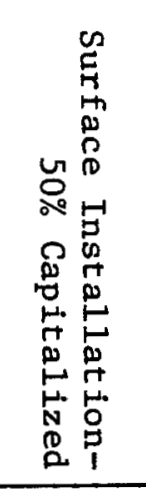 & 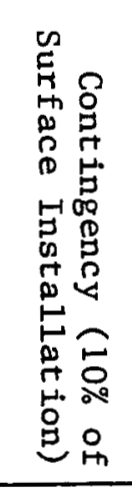 \\
\hline $\begin{array}{l}1 \\
2 \\
3\end{array}$ & $\begin{array}{l}3948.75 \\
3948.75 \\
3948.75\end{array}$ & $\begin{array}{l}789.5 \\
789 \cdot 5 \\
789.5\end{array}$ & $\begin{array}{l}1566.7 \\
1566.7 \\
1566.7\end{array}$ & $\begin{array}{l}62.5 \\
62.5 \\
62.5\end{array}$ & $\begin{array}{l}83.33 \\
83.33 \\
83.33\end{array}$ & $\begin{array}{l}171.0 \\
171.0 \\
171.0\end{array}$ & $\begin{array}{l}1316.25 \\
1316.25 \\
1316.25\end{array}$ & $\begin{array}{l}263.25 \\
263.25 \\
263.25\end{array}$ & $\begin{array}{l}1566.7 \\
1566.7 \\
1566.7\end{array}$ & $\begin{array}{l}157.0 \\
157.0 \\
157.0\end{array}$ \\
\hline $\begin{array}{l}\text { Accounting } \\
\text { Lifetime }\end{array}$ & $1 \mathrm{yr}$ & $1 \mathrm{yr}$ & $1 \mathrm{yr}$ & $1 \mathrm{yr}$ & $1 \mathrm{yr}$ & $1 \mathrm{yr}$ & $10 \mathrm{yr}$ & $10 \mathrm{yr}$ & $10 \mathrm{yr}$ & $10 \mathrm{yr}$ \\
\hline $\begin{array}{l}\text { Cost } \\
\text { Escalation }\end{array}$ & $9 \%$ & $9 \%$ & $9 \%$ & $9 \%$ & $9 \%$ & $9 \%$ & $9 \%$ & $9 \%$ & $9 \%$ & $9 \%$ \\
\hline
\end{tabular}


Table 2-4c

Cost Accounts: Stage IV

(thousands, 1980 \$)

\begin{tabular}{|c|c|c|c|c|c|c|c|}
\hline Interva I & 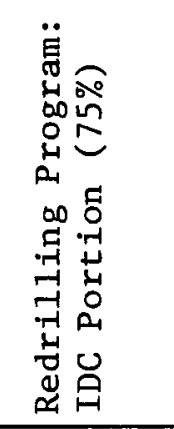 & 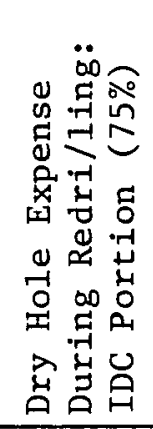 & 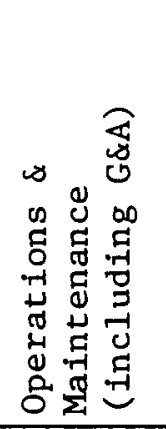 & 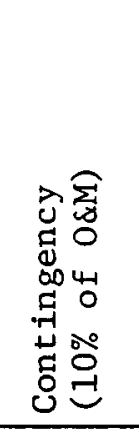 & 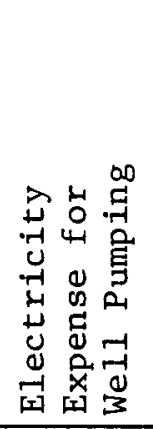 & 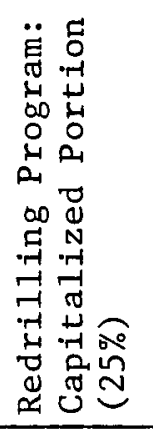 & 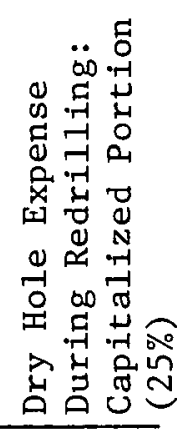 \\
\hline 1 & 0 & 0 & 2093.0 & 209.0 & 514.0 & 0 & 0 \\
\hline 2 & 0 & 0 & 2093.0 & 209.0 & 526.0 & 0 & 0 \\
\hline 3 & 0 & 0 & 2093.0 & 209.0 & 537.0 & 0 & 0 \\
\hline 4 & 0 & 0 & 2093.0 & 209.0 & 549.0 & 0 & 0 \\
\hline 5 & 0 & 0 & 2093.0 & 209.0 & 560.0 & 0 & 0 \\
\hline 6 & 0 & 0 & 2093.0 & 209.0 & 572.0 & 0 & 0 \\
\hline 7 & 0 & 0 & 2093.0 & 209.0 & 584.0 & 0 & 0 \\
\hline 8 & 0 & 0 & 2093.0 & 209.0 & 595.0 & 0 & 0 \\
\hline 9 & 0 & 0 & 2093.0 & 209.0 & 607.0 & 0 & 0 \\
\hline 10 & 0 & 0 & 2093.0 & 209.0 & 618.0 & 0 & 0 \\
\hline 11 & 0 & 0 & 2093.0 & 209.0 & 630.0 & 0 & 0 \\
\hline 12 & 0 & 0 & 2093.0 & 209.0 & 641.0 & 0 & 0 \\
\hline 13 & 0 & 0 & 2093.0 & 209.0 & 653.0 & 0 & 0 \\
\hline 14 & 0 & 0 & 2093.0 & 209.0 & 665.0 & 0 & 0 \\
\hline 15 & 12450.0 & 2490.0 & 2093.0 & 209.0 & 676.0 & 4150.0 & 830.0 \\
\hline 16 & 0 & 0 & 2093.0 & 209.0 & 688.0 & 0 & 0 \\
\hline 17 & 0 & 0 & 2093.0 & 209.0 & 699.0 & 0 & 0 \\
\hline 18 & 0 & 0 & 2093.0 & 209.0 & 711.0 & 0 & 0 \\
\hline 19 & 0 & 0 & 2093.0 & 209.0 & 722.0 & 0 & 0 \\
\hline 20 & 0 & 0 & 2093.0 & 209.0 & 734.0 & 0 & 0 \\
\hline 21 & 0 & 0 & 2093.0 & 209.0 & 745.0 & 0 & 0 \\
\hline 22 & 0 & 0 & 2093.0 & 209.0 & 757.0 & 0 & 0 \\
\hline 23 & 0 & 0 & 2093.0 & 209.0 & 769.0 & 0 & 0 \\
\hline 24 & 0 & 0 & 2093.0 & 209.0 & 780.0 & 0 & 0 \\
\hline 25 & 0 & 0 & 2093.0 & 209.0 & 792.0 & 0 & 0 \\
\hline 26 & 0 & 0 & 2093.0 & 209.0 & 803.0 & 0 & 0 \\
\hline 27 & 0 & 0 & 2093.0 & 209.0 & 815.0 & 0 & 0 \\
\hline 28 & 0 & 0 & 2093.0 & 209.0 & 826.0 & 0 & 0 \\
\hline 29 & 0 & 0 & 2093.0 & 209.0 & 838.0 & 0 & 0 \\
\hline 30 & 0 & 0 & 2093.0 & 209.0 & 850.0 & 0 & 0 \\
\hline \multicolumn{8}{|l|}{ Accounting } \\
\hline Lifetime & $1 \mathrm{yr}$ & $1 \mathrm{yr}$ & $1 \mathrm{yr}$ & $1 \mathrm{yr}$ & $1 \mathrm{yr}$ & $10 \mathrm{yr}$ & $10 \mathrm{yr}$ \\
\hline \multicolumn{8}{|l|}{ Cost } \\
\hline Escalation & $9 \%$ & $9 \%$ & $9 \%$ & $9 \%$ & $10 \%$ & $9 \%$ & $9 \%$ \\
\hline
\end{tabular}


The energy output will grow linearly as the gross power output expands to $64.1 \mathrm{MW}$ at the end of 30 years.

There is no other source of revenue for the reservoir other than the sale of heat for electricity production during Stage IV. We assume a zero scrap value; this is based on the assumption that the resale value of the land and facilities at the end of Stage IV, would be offset by the expense of restoring the land for the alternative uses in agriculture. 2.2.5 Probabilistic Assumptions

Uncertain variables are entered in the GPCM as probability distribubutions rather than point estimates. In the Heber Site Study there are four uncertain variables: length of stages 1,2 , and 4, and well flow rate. The density functions for the Base Case Set of Assumptions are shown in Table 2-5. The Base Case Set scenarios and their associated probabilities are shown in Tables 2-6 and 2-7.

The probability for an entire scenario is the product of the probabilities of the outcomes for each of the uncertain events. For example, using Table 7 the probability of Scenario 1 is

$$
(.2) \times(.8) \times(1.0) \times(.2) \times(.2)=.0064
$$

(This is shown in Table 2-8.)

In the Base Case, uncertain events are not conditional upon the outcomes of other uncertain events; however, the GPCM does have the power to have uncertain events conditional upon the outcome of other events. This capability is used in a sensitivity analysis in Section 2.4.6. 


\begin{tabular}{ccc} 
Variable & Possible Values & \multicolumn{2}{c}{ Associated Probability } \\
\cline { 2 - 3 } Stage 1 & $3 \mathrm{yr}$ & 0.2 \\
& $5.5 \mathrm{yr}^{*}$ & 0.6 \\
$8 \mathrm{yr}$ & 0.2 \\
Stage 2 & $1 \mathrm{yr}^{*}$ & 0.8 \\
& $1.5 \mathrm{yr}$ & 0.2 \\
Stage 3 & $2.5 \mathrm{yr}^{*}$ & 1.0 \\
Stage 4 & $20 \mathrm{yr}^{*}$ & 0.2 \\
& $30 \mathrm{yr}$ & 0.7 \\
& $35 \mathrm{yr}$ & 0.1 \\
Well Flow Rate & $1035 \mathrm{GPM}$ & 0.2 \\
& $1380 \mathrm{GPM}$ & 0.6 \\
& $1725 \mathrm{GPM}$ & 0.2
\end{tabular}

*This value is used in the Reference Scenario.

Source: Based on information provided by Chevron. 
Table 2-6

Base Case Set Scenarios

Stage 1

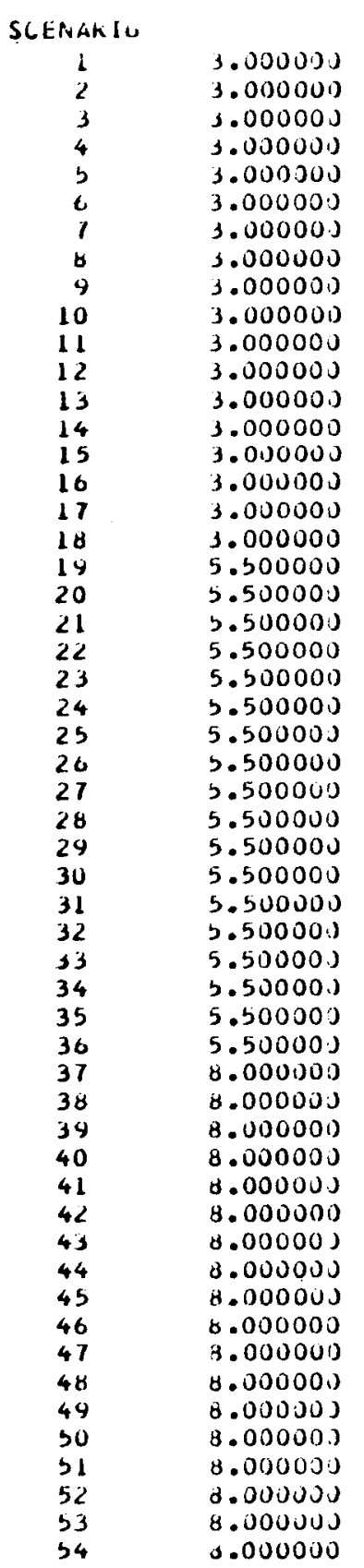

\section{Stage 2}

1.000000

1.000000

1.000000

1.000000

1.000000

1.000000

1.000000

1.000000

1.000000

1.500000

1. 500000

1.500000

1.500000

1.500000

1.500000

1.500000

1.500000

1.51)0000

1.000000

1.000000

1.000000

1.000000

1.000000

1.000000

1.000000

1.000000

1.000000

1.500000

1.500000

1.500000

1.500000

1.500000

1.500000

1.500000

1.500000

1.500000

1. 000000

1.000000

1.000000

1.000000

1.000000

1.000000

1.000000

1.000000

1.000000

1.500000

1.500000

1.500000

1.500000

1.500000

1.500000

1.500100

1.5001100

1.500000

\section{Stage 3}

2.500000

2.500000

2.500000

2.500000

2.500000

2. 500000

2. 500000

2.500000

2.500000

2.500000

2. 500000

2.500000

2.500000

2.500000

2.500000

2. 500000

2. 50.0000

2.500000

2.500000

2.500000

2.500000

2.500000

2. 500000

2.500000

2.500000

2.500000

2.500000

2.500000

2.500000

2.500000

2.500000

2.500000

2. 500000

2.500000

2.500000

2.500000

2.500000

2.500000

2.500000

2.500000

2.500000

2.500000

2.500000

2.500000

2.500000

2.500000

2.500000

2. 500000

2.500000

2. 500000

2.500000

2.500000

2.500000

2.500000
Stage 4

20.000000

20.000000

20.000000

30.000000

30.001000

30.000000

35.000000

35.000000

35.000000

20.000000

20.002000

20.000000

30.000000

30.000000

30.000000

35.000000

35.000000

35.000000

20.000000

20.000000

20.000000

30.000000

30.000000

30.000000

35.000000

35.000000

35.000000

20.000000

20.000000

20.000000

30.000000

30.000000

30.000000

35.000000

35.000000

35.000000

20.000000

20.000000

20.001000

30.000000

30.000000

30.001002

35.000000

35.000000

35.000000

20.000000

20.00 .0000

20.000000

30.003000

30.00030

30.000000

35.000 .100

35. J) ग000

35.000000
Flow Rate

1035.000000

1380.1000000

1725.000003

1035.000001

1380.00000 )

1725.000000

1035.000000

1380.000000

1725.000000

1035.000000

1380.000000

1725.000000

1035.000000

1380.000000

1725.000000

1035.000000

1380.000000

1725.000000

1035.000000

1380.000000

1725.000000

1035.000000

1380.000000

1725.000000

1035.000000

1380.000000

1725.000000

1035.000000

1380.000000

$1725.00000 \mathrm{~J}$

1035.000000

1380.000000

1725.000000

1035.000000

1380.000000

1725.000000

1035.000000

1380.000000

1725.000000

1035.000000

1380.000000

1725.000000

1035.000000

1380.000000

1725.000000

1035.000000

1380.000000

1725.000000

1035.000000

1380.00000 )

1725.00000 )

1035.000000

1380.000000

1725.000003

(Stages are in years, flow rate is GPM per production well) 
Table 2-7

Probabilities in Base Case Set Scenarios

Stage 1

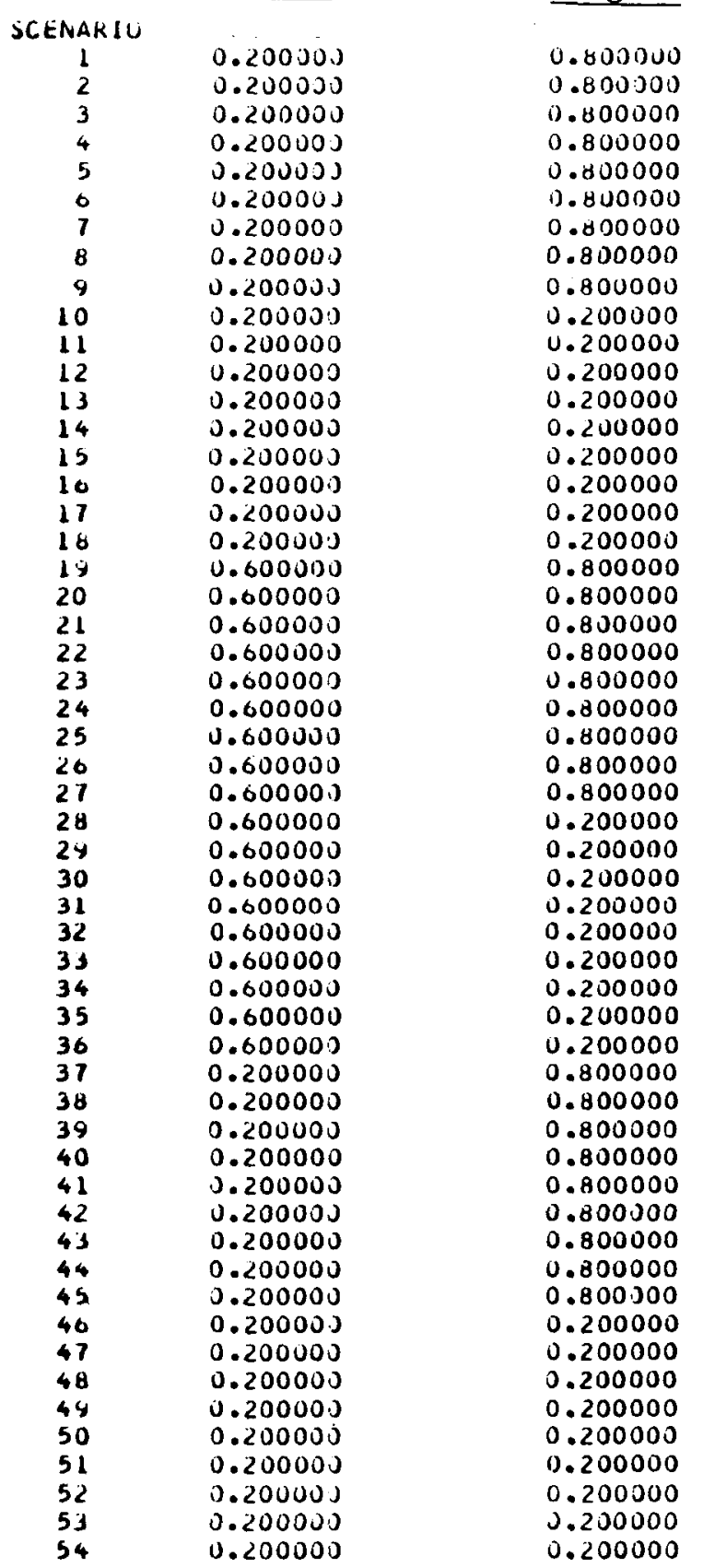

\begin{tabular}{l} 
Stage 3 \\
\hline 1.000000 \\
1.000000 \\
1.000000 \\
1.000000 \\
1.0100000 \\
1.000000 \\
1.000000 \\
1.000000 \\
1.000000 \\
1.000000 \\
1.000000 \\
1.000000 \\
1.000000 \\
1.000000 \\
1.000000 \\
1.000000 \\
1.000000 \\
1.000000 \\
1.000000 \\
1.000000 \\
1.000000 \\
1.000000 \\
1.000000 \\
1.000000 \\
1.000000 \\
1.000000 \\
1.000000 \\
1.000000 \\
1.000000 \\
1.000000 \\
1.000000 \\
1.000000 \\
1.000000 \\
1.000000 \\
1.000000 \\
1.000000 \\
1.000000 \\
1.000000 \\
1.000000 \\
1.000000 \\
1.000000 \\
1.000000 \\
1.000000 \\
1.000000 \\
1.000000 \\
1.000000 \\
1.000000 \\
1.000000 \\
1.000000 \\
1.000000 \\
1.000000 \\
1.000000 \\
1.000000 \\
1.000000 \\
\end{tabular}

\section{Stage 4}

0.200000

0.200000

0.200000

0.700000

0.700000

0.700000

0.100000

0.100000

0.100000

0.200000

0.200000

0.200000

0.700000

0.700000

0.700000

0.100000

0.100000

0.100000

0.200000

0.200000

0.200000

0.700000

0.700000

0.700000

0.100000

0.100000

0.100000

0.200000

0.200000

0.200000

0.700000

0.700000

0.700000

0.100000

0.100000

0.100000

0.200000

0.200000

0.200000

0.700000

0.700000

0.700000

0.100000

0.100000

0.100000

0.200000

0.200000

0.200000

0.700000

0.700000

0.700000

0.100000

0.100000

0.100000
Flow Rate

0.200000

0.600000

$0.20000)$

0.200000

0.000000

0.200000

0.200000

0.603000

$0.20000 \mathrm{~J}$

0.200000

0.600001

0.200000

0.200000

0.600000

0.200000

0.200000

0.000000

0.200000

0.200000

0.600000

0.200000

0.200000

0.600000

0.200000

0.200000

0.600000

0.200000

0.200000

0.600000

0.200000

0.200000

0.600000

0.200000

0.200000

0.600000

0.200000

0.200000

0.600000

0.200000

0.20000 )

0.600003

0.200000

0.200000

0.600003

0.200000

0.200000

1.600000

0.200000

0.200000

0.600000

0.20000 )

0.20000 J

0.600000

0.200000 


\subsection{RESULTS OF THE BASE CASE SET OF ASSUMPTIONS}

This section presents the results of operating the GPCM with the Base Case Set inputs as described in Section 2.2.

\subsubsection{Profit in the Base Case Set}

The present value of profit in the Base Case Set has an expected value of $\$ 5.78$ million; however, the Reference Scenario value is $\$ 7.64$ million. It must be remembered that the model uses a revenue-requirements method of computation (Reference 8 ). Therefore, profit is the residue from revenues after substracting all costs including taxes and a $15 \%$ capital payment.

The profit for all scenarios is shown in Table 2-8. The cumulative distribution profit function is shown in Figure 2-1.

2.3.2 Cost in the Base Case Set

The costs of producing heat in the Base Case Set are shown on

Table 2-9. For each scenario the cost shown is the cost in a real levelized stream beginning in the first year of the operation, Stage IV, and continuing to the end of the operation. ${ }^{6}$ The stream is real levelized and will rise with the rate of energy inflation. Thus, for the Reference Scenario, the cost is $36.97 \mathrm{mills} / \mathrm{kWh}$ beginning 9 years after the start of exploration in 1980 . This cost will be $40.67 \mathrm{mills} / \mathrm{kWh}$, or $10 \%$ higher, the following year. In the ninth year after exploration, the energy price will have risen from 17.5 $\mathrm{mills} / \mathrm{kWh}$ to $41.26 \mathrm{mills} / \mathrm{kWh}$. Comparing the first year real levelized cost, $36.97 \mathrm{mills} / \mathrm{kWh}$, to the first year price, $41.26 \mathrm{mills} / \mathrm{kWh}$, we see there is a profit based on levelized costs of 3.70 mills on each $\mathrm{kWh}$ sold. There will also be positive profits in each of the remaining years of operation as both the price and the real levelized cost stream rise at $10 \%$.

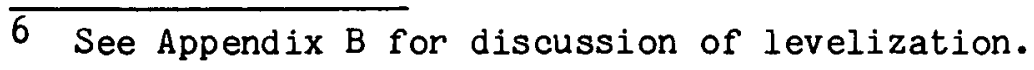




\begin{tabular}{|c|c|}
\hline SCENAKIC & FKCHABILITY \\
\hline 46 & 0.001000 \\
\hline 37 & $C \cdot O C E+C D$ \\
\hline 28 & C. $C 04900$ \\
\hline 19 & 0.014200 \\
\hline 20 & E.cc1600 \\
\hline 1 & $1) . r(t 400)$ \\
\hline 47 & $0 .(048 n 0)$ \\
\hline $3 \varepsilon$ & 0.019200 \\
\hline 25 & 0.014400 \\
\hline 20 & c.c57000 \\
\hline 48 & $0.1: 01600$ \\
\hline 49 & 0.005000 \\
\hline 39 & c.cetino \\
\hline 40 & 0.0224100 \\
\hline 11 & 0.004300 \\
\hline 2 & $\therefore C 15200$ \\
\hline$\equiv 1$ & 0.016000 \\
\hline 30 & $0 \cdot(c 4 \sin 0$ \\
\hline 22 & $0 . c t 7200$ \\
\hline 21 & C.C19200 \\
\hline 52 & $c \cdot c c 0300$ \\
\hline 43 & $0.10320)$ \\
\hline 13 & 0.0500 \\
\hline 4 & $0.022+110$ \\
\hline 12 & $0.0016 .7 n$ \\
\hline 3 & $0.00(40)$ \\
\hline $50 i$ & C.c16800 \\
\hline 34 & $0.00240,0$ \\
\hline 25 & c.ccoso \\
\hline 41 & $r \cdot r \in 7200$ \\
\hline 16 & i.cecs:10 \\
\hline 32 & 0.050400 \\
\hline 7 & $\operatorname{coc} 0200$ \\
\hline 53 & 0.002400 \\
\hline 23 & 0.2016100 \\
\hline 51 & $r .305030$ \\
\hline 14 & $c .(096 ; 0)$ \\
\hline 42 & $0.0,224110$ \\
\hline 14 & C.c16800 \\
\hline 5 & 0.067200 \\
\hline 35 & $0 . r c 7200$ \\
\hline 54 & $\operatorname{coc} c 800$ \\
\hline 33 & 0.016800 \\
\hline 26 & 0.028800 \\
\hline 24 & $\therefore .667200$ \\
\hline 45 & 0.003200 \\
\hline 17 & 0.002400 \\
\hline 36 & $0.00240,0$ \\
\hline 15 & C.005600 \\
\hline 9 & c.cco5:;0 \\
\hline 27 & c. $\cos \theta \operatorname{coc}$ \\
\hline 0 & 0.0224110 \\
\hline 18 & o.rcosno \\
\hline 9 & $0.0,03200$ \\
\hline
\end{tabular}

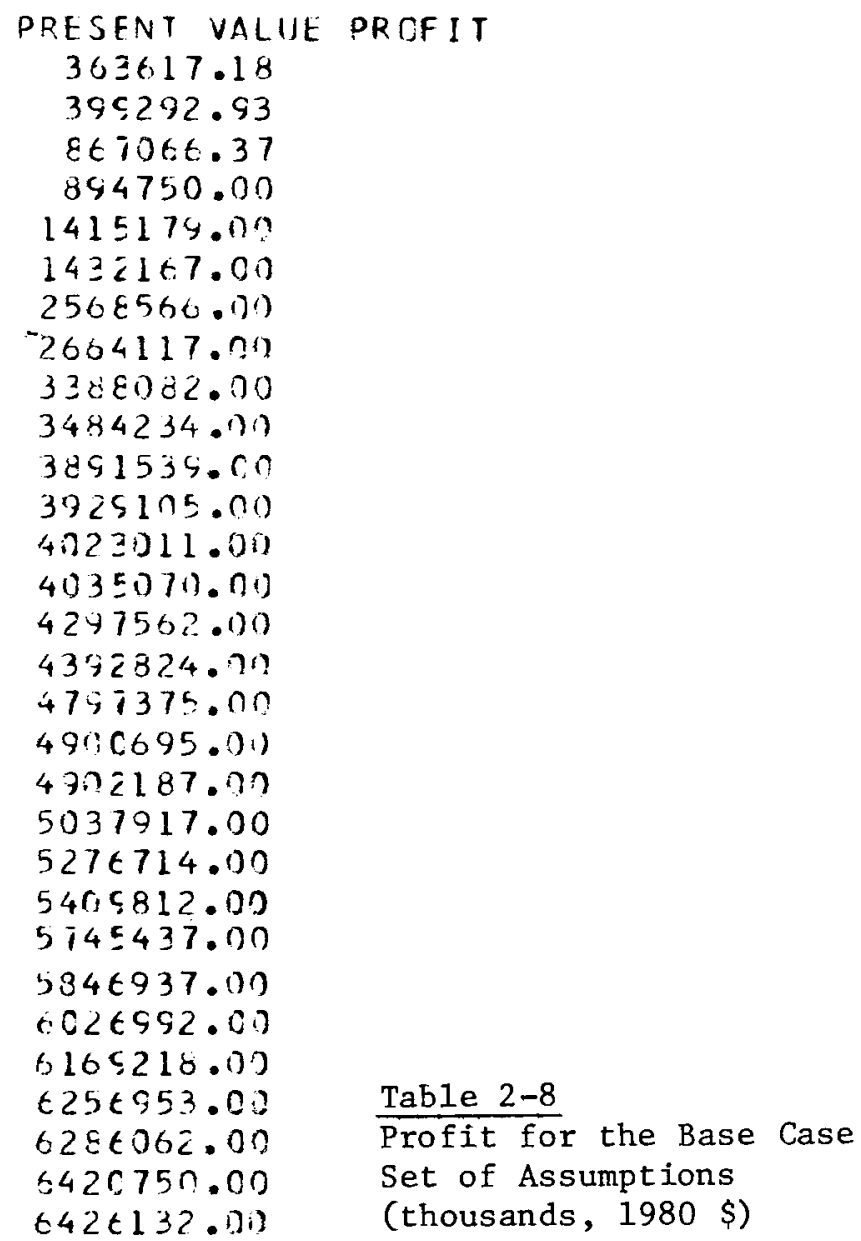

Table 2-8

Profit for the Base Case Set of Assumptions (thousands, 1980 \$) 


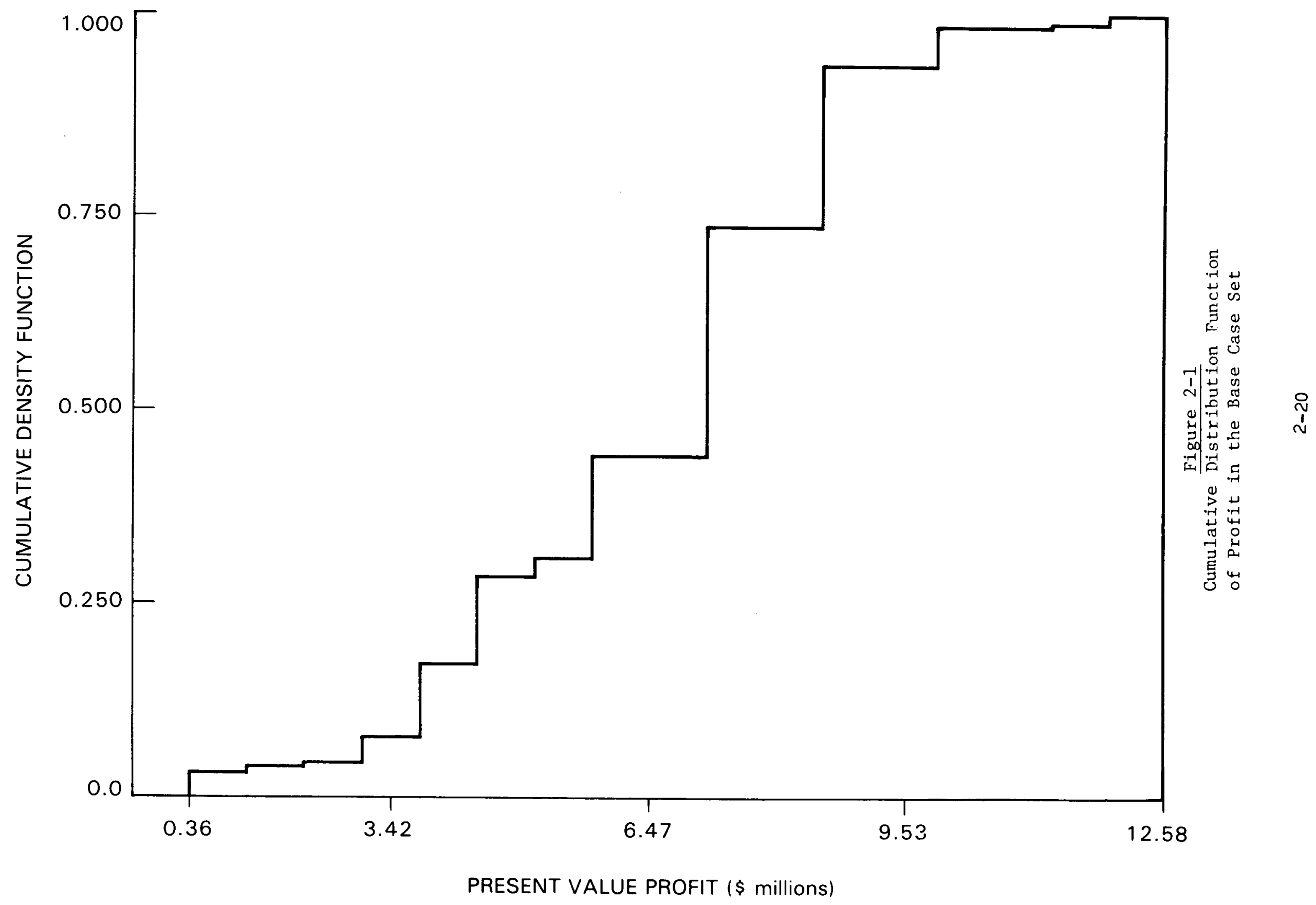


Table 2-9

Base Case Set Levelized Cost for First Year of Operation

\begin{tabular}{|c|c|c|c|c|c|c|}
\hline $\begin{array}{l}\text { Years to } \\
\text { Operation }\end{array}$ & LEC* & LEC in $1980 \$$ & Scenario & $\begin{array}{l}\text { Years to } \\
\text { Operation }\end{array}$ & LEC* & LEC in $1980 \$$ \\
\hline $\begin{array}{l}6.5 \\
6.5 \\
6.5 \\
6.5 \\
6.5 \\
6.5 \\
6.5 \\
6.5 \\
6.5 \\
7 \\
7 \\
7 \\
7 \\
7 \\
7 \\
7 \\
7 \\
7 \\
9 \\
9 \\
9 \\
9 \\
9 \\
9 \\
9 \\
9 \\
9\end{array}$ & $\begin{array}{l}31.80 \\
30.33 \\
29.45 \\
30.19 \\
28.95 \\
28.20 \\
29.72 \\
28.55 \\
27.85 \\
33.35 \\
31.81 \\
30.89 \\
31.65 \\
30.35 \\
29.58 \\
31.16 \\
29.94 \\
29.20 \\
40.63 \\
38.81 \\
37.71 \\
38.50 \\
36.96 \\
36.03 \\
37.88 \\
36.43 \\
35.55\end{array}$ & $\begin{array}{l}17.12 \\
16.32 \\
15.85 \\
16.25 \\
15.58 \\
15.18 \\
16.00 \\
15.37 \\
14.99 \\
17.11 \\
16.32 \\
15.85 \\
16.24 \\
15.58 \\
15.18 \\
15.99 \\
15.36 \\
14.98 \\
17.23 \\
16.46 \\
15.99 \\
16.33 \\
15.67 \\
15.28 \\
16.07 \\
15.45 \\
15.08\end{array}$ & $\begin{array}{l}28 \\
29 \\
30 \\
31 \\
32 \\
33 \\
34 \\
35 \\
36 \\
37 \\
38 \\
39 \\
40 \\
41 \\
42 \\
43 \\
44 \\
45 \\
46 \\
47 \\
48 \\
49 \\
50 \\
51 \\
52 \\
53 \\
54\end{array}$ & $\begin{array}{l}9.5 \\
9.5 \\
9.5 \\
9.5 \\
9.5 \\
9.5 \\
9.5 \\
9.5 \\
9.5 \\
11.5 \\
11.5 \\
11.5 \\
11.5 \\
11.5 \\
11.5 \\
11.5 \\
11.5 \\
11.5 \\
12 \\
12 \\
12 \\
12 \\
12 \\
12 \\
12 \\
12 \\
12\end{array}$ & $\begin{array}{l}42.62 \\
40.72 \\
39.57 \\
40.38 \\
38.77 \\
37.80 \\
39.73 \\
38.21 \\
37.30 \\
51.97 \\
49.70 \\
48.34 \\
49.14 \\
47.23 \\
46.08 \\
48.33 \\
46.52 \\
45.44 \\
54.43 \\
52.17 \\
50.75 \\
51.55 \\
49.56 \\
48.36 \\
50.70 \\
48.81 \\
47.68\end{array}$ & $\begin{array}{l}17.23 \\
16.46 \\
16.00 \\
16.33 \\
15.68 \\
15.29 \\
16.07 \\
15.45 \\
15.08 \\
17.37 \\
16.61 \\
16.16 \\
16.42 \\
15.78 \\
15.40 \\
16.15 \\
15.55 \\
15.18 \\
17.38 \\
16.62 \\
16.17 \\
16.43 \\
15.79 \\
15.41 \\
16.15 \\
15.55 \\
15.19\end{array}$ \\
\hline
\end{tabular}

* LEC is real levelized energy cost starting the year of operation in Stage IV, expressed in mills $/ \mathrm{kWh}$. 
Comparisons of cost between different scenarios with different times before operation can be misleading. For example, the first year real levelized cost for Scenario 10 is $33.35 \mathrm{mills} / \mathrm{kWh}$. Because this cost is less than the first year real levelized cost of the Reference Scenario, one is tempted to conclude that Scenario 10 is more profitable than the Reference Scenario. However, the real levelized stream for Scenario 10 would start only 7 years after exploration, rather than 9, and the energy price would be only $34.10 \mathrm{mills} / \mathrm{kWh}$. The actual profit for Scenario 10 is $\$ 1.41$ million, which would make it less profitable than the Reference Scenario, even though its first year levelized cost is lower.

When first year levelized costs are deflated to 1980 dollars, the cost can be compared to the energy price of $17.5 \mathrm{mills} / \mathrm{kWh}$ to determine whether a scenario is profitable. However, comparing the LEC in 1980 dollars for scenarios with different times before the start of operations can still be misleading. For example, comparing the LEC in 1980 dollars for scenarios 26 and 51 , it might be concluded that Scenario 51 is more profitable because it has a lower cost; however, Table 2-8 shows that Scenario 26 is more profitable. This is true because the profit in Scenario 51 must be discounted back more periods than Scenario 26 as it is 12 years before Stage IV in Scenario 51 , and only 9 years in Scenario 26. 2.2.3 Base Case Set in 1990

While the project has been viewed from the year 1980 , it is also useful to examine the project in terms of a different year to see the impact of inflation. Table 2-10 examines selected items of the Reference Scenario for the year 1990, which is the second year of the operating stage, Stage IV. Table 2-11 expresses the profits in terms of 1990 dollars. 
Table 2-10

Reference Scenario in 1990 (1990\$)

$\begin{array}{lc}\text { Energy Price } & 45.39 \\ \text { Real Levelized Energy Cost } & 40.67 \\ \text { Annual Operating Expenses (thousands, 1990\$) } & \\ \text { O\&M } & 4955 \\ \text { Electricity Expense for Pumping } & 1245 \\ \text { Contingency } & 495 \\ \text { Cost of Wells* (thousands, 1990\$) } & 1445 \\ 6000 \mathrm{ft} \text { Production } & 1640 \\ 6000 \mathrm{ft} \text { Injection } & \end{array}$

*No wells are drilled in 1990.

Table 2-11

Present Value of Profits in 1980 for the

Base Case Set expressed in 1990 Dollars

(Millions, 1990\$)

$\begin{array}{lr}\text { Expected Profit } & 13.68 \\ \text { Standard Deviation } & 5.92 \\ \text { Minimum Profit } & .86 \\ \text { Maximum Profit } & 29.79 \\ \text { Reference Scenario } & 18.07\end{array}$


Sensitivity analysis on the Base Case Set was done for energy, price, discount rate, capacity factor, investment tax credit, energy escalation, general price escalation, well life, and correlated uncertain events. Results are shown in Table 2-12.

\subsubsection{Sensitivity to Energy Price}

As would be expected, profit is very sensitive to the price received for the electricity produced. A $2.5 \mathrm{mill} / \mathrm{kWh}$ increase in price translates into a $\$ 4.4$ million increase in the present value of expected profits and a $\$ 4.6$ million increase for the Reference Scenario.

A change in the energy price also affects the cost of production. A $2.5 \mathrm{mill} / \mathrm{kWh}$ increase in the 1980 price results in $3.3 \mathrm{mill} / \mathrm{kWh}$ increase, or $1.4 \mathrm{mill} / \mathrm{kWh}$ in 1980 dollars, in first year real levelized cost for the Reference Scenario. Costs increase with price because cost includes royalty and taxes; royalty payments increase with price, and taxes increase with profit which increases with price.

\subsubsection{Sensitivity to Discount Rate}

An increase in the discount rate will lower profits and raise costs. When cash flows are evaluated using a $20 \%$ discount instead of $15 \%$, as in the Base Case Set, present value of expected profits declines by $\$ 7.1$ million dollars, making it negative; and first year real levelized cost rises by $5 \mathrm{mills} / \mathrm{kWh}$.

The discount rate used in this analysis is the required after tax return on capital. Although $20 \%$ may seem high, it must be remembered that it is a nominal rate of return. When adjusted for $9 \%$ general inflation, nominal returns of 15 and $20 \%$ become 5.5 and $10.1 \%$ real returns, respectively. For a project with the risks of a geothermal reservoir, these are not unreasonable. 
Table 2-12: Sensitivity Results to Base Case Set at Heber

\begin{tabular}{|c|c|c|c|c|c|c|c|c|}
\hline & & Pres & ent Value $P$ & rofit (Mi & Ilions, I & $980 \$)$ & Reference Scenario & LEC* \\
\hline & & $\begin{array}{l}\text { Expected } \\
\text { Value }\end{array}$ & $\begin{array}{l}\text { Standard } \\
\text { Deviation }\end{array}$ & Minimum & Maximum & $\begin{array}{l}\text { Reference } \\
\text { Scenario }\end{array}$ & Nominal & $1980 \$$ \\
\hline Base Case & & 5.78 & 2.50 & 0.36 & 12.58 & 7.64 & 36.97 & 15.68 \\
\hline $\begin{array}{l}\text { Energy } \\
\text { Price } \\
\text { (mills/kWh) }\end{array}$ & $\begin{array}{l}15 \\
20 \\
30\end{array}$ & $\begin{array}{r}1.34 \\
10.16 \\
27.30\end{array}$ & $\begin{array}{l}2.16 \\
2.84 \\
4.70\end{array}$ & $\begin{array}{r}-2.90 \\
3.59 \\
16.50\end{array}$ & $\begin{array}{r}7.06 \\
18.11 \\
40.20\end{array}$ & $\begin{array}{r}3.02 \\
12.25 \\
30.70\end{array}$ & $\begin{array}{l}33.67 \\
40.24 \\
53.44\end{array}$ & $\begin{array}{l}14.28 \\
17.07 \\
22.66\end{array}$ \\
\hline $\begin{array}{l}\text { Discount } \\
\text { Rate }\end{array}$ & $\begin{array}{l}16 \% \\
20 \%\end{array}$ & $\begin{array}{r}3.48 \\
-1.30\end{array}$ & $\begin{array}{l}2.02 \\
1.03\end{array}$ & $\begin{array}{l}-0.84 \\
-3.44\end{array}$ & $\begin{array}{l}9.26 \\
1.68\end{array}$ & $\begin{array}{r}5.06 \\
-0.52\end{array}$ & $\begin{array}{l}37.85 \\
41.95\end{array}$ & $\begin{array}{l}16.05 \\
17.79\end{array}$ \\
\hline $\begin{array}{l}\text { Capacity } \\
\text { Factor }\end{array}$ & $\begin{array}{l}65 \% \\
60 \%\end{array}$ & $\begin{array}{l}3.27 \\
0.91\end{array}$ & $\begin{array}{l}2.30 \\
2.12\end{array}$ & $\begin{array}{l}-1.42 \\
-3.25\end{array}$ & $\begin{array}{l}9.53 \\
6.48\end{array}$ & $\begin{array}{l}5.09 \\
2.54\end{array}$ & $\begin{array}{l}38.17 \\
39.58\end{array}$ & $\begin{array}{l}16.19 \\
16.78\end{array}$ \\
\hline $\begin{array}{l}\text { Investment } \\
\text { Tax Credit }\end{array}$ & $25 \%$ & 7.06 & 2.43 & 1.53 & 13.78 & 8.82 & 36.31 & 15.40 \\
\hline $\begin{array}{l}\text { Energy } \\
\text { Escalation }\end{array}$ & $\begin{array}{r}11 \% \\
9 \%\end{array}$ & $\begin{array}{r}12.21 \\
0.61\end{array}$ & $\begin{array}{l}3.44 \\
1.84\end{array}$ & $\begin{array}{r}5.12 \\
-\quad 3.55\end{array}$ & $\begin{array}{r}20.42 \\
6.25\end{array}$ & $\begin{array}{r}14.55 \\
2.04\end{array}$ & $\begin{array}{l}37.42 \\
36.73\end{array}$ & $\begin{array}{l}14.63 \\
16.91\end{array}$ \\
\hline $\begin{array}{l}\text { General } \\
\text { Inflation }\end{array}$ & $\begin{array}{r}10 \% \\
8 \%\end{array}$ & $\begin{array}{l}2.26 \\
8.77\end{array}$ & $\begin{array}{l}2.25 \\
2.68\end{array}$ & $\begin{array}{r}-2.86 \\
3.13\end{array}$ & $\begin{array}{r}8.96 \\
15.60\end{array}$ & $\begin{array}{r}4.02 \\
10.67\end{array}$ & $\begin{array}{l}39.00 \\
35.24\end{array}$ & $\begin{array}{l}16.54 \\
14.95\end{array}$ \\
\hline Well Life & $\begin{array}{l}10 \mathrm{yr} \\
30 \mathrm{yr}\end{array}$ & $\begin{array}{l}2.50 \\
8.63\end{array}$ & $\begin{array}{l}2.65 \\
2.40\end{array}$ & $\begin{array}{r}-2.50 \\
3.00\end{array}$ & $\begin{array}{r}9.67 \\
15.16\end{array}$ & $\begin{array}{r}4.62 \\
10.37\end{array}$ & $\begin{array}{l}38.67 \\
35.42\end{array}$ & $\begin{array}{l}16.40 \\
15.02\end{array}$ \\
\hline $\begin{array}{l}\text { Correlated } \\
\text { Events }\end{array}$ & & 5.84 & 2.46 & .36 & 12.58 & 7.64 & 36.97 & 15.68 \\
\hline
\end{tabular}

Reference Scenario LEC*

* LEC is real levelized energy cost starting the first year of operation in Stage IV, expressed in mills/kWh. 


\subsubsection{Sensitivity to Capacity Factor}

A reduction in capacity factor from 70 to $65 \%$ will reduce the quantity of output sold. It lowers both expected profits and Reference Scenario profits by $\$ 2.5$ million, and increases first year levelized cost by $1.2 \mathrm{mill} / \mathrm{kWh}$.

2.4.4 Sensitivity to Investment Tax Credit

The investment tax credit (ITC) was increased from 10 to $25 \%$ and only marginal changes were observed. Present value profit rose about $\$ 1.2$ million for most scenarios. The change in ITC had the greatest impact on scenarios with the greatest capital investment, namely, those with low flow rates and high investment in wells.

The increase in ITC would have had a greater effect if a lower percentage of drilling and surface installation expenses had been indirect drilling costs (IDC). In the Base Case, $75 \%$ of drilling and $50 \%$ of surface installation costs were IDC. With ITC at $25 \%$ rather than $10 \%$, one might consider capitalizing a greater proportion. 2.4.5 Sensitivity to Energy Escalation Rate

Profit is very sensitive to the energy escalation rate, the rate at which the price of the heat increases. A $1 \%$ increase in the energy escalation rate, from 10 to $11 \%$, increases expected profit by about $\$ 6.4$ million. Because these projects are long, a total of 39 years for the Reference Scenario, the addition of a $1 \%$ escalation increase is very significant.

\subsubsection{Sensitivity to General Inflation Rate}

Profit was slightly less sensitive to changes in general inflation than to changes in energy escalation. A $1 \%$ rate of increase in general inflation from 9 to $10 \%$ reduced expected profits by about $\$ 3.5$ million. 
The high sensitivity of profits to energy inflation rate and the general inflation rate indicates the use of caution when choosing their values.

\subsubsection{Sensitivity to Well Life}

The Base Case Set assumed well life was 15 years. That meant the wells would all be replaced once in a 30-yr operating life. If well life were only $10 \mathrm{yr}$, wells would have to be replaced twice, and if well life were 30 yr, no replacement would be required.

As the results show, profit is sensitive to well life. It is especially sensitive for scenarios where there is a low flow rate and more wells are needed.

\subsubsection{Sensitivity to Correlated Events}

In this study we exploit a property of the GPCM not used in the Base Case Set: the ability to model the reservoir where the distribution of an uncertain variable depends upon the value taken by another uncertain variable. We will assume that the distribution of the flow rate depends upon the length of time required in exploration, Stage $I$. The distribution used is defined in Table 2-11.

Table 2-13. Flow Rate Correlated to Stage I

\begin{tabular}{ccc}
$\begin{array}{c}\text { Outcome of Stage I } \\
\text { (yr) }\end{array}$ & $\begin{array}{r}\text { Possible Value } \\
\text { (GPM) }\end{array}$ & Associated Probability \\
\hline \multirow{2}{*}{3} & 1035 & 0.1 \\
& 1380 & 0.1 \\
& 1725 & 0.8 \\
& 1035 & 0.15 \\
& 1380 & 0.35 \\
& 1725 & 0.50 \\
& & \\
& 1035 & 0.2 \\
& 1380 & 0.6 \\
& 1725 & 0.2
\end{tabular}

Source: JPL Estimates 
The cumulative distribution of profit in this case is shown in Figure 2-2. Comparison of Figures 2-1 and 2-2 shows that the distribution of profit in the base case is probabilistically dominated by the distribution of profit in the correlated event case. ${ }^{7}$ With no assumptions about the utility function of an investor other than that more profit is preferred to less, we can conclude that an investor would prefer to invest in a geothermal project with the characteristics of the correlated events case, rather than a project with the base case characteristics.

The correlated events case cannot be handled by the standard Monte Carlo type model, and the ability to handle such correlated input data is a prominent feature of the GPCM.

7 Probabilistic dominance is also known as stochastic dominance. For a discussion of probabilistic dominance see Reference 9. 


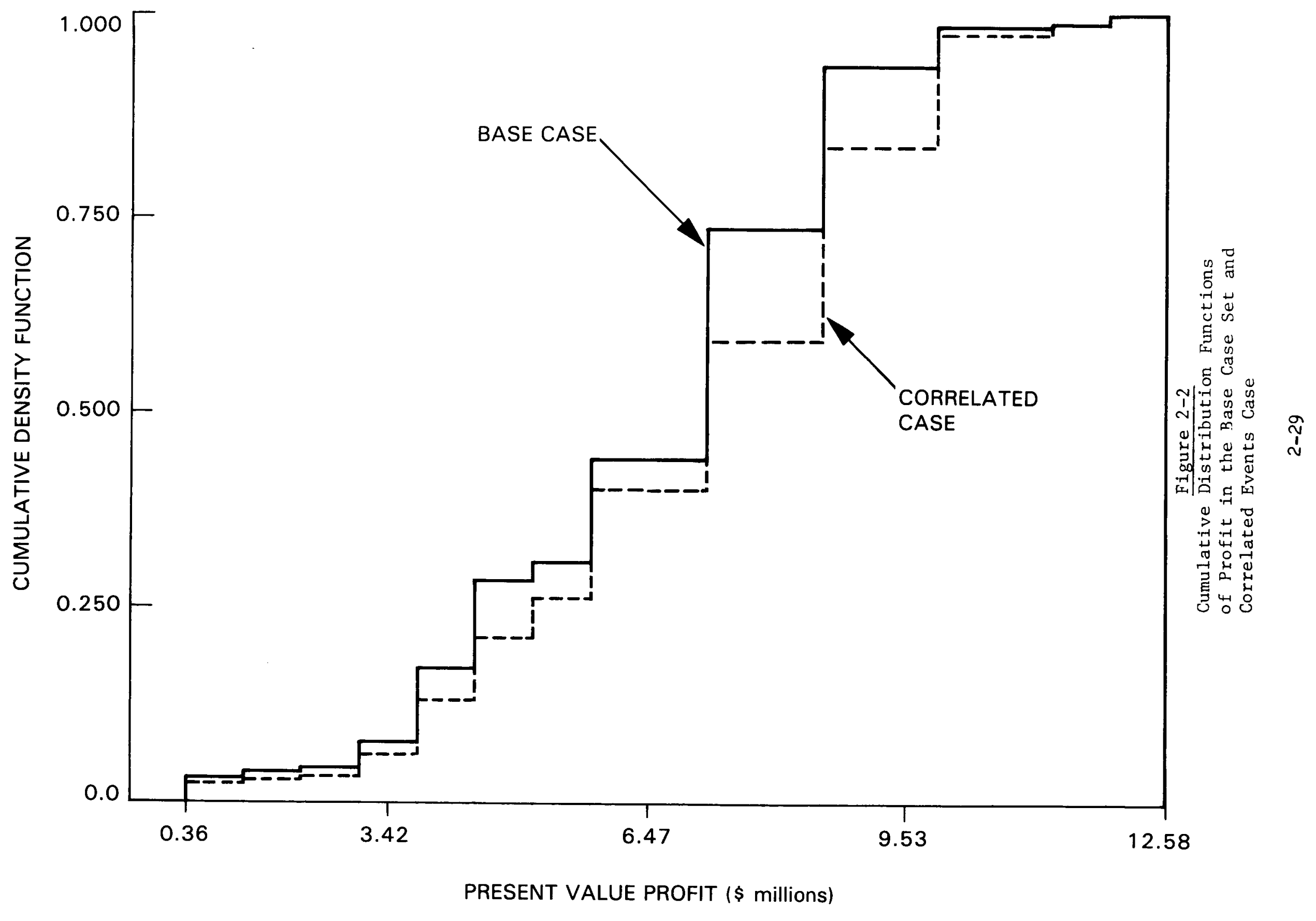


1. Cassell, T. A. V., et al, Geothermal Investment and Policy Analysis with Evaluation of California and Utah Resource Areas, U.S. Dept. of Energy, Oct. 1979.

2. Energy Review, Data Resources, Inc., Lexington, MA., Summer, 1981.

3. Crude Oil Windfall Profit Tax Act of 1980, Sec. 221, 26, U.S.C. 46.

4. Internal Revenue Code, Sec. 611 .

5. Grieder, B., Economic Risk of Geothermal Projects, Paper presented at Geothermal Resources Seminar, San Francisco, CA, April 8, 1980.

6. Heber Geothermal Project, Proposal submitted to U.S. Dept. of Energy by San Diego Gas \& Electric, San Diego, CA, December 1979.

7. Holt, B., and Ghormley, E. L., Energy Conversion for Geothermal Power Generation at Heber, California, Valles Caldera, New Mexico, and Raft River, Idaho Case Studies, Electric Power Research Institute, Palo Alto, CA., November 1976.

8. Doane, J. W., et al, The Cost of Energy from Utility-Owned Solar Electric Systems, Jet Propulsion Laboratory, California Institute of Technology, Pasadena, CA, June 1976.

9. Keeney, R. L. and Raiffa, H., Decisions With Multiple Objectives, John Wiley \& Sons, Inc., New York, 1976. 
CHAPTER 3

THE GEOTHERMAL PROBABILISTIC COST MODEL

3.1 INTRODUCTION TO THE MODEL AND THE REFERENCE SCENARIO

The development of a geothermal energy resource presents a potential investor with a number of uncertainties, both in the geothermal resource and in the development process itself. These elements of uncertainty can be incorporated into cost estimates properly if probabilistic cost models are used. This chapter provides the reader with a description of one such model that has been developed at the Jet Propulsion Laboratory. The model calculates the probability distribution for the cost of a project, as well as for other financial factors such as profit and required capital. It has long been a tradition to provide a single point estimate for these factors, but it is our conviction that at best such estimates are expected costs and more often tend to be on the low side. Expected cost alone provides a limited amount of information. Usually, the expected cost for a new technology is higher than the current conventional energy cost. Thus, based on the criteria of expected cost alone, such a new technology would not appear economicaly attractive. However, the variance of the cost estimate may be large enough to indicate that there may be a significant probability that the new technology is competitive. This is illustrated in Figure 3-1.

\subsubsection{THE REFERENCE SCENARIO}

Many projects or processes can be considered as occurring in stages, with the cost of the activities for the project being dependent upon the duration of the stage in which they occur. In projects of this type with long time-horizons, it is often the case that the duration of at least some of the stages (and hence the cost of the activities in those stages) will be 


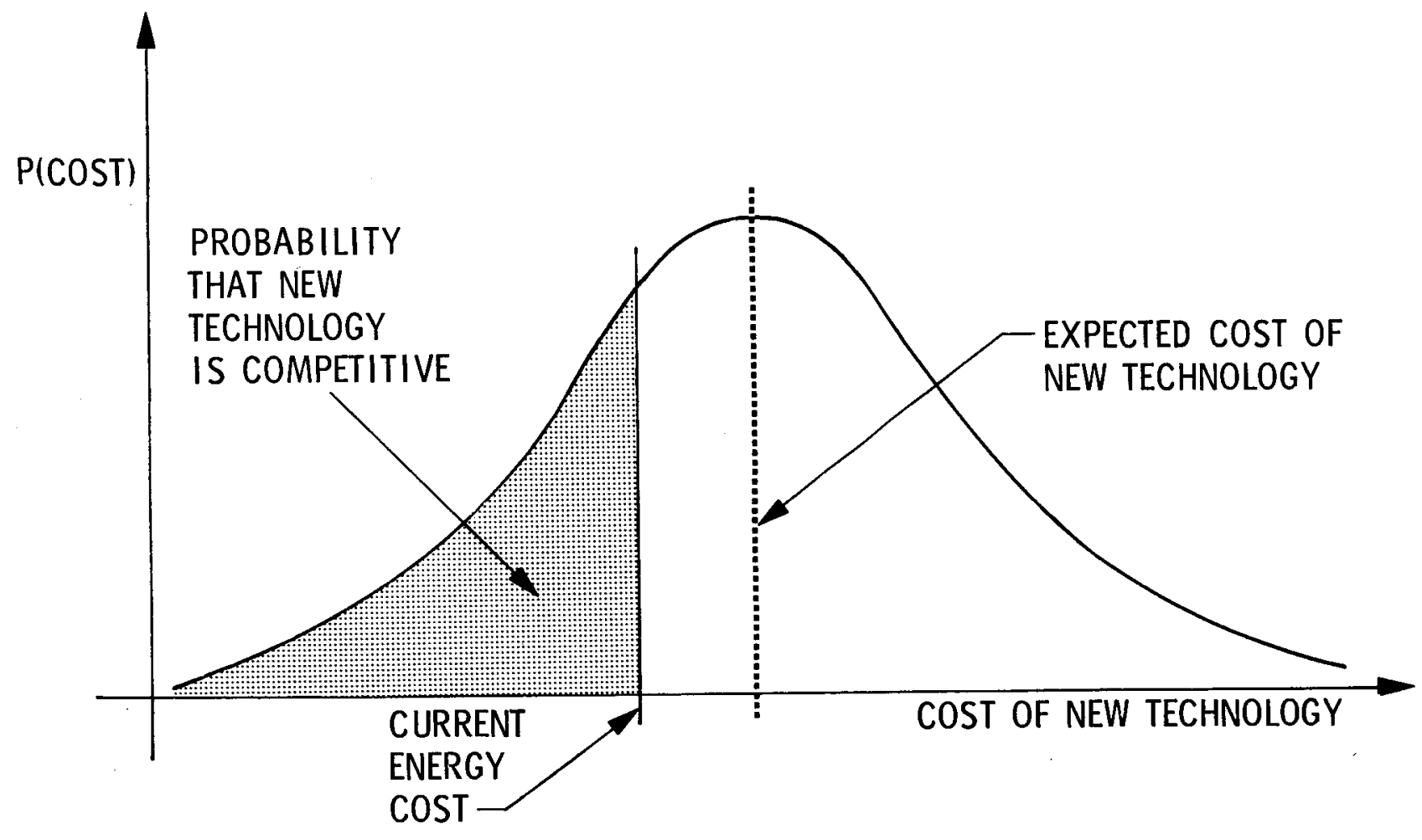

Figure 3-1. Expected Cost of a New Technology 
uncertain. Thus, final cost and profit will be sensitive to the length of time required to complete each of those stages. In addition to the stage durations, other variables that have an effect on cost, such as phrsical parameters, may also be uncertain.

The model described in this paper deals with these uncertainties by considering individually all permutations of times (for the stage durations) and values (for the uncertain physical variables). From each such permutation of times and values, a 'scenario' is constructed and then analyzed. It would be quite costly to have an architectural/engineering firm actually calculate the costs associated with all possible combinations of these variables (e.g., well flow rates, reservoir depth, fluid temperature, and permitting and construction times) for a given site. To avoid the enormous information costs of generating these cost accounts for each such combination, the morel makes use of a Reference Scenario. A Reference Scenario is defined as the most likely developmental pattern. Cost-accounts are input into the program for only this Reference Scenario. For all other scenarios, only their stage times, physical parameter values, and the associated probabilities are input: their cost accounts are derived within the program by modifying the appropriate Reference Scenario cost accounts for any differences in the length of the stages or for any differences in the values of the physical parameters. Thus, as described in Section 3.4.2.1, the Reference Scenario is really a baseline case from which all other scenarios are derived. As a result, the lengthy and difficult task of providing detailed cost accounts for the site under study has to be performed only once (for the Reference Scenario).

The Reference Scenario also serves as a standard form for presenting data for the model. It is important to note that the mathematical model developed is flexible enough to handle as many stages and cost accounts as 
the user desires. The Reference Scenario framework described in Section 3.2 provides a suggested framework for aggregating the accounts in the model and for organizing the data collection.

The user of this model should realize that the amount of data required, and therefore the computer cost, will vary with the number of stages identified, as can be seen from the sample decision tree in Figure 3-2. For example, if there were eight stages with two alternatives in each stage, there would be $256\left(2^{8}\right)$ scenarios. If, additionally, there were two physical variables with two possible outcomes each, the total number of scenarios would be $2^{8} \times 2^{2}=2^{10}$. Therefore, the user should always try to delineate only the essential stages.

It should be noted again that a Reference Scenario must be defined for each site where the model is applied. This is in keeping with the Federal Geothermal Energy Program recognition of the need to focus "not only on generic research and development, administrative and policy initiatives, but also on site-specific development requirements." By demonstrating the risk associated with the development of each site in that site's cost distribution (i.e., density function), the model will be helpful in fulfilling these requirements.

The next section describes the Reference Scenario framework for the model. Section 3.3 provides the rationale for treating specific factors as random variables. These are presented before the formal model (Section 3.4) to provide the reader with background information that should be useful for understanding the model.

3.2 REFERENCE SCENARIO FOR A GEOTHERMAL RESERVOIR

As described in the preceding section, a probabilistic cost model has been developed to analyze the development of a geothermal resource. Although 


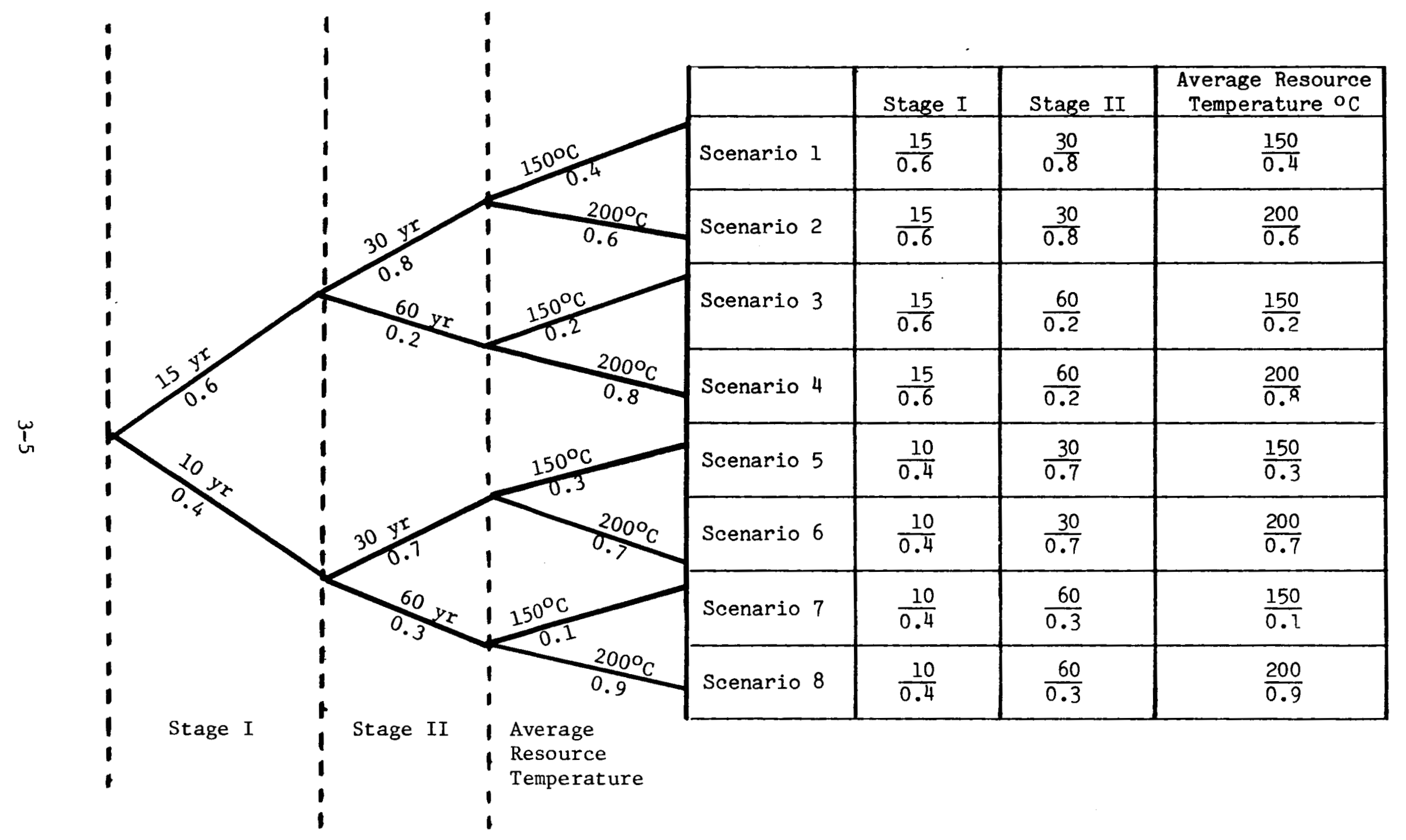

Figure 3-2

Completion Time of each Stage and the Conditional Probability

of its Occurrence: Project of Two Stages and One Resource Characteristic 
the model can be applied to the development of the reservoir for the production of steam as well as to the construction of a power plant for the generation of electricity, this section describes only the development of the reservoir. ${ }^{1}$ The model examines the time-dependent activities, as well as the time-independent activities, that must be completed before the developer of the geothermal reservoir can provide steam to the owner of a power plant on an ongoing basis. About $60 \%$ of the cost of electricity from a geothermal facility is attributable to the production of steam (see Figure 3-3). About $10 \%$ is due to annual expenses related to the power plant, and the remaining $30 \%$ is allocated to the initial power plant investment. The cost of geothermal steam is about equally dependent on the cost of field development (45\%) and the cost of operating the field (46\%). The remainder of the cost is due to field exploration. 2

The Reference Scenario for the development of a geothermal reservoir is structured around the essential processes or stages of development. Only the stages that are important from the standpoint of cost or time will be explicitly incorporated in the Reference Scenario. Minor stages have been aggregated to form these generic stages.

Each geothermal area has different geologic characteristics and construction requirements and perhaps even different permitting procedures depending on the state in which it is located and whether it is on private, state, or federal property. Therefore, data collected from the experience at one site might not be relevant to another. The application of the cost model

1 The model may be applied to any investment project with uncertainty, as long as the user can provide $a l l$ the required cost data and engineering relationships.

2 The percentages differ for individual sites. The objective here is to give the reader a reference point for evaluating the importance of various cost accounts. 


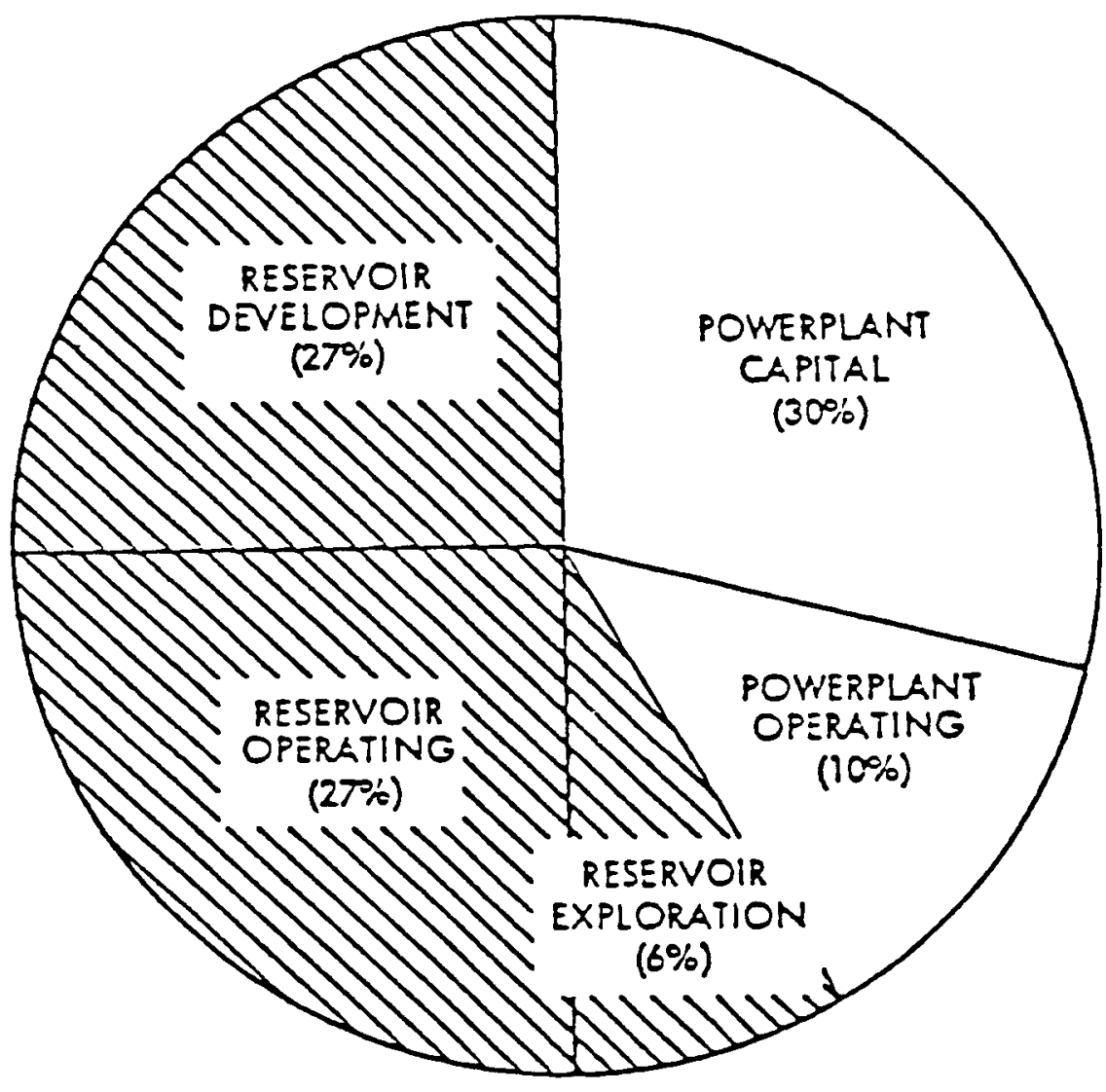

COSTS DESCRIBED IN
THE REFERENCE
SCENARIO FOR A
GEOTHERMAL RESERVOIR

Figure 3-3: Approximate Distribution of the Cost of Electricity Generated from a Geothermal Source (from Reference 2) 
will require the definition of a Reference Scenario at each site. The specific data (cost, time, conditional probabilities, and technologv) is site-dependent.

\subsubsection{Stages of Geothermal Reservoir Development}

The developer is responsible for the exploration of the geothermal resource and the definition of its capacity and characteristics. His responsibilities also include the subsequent drilling of the production and reinjection wells, and the construction and operation of the transmission system that brings the geothermal resource to the "front door" of the utility's power plant. In essence, the developer's activities can be viewed as occurring in four stages. The next four subsections will elaborate on these stages.

\subsubsection{Stage I: Proving the Resource}

Objective. The objective of Stage $I$ is to find a geologic anomaly that allows for the extraction of the Earth's internal heat at a cost, competitive with other electrical generation technologies. Establishing the temperature of the resource, as well as the existence of water to transfer heat from the deep igneous heat source to a geothermal reservoir shallow enough to be tapped by drill holes, is the goal for this stage. The criteria for success in this stage is the existence of the confirmatory geologic data required to convince an electric utility company that its investment at the field is warranted. The last activity in the stage is an agreement with the utility to pursue the necessary permits for building a power plant.

The amount of time necessary is the major element of uncertainty in this stage, reflecting the geological uncertainty about the quality and size of the reservoir based on preliminary geologic data. For example, 
Reference 3 estimates that 128 areas must be examined in order to get one successful site. This assumption is not appropriate to the Heber site because earlier exploration by oil and gas companies had revezled the geothermal anamoly while looking for natural gas reserves.

Cost Accounts. Stage I includes three major activities: preliminary resource identification and land leasing; exploration well permitting; and exploratory drilling and complete well logging. The assumptions and data sources for each activity are described below.

a. Preliminary Resource Identification and Land Leasing. Few models and sources consider this activity explicitly, so little detailed data is available. For Heber, this activity (and the next) are already completed. In fact, as noted above, this activity was completed by oil exploration companies many years ago. In reality, elements of these three activities are usually done at the same time.

Although the cost of a lease can become significant when viewed from the perspective of the number of leases required before finding a successful site, the time delay associated with the leasing of federal land is of prime importance in this model. There has been evidence that considerable variations in the time required may occur. Reference 4 has indicated 28 months as a good working number (see Figurs 3-4).

b. Exploration Well Permits. At this time, there seem to be two philosophies as to the nature of this early development permitting process:

(1) The application should be made for the entire geothermal field and thus eliminate the future uncertainty regarding the acquisition of the proper authority to develop the resource. The large oil companies seem to prefer this option because it helps them in their subsequent negotiations with electric utilities. 

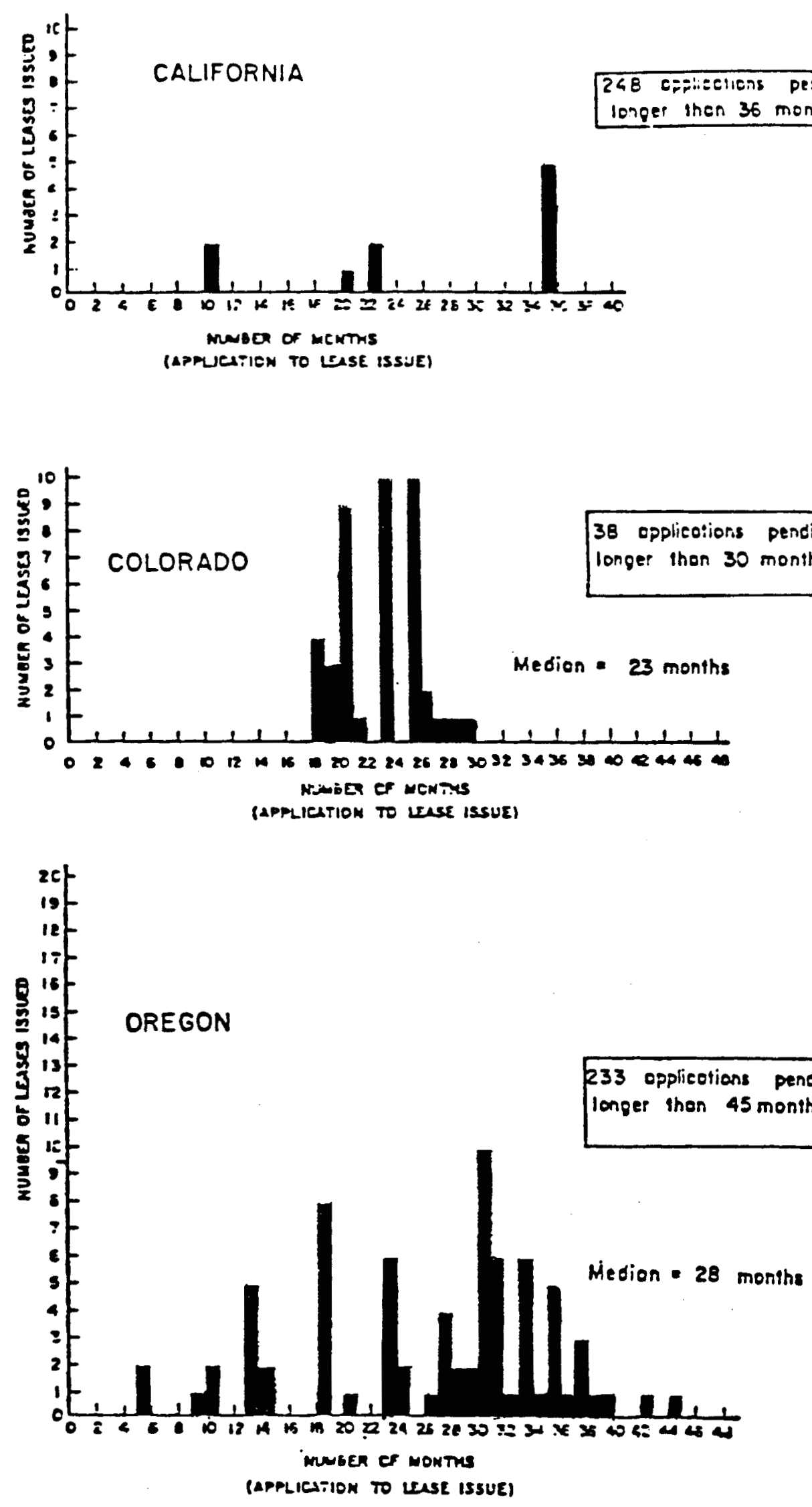

Figure 3-4

Time Lapse by Month from Non-competitive Lease Application to Lease Issuance (from Reference 4) 
(2) The application should be made as if the one exploratory well is the only well to be drilled at the site. Future production and reinjection wells must then be approved under a separate permitting process if development takes place. This approach is favored by smaller companies that cannot afford the up-front costs of an environmental impact analysis without having a higher assurance of the economic success of the geothermal resource.

The former approach is more expensive because of the scope of analysis. However, in California under $A B 884$, the upper limit on the time required to receive or to be denied authority to continue with the development project is the same.

\section{c. Exploratory Drilling and Complete Well Logging. During} exploratory drilling, some further resource identification tests are done, including flow tests, reservoir modeling, material tests, and reinjection experiments.

Beginning now, the parties involved in the geothermal development (e.g., the field developer and the plant operator) will start to negotiate on the contractual terms for the sale of the geothermal energy to the electric utility. During the early development of geothermal resources this has been a slow and tedious process because of utility skepticism over the reliability and cost effectiveness of the investment. The electric utility wants assurance of the capacity (MWe years) of the resource to justify its investment in support facilities (substations, transmission lines) for its power plants. A typical figure for the required capacity is 200 MWe for 30 years. 


\subsubsection{Stage II: Development Permits Application, Review, and Approval}

Objective. Having completed Stage I, the producer and the electric utility must now apply for the necessary permits from the federal, state, and local authorities to develop the resource and construct a power plant. No capital investment by either the producer or the electric utility will take place prior to the completion of approval on all necessary permits. Therefore, this stage must eventually include the activities of both the utility and the developer.

Permits for the Developer. The necessary permits for the developer were discussed under the process of exploratory well drilling. As noted, in California, the upper limits of time allotted to application review should help to reduce the uncertainty over the time required to get a decision.

This scenario assumes that the developer will seek approval for full field development and not just for the wells required to produce energy for the first scheduled power plant. This assumption is made because full field permits will provide the utility with greater assurance as to the viability of capital investment at that site.

In addition, with the passage of the $A B 884$, the maximum time required for a full field permit and a one power plant reservoir permit is identical. This maximum time is $1-1 / 2$ years after the completed application is received by the lead agency. Therefore, the producer will be saving time in the long run by avoiding permit applications and reviews for the wells for future power plants. The direct cost for the permits to the developer are minimal since the required permits do not involve filing fees. However, the indirect costs incurred for environmental studies and for preparing applications could be expensive, though probably not influential, in relation to the total capital cost. 


\subsubsection{Stage III: Reservoir Development}

Objective. The developer and the electric utility are now in $a$ position to begin the actual development and construction of their respective facilities. By now, the characteristics of the resource have been established, the developer has agreed with the utility on the price and amount of heat to be sold, and all the necessary permits and authorizations have been received. This stage for the developer includes the development and start-up operation for $a l l$ the production and reinjection wells, and the construction and testing of the geothermal transmission system.

Stage III is different from Stages I and II in that engineering and procurement uncertainties affect the actual time involved. Stage I is characterized by the geologic uncertainty, and Stage II is determined by the administrative procedures of several bureaucracies. The following section looks at the cost accounts and their relationships to the tasks.

Cost Accounts. The largest single expenditure for Stage III is the drilling of wells. The Reference Scenario for Heber has thirteen production wells and seven injection wells ${ }^{3}$ at depths ranging from 4000 ft to 10,000 ft. $75 \%$ of this cost will be treated as intangible drilling costs and $25 \%$ will be capitalized. The second largest expense is for surface facilities, which also includes the cost of down hole pumps for the production wells. Half of this cost is treated as intangible drilling costs and the other half is capitalized.

\subsubsection{Stage IV: Operation of the Facility}

Objective. Stage IV describes the costs incurred by the developer over the economic life of the power plant. These include the general

3 Of the 13 production wells, two will be spares, and of the 7 injection wells, one will be a spare. 
operation and maintenance of the existing equipment as well as the development of new production wells to maintain the necessary energy flow to the power plant. For example, if the flow rate from existing wells decreases or the temperature of the resource degrades, more wells will be required to make up the difference. Also, with time, some wells might fail and have to be abandoned necessitating new wells to be drilled nearby to take advantage of the known resource. Although this degradation is not modeled explicitly by this study, a redrilling program is assumed to take place and new wells are scheduled to keep the heat content constant for the life of the geothermal field.

Success in this stage is defined as being able to continually operate the reservoir at some stated capacity for the life of the power plant. The treatment of various levels of non-success and its effect on cost has not yet been completed.

Cost Accounts. The frequency of subsequent drilling-related activities and the annual operation and maintenance costs are given in the site-study in Table 2-4c.

3.3 SOURCES OF UNCERTAINTY IN THE DEVELOPMENT OF GEOTHERMAL RESOURCES The uncertainty surrounding the successful development of a geothermal can arise from a large number of sources. But, although many sources may contribute to the uncertainty, only those that impact the ultimate cost to a substantial degree need to be considered further. If changing the value of a variable within a realistic range introduces significant changes in the costs of power, then that variable is considered to be important. In this section the identification of important variables will be done in two steps. The first step is to identify those variables whose per unit variations have the greatest impact on final cost. This is obtained by 
varying the value of a given parameter, and dividing the resulting change in power cost by the change in the parameter.

The second step is the determination of how much each parameter might reasonably be expected to vary from an assumed mean value. Some variables can be expected to have a value that falls within a narrow range, while others can be expected to fall somewhere within a wide range of values. Thus, the second step identifies those variables that can be expected to have the largest fluctuation in their own values, while the first step identifies those variables whose per unit changes cause the largest variation in cost. Accordingly, those variables whose per unit influence on total cost is high and which can fluctuate widely will be more important sources of uncertainty than those variables whose per unit influence on total cost is likewise high, but which are not expected to fluctuate very much, and so on.

The first step is exemplified by Table 3-1, which is the result of $a$ sensitivity analysis from Reference 7 . This shows the change in final cost due to a change in a given parameter. The first item has the highest finzl cost change per unit parameter change (obtained by dividing the reduction in power cost by the change in the parameter), with the following items listed in descending order.

The second step is the determination of how much each parameter can reasonably be expected to change. For example, although the cost of capital is the second most sensitive variable, producing a $0.62 \%$ reduction in power cost for every 1\% change in the cost of capital, it is not likely that the cost of capital would vary by more than $5 \%$ for a particular company. This number is known as soon as a utility company is known, and thus the cost of capital would not be considered an important variable as far as its contribution to the uncertainty of the final cost of the resource is concerned. 
Table 3-1: Results of Sensitivity Analysis for

Reference Case with Power Cost $=28.2$ Mills/kW-hr (from Reference 7)

\begin{tabular}{|c|c|c|c|c|}
\hline Parameter & Reference Value & New Value & $\begin{array}{c}\text { Change In } \\
\text { Parameters, } \\
8\end{array}$ & $\begin{array}{l}\text { Reduction in } \\
\text { Power Cost, } 8\end{array}$ \\
\hline Wellhead Temperature & $200^{\circ} \mathrm{C}$ & $250^{\circ}$ & +25 & 19 \\
\hline Cost of Capital & & (Reduced by half) & -50 & 31 \\
\hline Cost per Well & $\$ 500,000$ & $\$ 300,000$ & -40 & 20 \\
\hline Well Flow Rate & $500,000 \mathrm{lb} / \mathrm{h}$ & $750,0001 b / h$ & -50 & 17 \\
\hline Plant Capital & $\$ 14.9$ million & $\$ 7.5$ million & -50 & 14 \\
\hline $\begin{array}{l}\text { Internal Power } \\
\text { Consumption }\end{array}$ & $10.5 \mathrm{MWe}$ & $5.25 \mathrm{MWe}$ & -50 & 11 \\
\hline Taxes & (A1l tax rates & reduced by $1 / 2$ ) & -50 & 10 \\
\hline $\begin{array}{l}\text { Cost of Transmission } \\
\text { and Disposal Systems }\end{array}$ & . & (Reduced by half) & -50 & 9 \\
\hline Reinjection Costs & Reinjection & No Reinjection & -100 & 16 \\
\hline Well Life & 10 years & 20 years & +100 & 10 \\
\hline $\begin{array}{l}\text { Excess Producing } \\
\text { Wells }\end{array}$ & $\begin{array}{l}20 \% \text { of Projec- } \\
\text { tion Wells }\end{array}$ & $\begin{array}{l}5 \% \text { of Production } \\
\text { Wells }\end{array}$ & -75 & 6 \\
\hline Cooling Tower & Included & Excluded & -100 & 6 \\
\hline Operating Expenses & & (Reduced by half) & -50 & 3 \\
\hline Royalty Payments & $10 \%$ & 0 & -100 & 5 \\
\hline Dry Wells & $\begin{array}{l}208 \text { of Produc- } \\
\text { tion Wells }\end{array}$ & $\begin{array}{l}58 \text { of Produc- } \\
\text { tion Wells }\end{array}$ & -75 & 4 \\
\hline Exploration Costs & Included & Excluded & -100 & 4 \\
\hline Plant Life & 30 years & 40 years & +33 & 1 \\
\hline \multicolumn{5}{|l|}{$\begin{array}{l}\text { Transmission and } \\
\text { Disposal Sy stems }\end{array}$} \\
\hline Maintenance Rate & 0.05 & 0.025 & -50 & 1 \\
\hline Intangible Write-off & Allowed & Not Allowed & -100 & $-10^{a}$ \\
\hline Plant Life & 30 years & 20 years & +33 & $-5^{a}$ \\
\hline
\end{tabular}

a Indicates an increase in cost of power. 
At this point, one problem with Table 3-1 should be mentioned. It provides sensitivities at a given point (at the reference cost given in the table). Like the concept of point elzsticity, this sensitivity is dependent on the point at which it is measured. It is a variable, and thus linear extrapolations may not be accurate.

The first five variables in Table 3-1 are:

(1) Wellhead temperature.

(2) Cost of capital.

(3) Cost per well.

(4) Well flow rate.

(5) Plant capital cost.

The following subsections discuss the uncertainty inherent in wellhead temperature, the cost of wells, and well flow rates. The mathematical model presented in Section 3.4 shows how these variables (wellhead temperature, cost per well, and well flow rate) are incorporated in the model. The computer program can handle any number of cost and resource uncertainties, but the user has to specify the scaling equations for each uncertainty.

\subsubsection{Wellhead Temperature}

Wellhead temperature, as is seen by Table $3-1$, heads the list as the variable to which power cost is most sensitive. By drilling deeper, higher temperatures can be reached. However, with existing technology, there must be a reservoir of water or steam to transport the heat. Typically, the presence of water creates convective cell and, as indicated by Figure 3-5 (Reference 8, page 72 ), a convective cell has a fairly constant temperature over its depth. Figure 3-6 shows this for the Mesa anomaly, which is some miles northeast of the Heber site. Using Figure 3-6, it is clear that, although a characteristic reservoir temperature can be listed, individual well temperatures can vary 
TEMPERATURE $\longrightarrow$

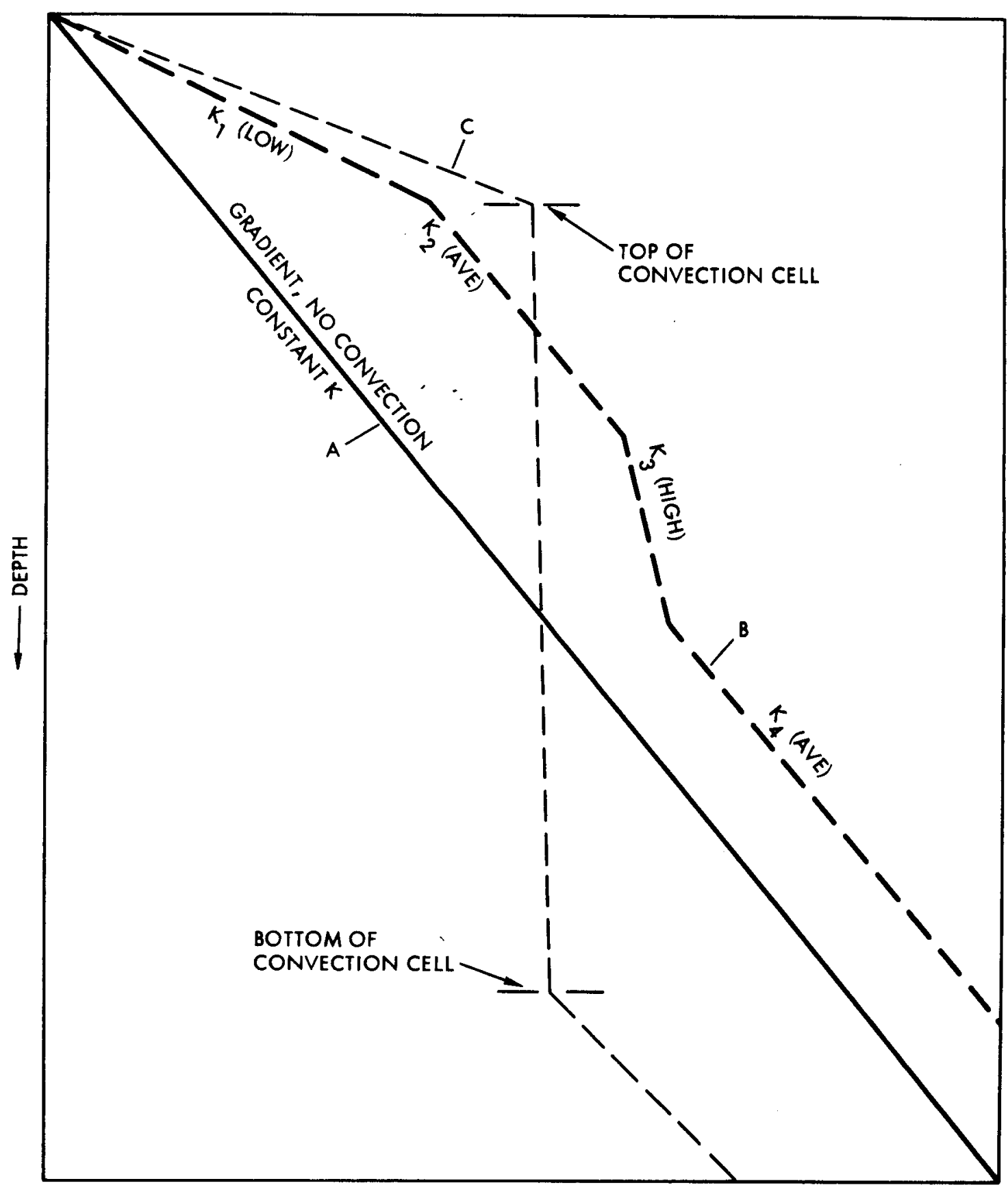

Figure 3-5

Temperature/Depth Relations, Where Heat Flow is Controlled by Thermal Conduction in Rocks of Constant Conductivity (A); Rocks of Variable Conductivity (B), or by Major Convective Disturbance (C) (from Reference 8) 


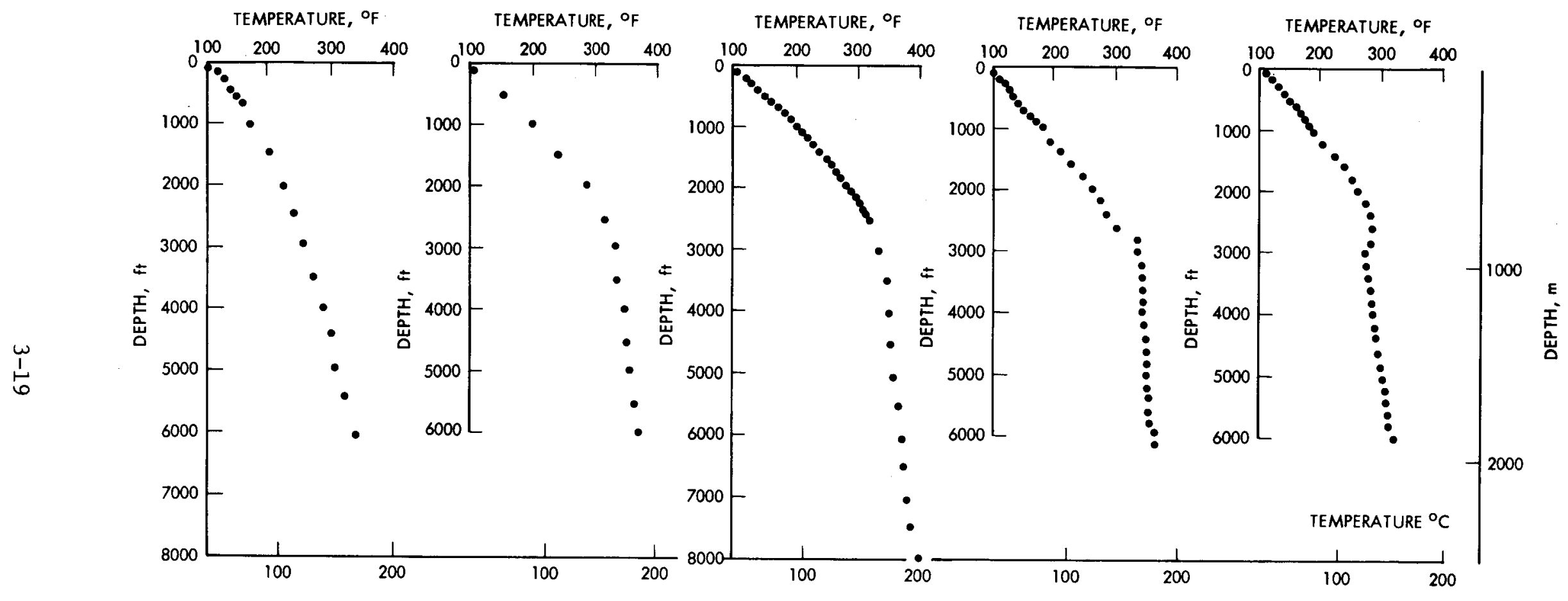

Figure 3-6

Distribution of Temperature with Depth for Five Geothermal Wells. The Depth Ranges are Shown in Feet and Correspond to the Clay Cap ( 0 to $600 \mathrm{~m})$, the Transition Zone $(600$ to $750 \mathrm{~m})$, the Upper Portion of the Geothermal Reservoir $(750$ to $900 \mathrm{~m})$, Two Additional Segments of the Reservoir 900 to $1525 \mathrm{~m}$ and 1525 to $2175 \mathrm{~m}$ ), and Below the Reservoir (2175 to $2448 \mathrm{~m}$ ). (from Reference 9) 
significantly. Taking a 5000-ft well, temperatures as shown in Figure 3-6 vary from $300^{\circ} \mathrm{F}$ to about $360^{\circ} \mathrm{F}$, a $20 \%$ variation. Because most wells reach $360^{\circ} \mathrm{F}$ somewhere near that depth, and hold it over a wide range of depths, $360^{\circ} \mathrm{F}$ would be considered the resource temperature.

Temperature affects plant cost in several ways. Decreases in temperature are anticipated. Chevron estimates $3 \%$ per year for Heber (Reference 10). Such a degradation of the resource can be compensated for by increased well flow rate. However, this depletes the reservoir more quickly and increases the capital cost requirements. Past a certain point, the power plants operating characteristics may need alteration. For example, Holt/Procon plans for roughly a $\$ 4$ million investment after 9 years of plant operation to re-optimize the initial power plant design points for the new, lower temperature at the Heber site (Reference 10).

\subsubsection{Cost per Well as a Function of Well Depth and Rock Type}

In the literature, the quoted value for the cost per well has ranged from $\$ 300,000$ to $\$ 2$ million dollars. Most of this variation is due to well depth. Figure 3-7 shows an estimate as to well cost per meter, with a $90 \%$ confidence interval. This estimate compares favorably with the medium hard to hard rock curves in Figure 3-8 which shows that the hardness of rock is an important determinant of drilling costs and thus well cost. The actual drilling costs used in the Heber site-study are discussed further in Section 2.2 .

\subsubsection{Well Flow Rates}

Figure 3-9 shows a $90 \%$ confidence interval for wellhead flow rate versus well depth. Using a 5000-ft deep reservoir, flow rates are about $375 \pm 125 \mathrm{Mlb} / \mathrm{h}$, a variation of about 33\%. Table 3-1 indicates that this variation would produce an $11 \%$ change in power costs. Figure 3-10 shows the variability of well flow rate over time. 


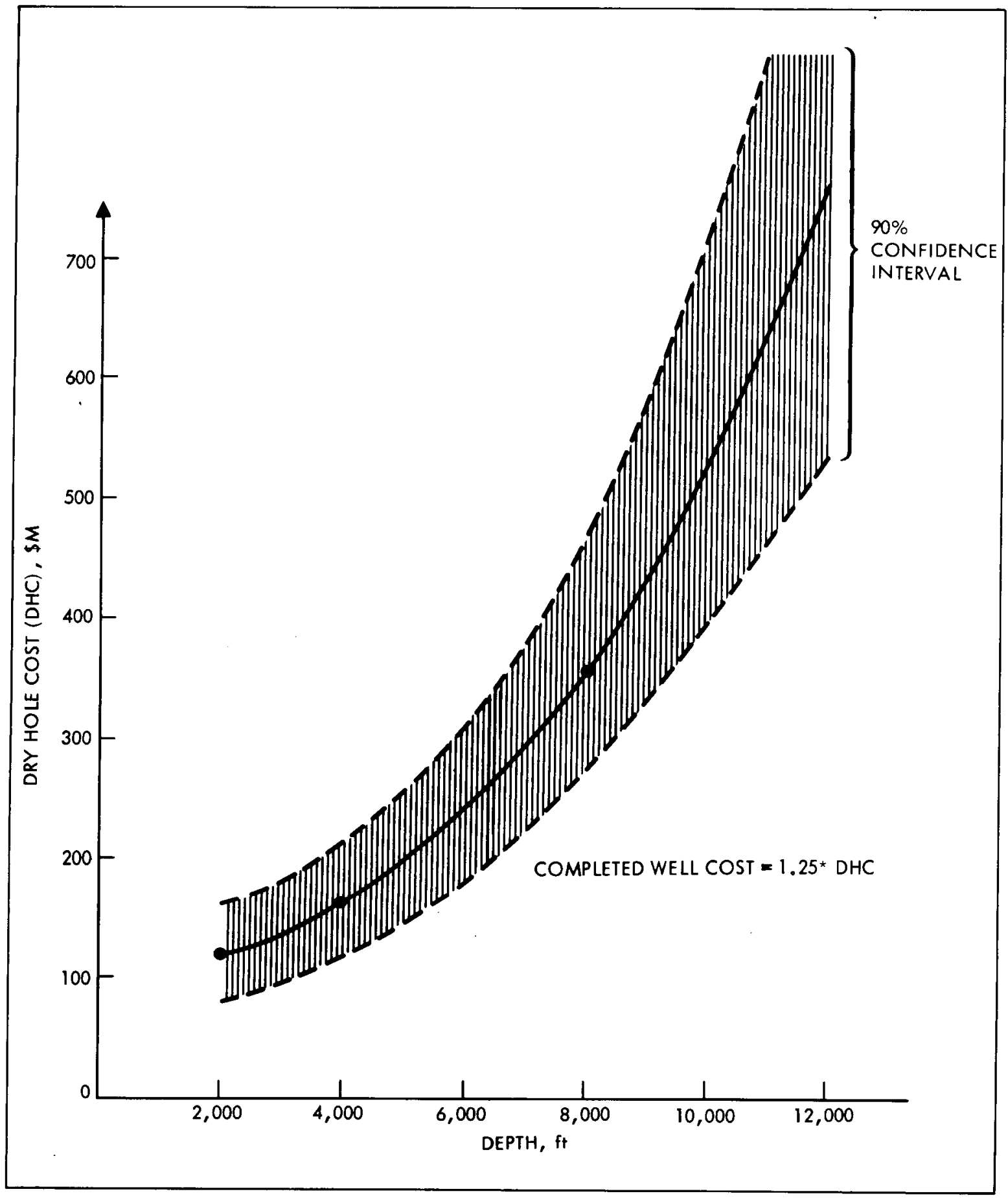

Figure 3-7

Effect of Depth on Geothermal Drilling Costs

(in 1975 dollars) (from Reference 11) 


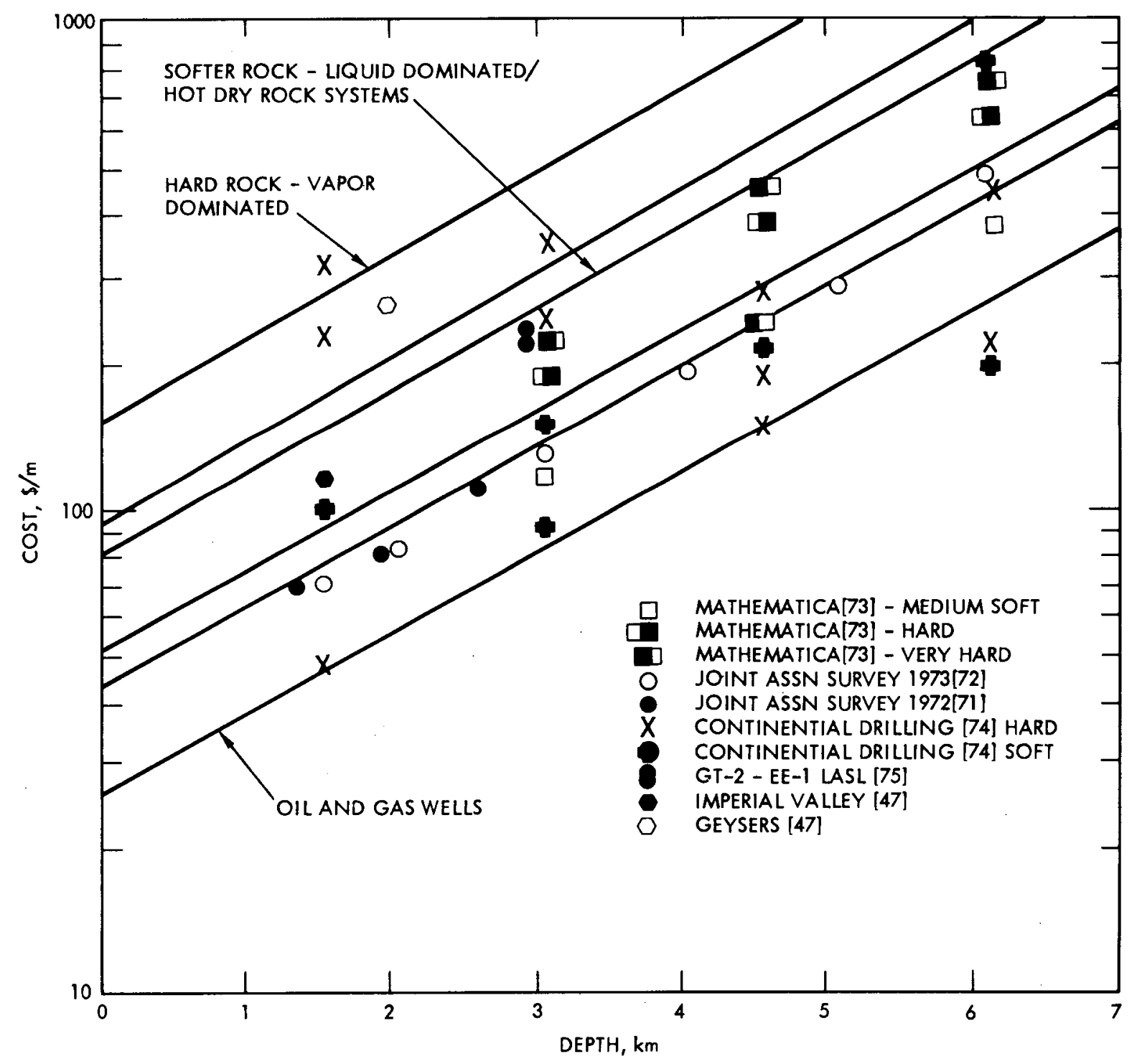

Figure 3-8

Well Costs Including Drilling and Casing as a Function of Depth (All costs are adjusted to 1976 dollars)(from Reference 5) 


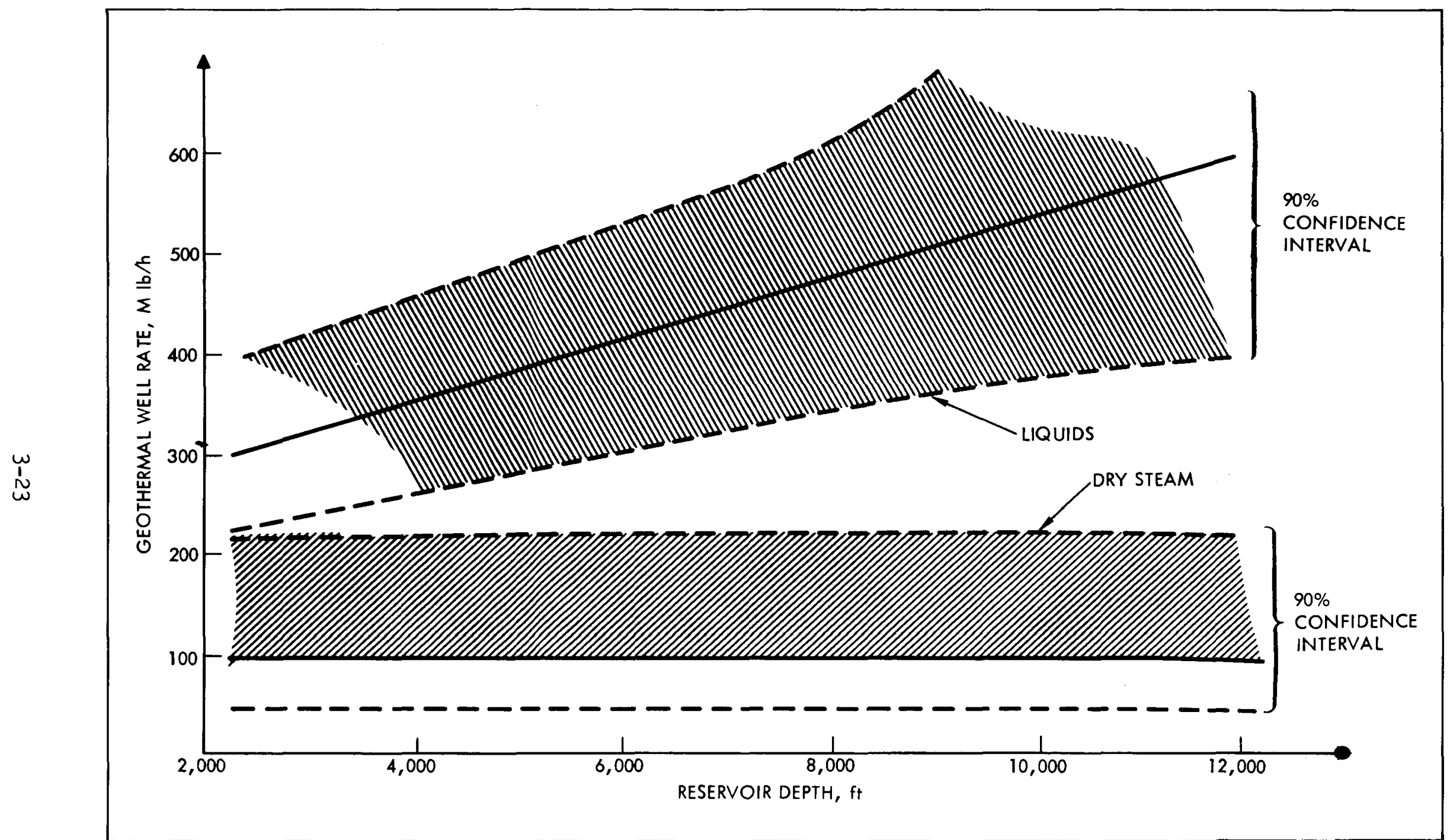

Figure 3-9. Effect of Reservoir Depth on Production Rate (from Reference 11) 


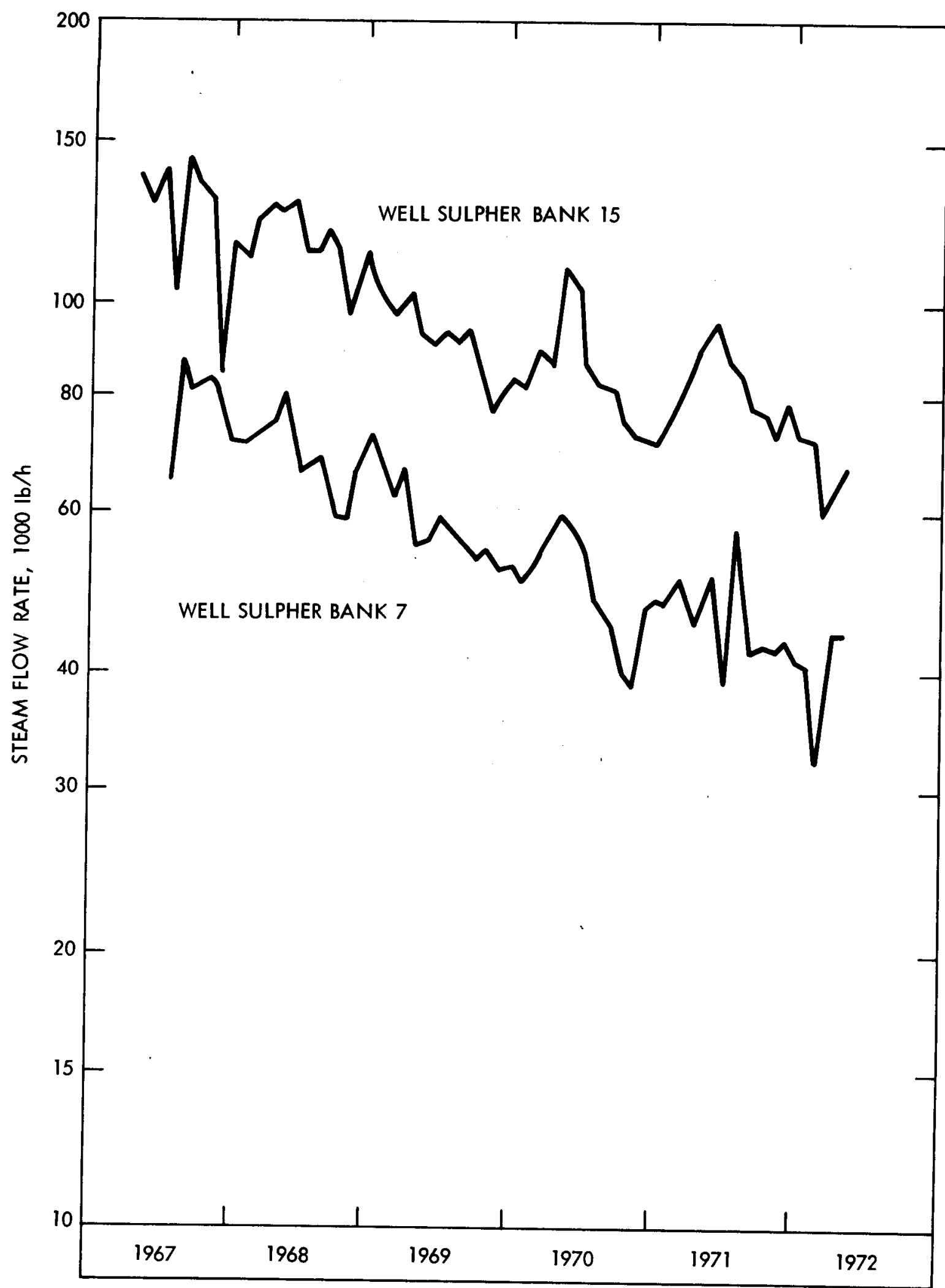

Figure 3-10

Steam-Production Rate vs Time for Geothermal Steam Wells at the Geysers

(from Reference 8) 


\subsubsection{Other Sensitive Variables}

Table 3-1 indicates that the cost of power is also sensitive to the cost of capital and to plant capital requirements. These variables are not treated stochastically in the model for the reasons given in the following paragraphs.

Cost of capital was used as an example previously to show that, although the cost of power might be sensitive to changes in a variable, the likely value of this variable will fall within a small range. If the average cost of capital for an electric utility company is $12 \%$, it is unlikely that the cost of capital would fall outside the range of $11 \%$ to $13 \%$. This small variation would only lead to a $5 \%$ change in the power cost. Thus, the effective influence of the cost of capital is not considered important. A similar argument holds for the producer, even though a large oil company has a higher debt/asset ratio than that of a small venture firm. Thus, once a firm is specified, the range in cost of capital for that firm should be small.

Table 3-2 shows a variety of "predictions" of geothermal capital costs. Variation is due to different resource temperatures, technologies used, cooling water availability and environmental controls required. Thus, one must be careful as to which plants can be compared. For the 200-mW steam plants, the cost per kilowatt was found to vary by $27 \%$ around the mean. Flash plant predictions for the same size plant varied by $30 \%$ about their average, and binary plants varied by $21 \%$ about their average. There were not enough small plants of the binary and flash type to do this for any but the 200-mW plants. Based on these results, if a $25 \%$ variation in power plant capital costs is assumed, only $a 7 \%$ change in power cost is expected.

The other variables listed in Table 3-1 can be similarly evaluated. Their effects on power cost can be calculated, with end result being the 
Table 3-2

Capital Costs (Field and Plant)

(from Reference 12)

\begin{tabular}{|c|c|c|c|c|c|}
\hline Source & Type & $\begin{array}{c}\text { Capacity, } \\
M N\end{array}$ & $\begin{array}{l}\text { Field } \\
\text { Investment } \\
\text { Costs } \\
(1976 \$), \\
\$ / \mathrm{kW} \\
\end{array}$ & $\begin{array}{l}\text { Generating } \\
\text { Plant } \\
\text { Investment, } \\
\$ / \mathrm{kW} \\
\end{array}$ & $\begin{array}{l}\text { Total } \\
\$ / \mathrm{kW}\end{array}$ \\
\hline Greider & Steam & 200 & $162 / \mathrm{kW}$ & 230 & 407 \\
\hline Greider & Flash & 200 & 172 & 429 & 617 \\
\hline Greider & Bi nary & 200 & 173 & 527 & 717 \\
\hline Barr & Steam & 200 & & 140 & \\
\hline Barr & Flash & 200 & & 232 & \\
\hline Barr & Binary & 200 & & 341 & \\
\hline Armstead & Steam & 200 & 103 & 173 & 277 \\
\hline Blomster & Flash & 55 & 174 & 274 & 447 \\
\hline $\begin{array}{l}\text { Holt and Brugman } \\
\text { at } 250 \% \mathrm{~F} \\
\text { at } 500 \% \mathrm{~F}\end{array}$ & Binary & 50 & & $\begin{array}{l}560 \\
297\end{array}$ & \\
\hline Holt $t^{a}$ & $\begin{array}{l}\text { Flash } \\
\text { Binary }\end{array}$ & $\begin{array}{l}50 \\
50\end{array}$ & $\begin{array}{l}200-300 \\
200-300\end{array}$ & $\begin{array}{l}450-550 \\
450-550\end{array}$ & $\begin{array}{l}650-850 \\
650-850\end{array}$ \\
\hline $\begin{array}{l}\text { Dan, Hersam } \\
\text { Kho and Kruml and }\end{array}$ & $\begin{array}{l}\text { Geysers } \\
\text { Unit } 14\end{array}$ & 110 & & 149 & \\
\hline Kmumland $b$ & $\begin{array}{l}\text { Geysers } \\
\text { Unit } 14\end{array}$ & 110 & & 260 & \\
\hline Goldsmith & (Flash) & & $150-200$ & $159-310$ & \\
\hline Geysers ${ }^{c}$ & $\begin{array}{l}\text { Geysers } \\
\text { Historical }\end{array}$ & 502 & 116 & 166 & \\
\hline Cerro Prietoc & (Flash) & 75 & & & 314 \\
\hline Racine & (Binary) & 50 & & $700-800^{d}$ & \\
\hline Hankin & (Flash) & 50 & & 742 & \\
\hline $\begin{array}{l}\text { Project } \\
\text { Independence }\end{array}$ & $\begin{array}{l}\text { (Brine) } \\
\text { (Geysers) }\end{array}$ & $\begin{array}{r}200 \\
1000\end{array}$ & & & $\begin{array}{c}560-860 \\
364 \mathrm{e}\end{array}$ \\
\hline
\end{tabular}

a Holt supersedes Holt and Brug̈man.

b Krumland supersedes Dan, Hersam, Kho, and Krumland.

c From Greider.

d Racines costs projected for 1982.

e Project Independence projected costs for 1980. 
demonstration of the importance of the three variables--wellhead temperature, cost per well (well depth and rock type), and well flow rate--relative to the others.

The only variable whose effect on cost has not been examined in the literature is the length of time required for the stages of development discussed in Section 3.2. Figure 3-11 shows the effect of the time lag from the signing of a contract between the producer and the electric utility to the start of fluid sales on the expected present worth of the venture. Data from PG\&E demonstrate the uncertainty about the time elapsed during one stage. The last three units $(13,14,15)$ at Geysers were expected to take 28, 36, and 28 months, respectively, to acquire the California Public Utilities Commission Certificate of Public Convenience and Necessity. These predictions were made almost two years before the certificate process. The actual realized times for units 13, 14, and 15 certification processes were 32, 33, and 26 months, respectively. 4

The time effect is explicitly discussed and stressed in the previous section. The computer model has the capability to handle this important factor, in addition to the resource uncertainties discussed above.

3.4 GEOTHERMAL PROBABILISTIC COST MODEL

3.4.1 Introduction to Probabilistic Modeling

Because the cost of developing a geothermal resource is intrinsically uncertain, no venture analysis technique can evaluate the cost or profit of a project with any degree of confidence without considering the uncertainties present. Partial accommodation of these uncertainties can produce results

4 Data from attachment to letter from Richard H. Peterson, Vice Chairman of the Board, Pacific Gas and Electric Company to Mr. Leo T. McCarthy, Speaker of the Assembly, California. The attachment is dated January 12, 1976. 


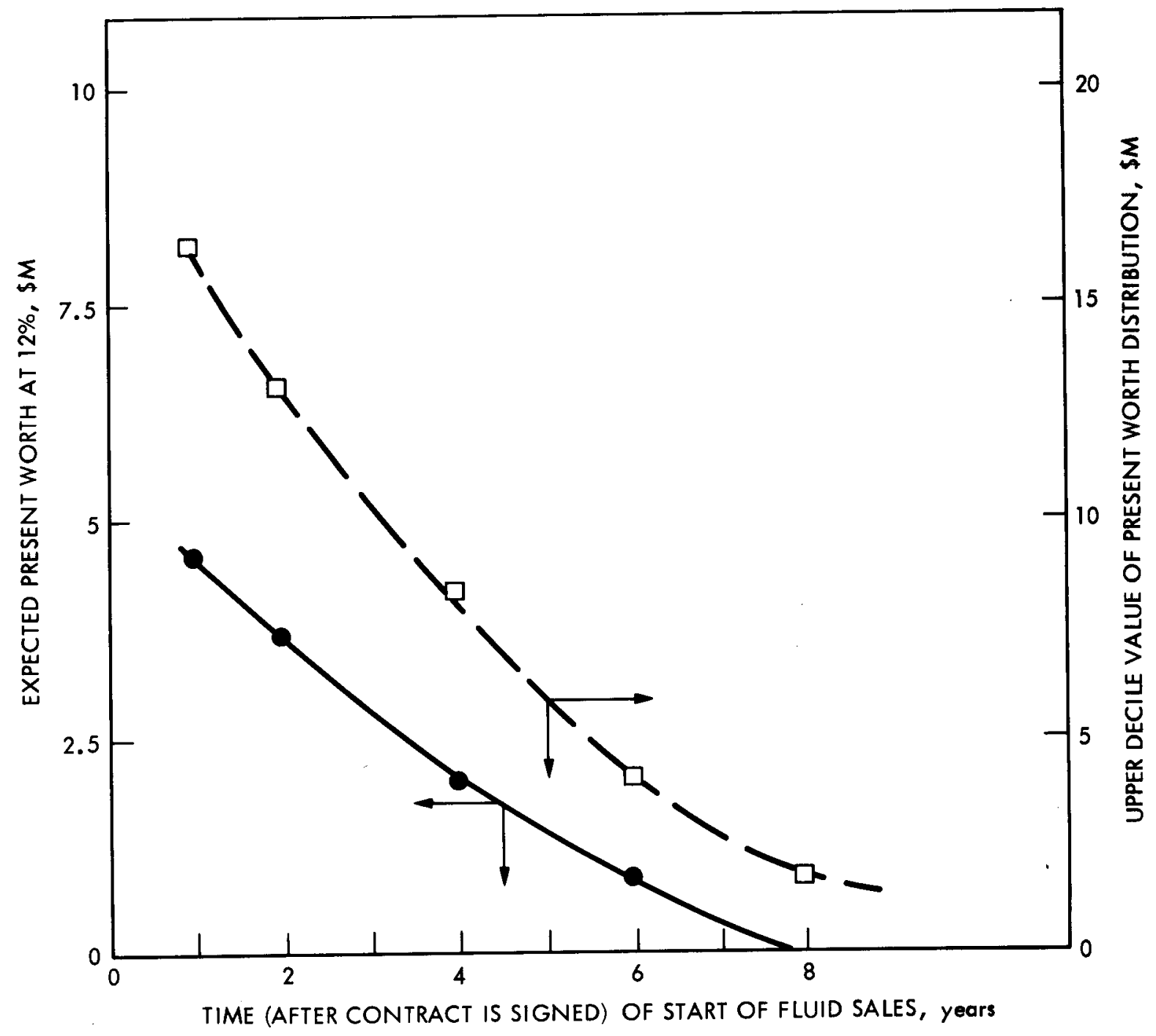

Figure 3-11

Effect of Time of Start of Fluid Sales on Expected Present Worth (from Reference 11) 
which are misleading. Probabilistic cost modeling, however, does provide the opportunity to properly incorporate these uncertainties into the final results. This paper describes one such model that has been developed at the Jet Propulsion Laboratory and discusses its application to a geothermal site at Heber, California.

The concept underlying probabilistic modeling is that the values for the model inputs are not known, but that their distributions can be estimated. A decision tree showing each possible sequence of events and the associated probabilities can then be constructed, and from this, project costs and other financial measures can be appropriately aggregated into probability distributions. By generating entire distributions, this model enables the inclusion of a decision-maker's risk preference into his investment decisions. The shaded area in Figure 3-1 shows that even though the expected cost of 3 new technology may be higher than the current cost of conventional technologies, there might be a considerable probability that the new technology is competitive with the existing technology. Likewise, there may be a significant probability that the cost of the new technology will reach unacceptable levels. The possibility for a decision maker to consider risk preference is precluded when only point estimates are made. It might be argued that calculating a point estimate requires less information than constructing a complete distribution. This is not true, however, because calculating the expected value implicitly uses all the relevant information contained in a probability distribution. This model uses that information explicitly and calculates the probability distributions for cost, required capital, and profit. The expected value and variance can be derived from these distributions, and risk preference may then be introduced.

The most distinguishing feature of the Geothermal Probabilistic Cost Model is that it allows the outcome of one variable to be dependent upon 
the outcomes of the other variables. Conditional probability distributions can thus be used. For example, the probability distribution for the length of a development stage may be dependent upon the lengths of the stages that precede it or upon the depths of the wells that have to be drilled, none of which may be known at the beginning of the project. In this way, any correlation--either positive or negative--between characteristics can be considered explicitly and a joint probability distribution that has all existing dependency relationships factored into it can be constructed. Therefore, this model can correctly aggregate the statistical variances in the stage time distributions. Unlike the expected value of the sum of two random variables (which is the sum of their expected values), the variance of the sum may be greater than, equal to, or less than the sum of their variances. It depends on whether the two random variables are positively, neutrally, or negatively correlated to one another. 5 The distributions in Figures $3-12 a$ and $3-12 b$ are of the same shape. The only difference is their orientation. With the major axis tilted to the right (indicating positive correlation), the distribution leads to a corresponding distribution of total project cost with a widespread (large) variance (see Figure 3-13a). The opposite case is obtained for the distribution having its major axis tilted to the left (indicating negative correlation). The corresponding distribution is more concentrated around its mean (low variance; see Figure 3-13b). The expected value approach can not capture all these results.

5 Let $x$ and $y$ be two random variables. Variance $(x+y)=\operatorname{Variance}(x)+$ Variance $(y)+2$ Covariance $(x, y)$. Variance $(x+y)=\operatorname{Var}$ iance $(x)+$ Variance $(y)$ if and only if Covariance $(x, y)=0$. 


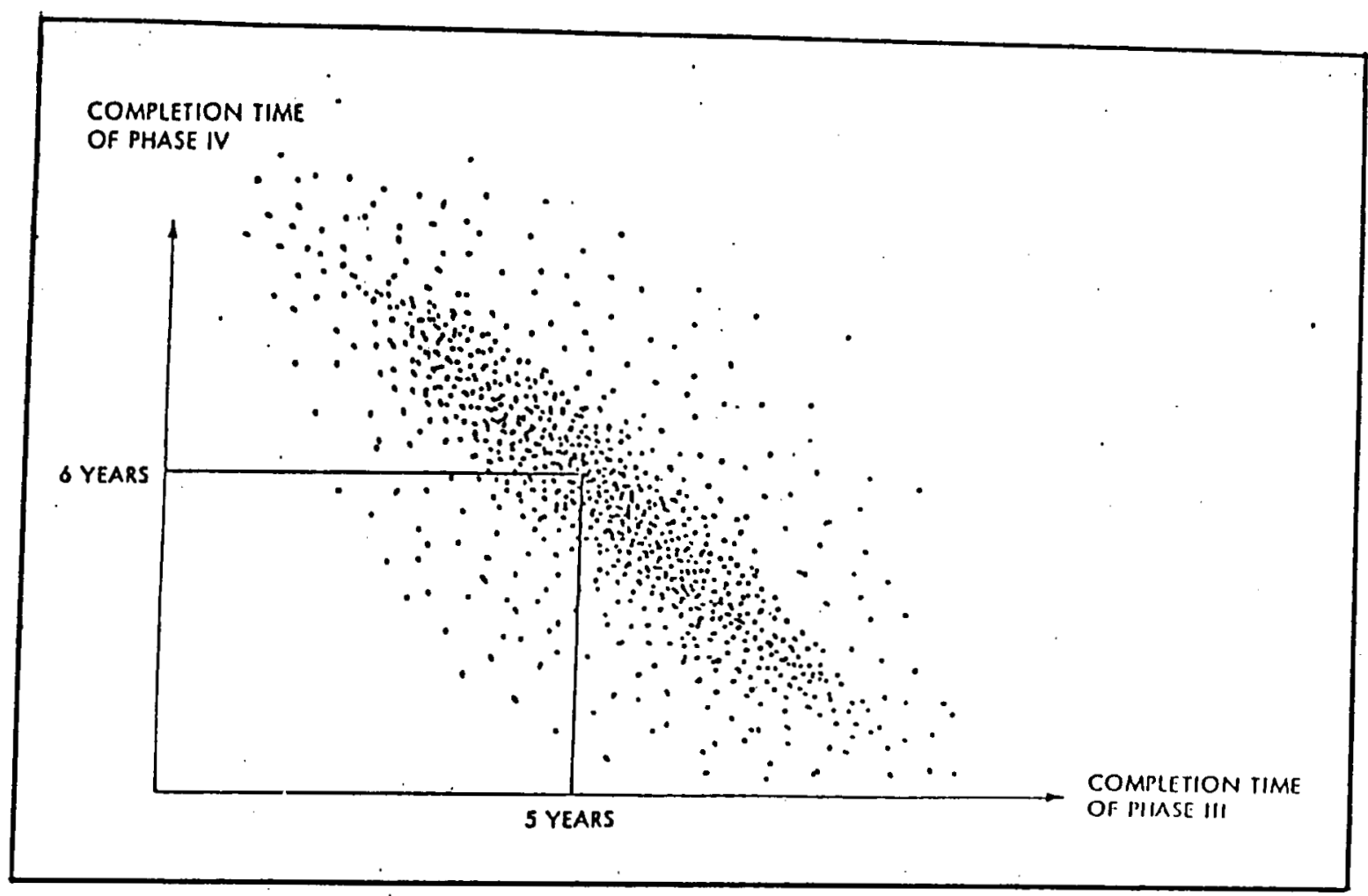

Figure 3-12a

Negatively Correlated Events

\section{COMPLETION TIME \\ OF PHASE $\|$}

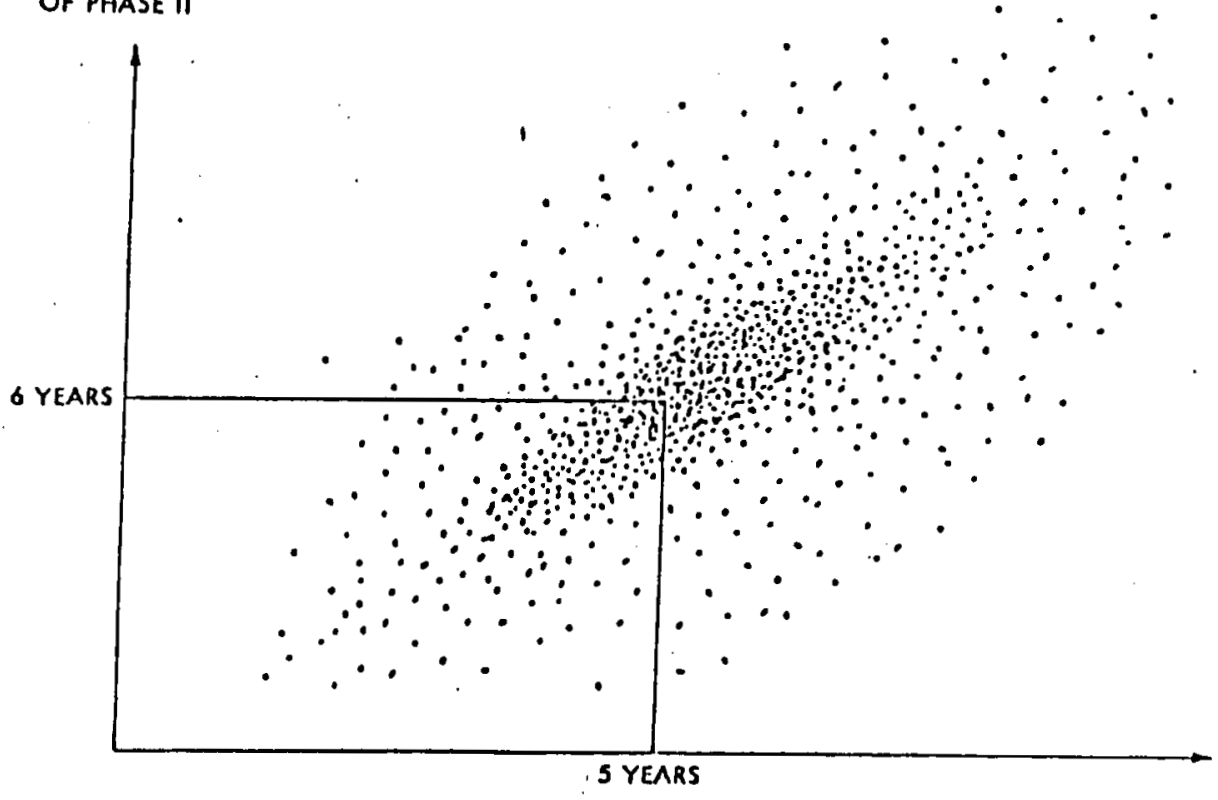

Figure 3-12b

Positively Correlated Events 


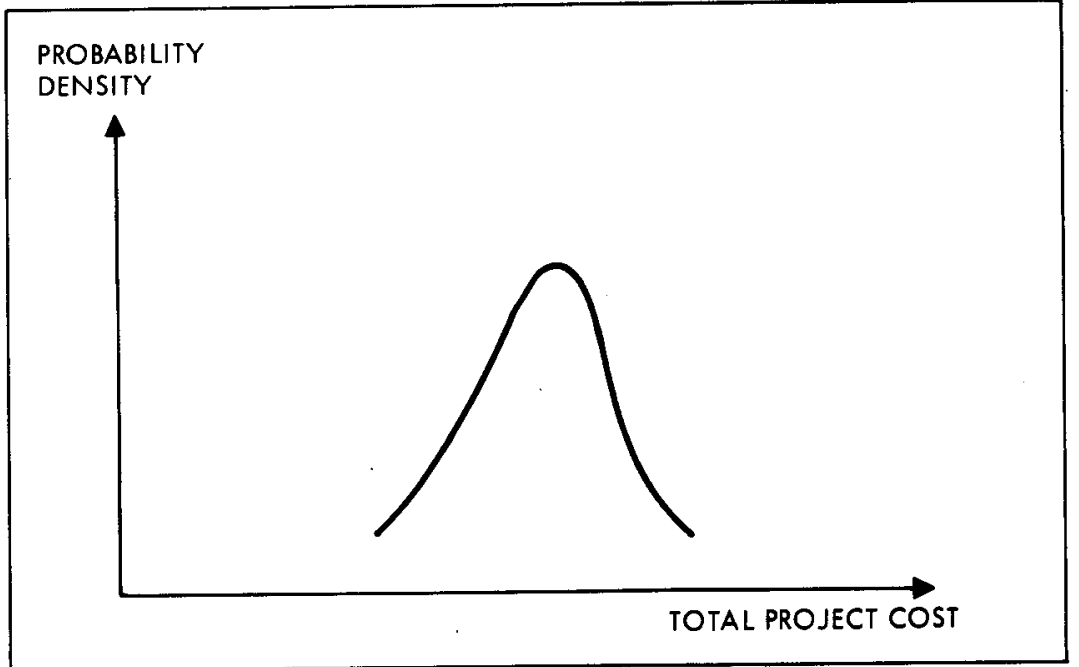

Figure 3-13a

Total cost of a Project when Time durations are negatively correlated

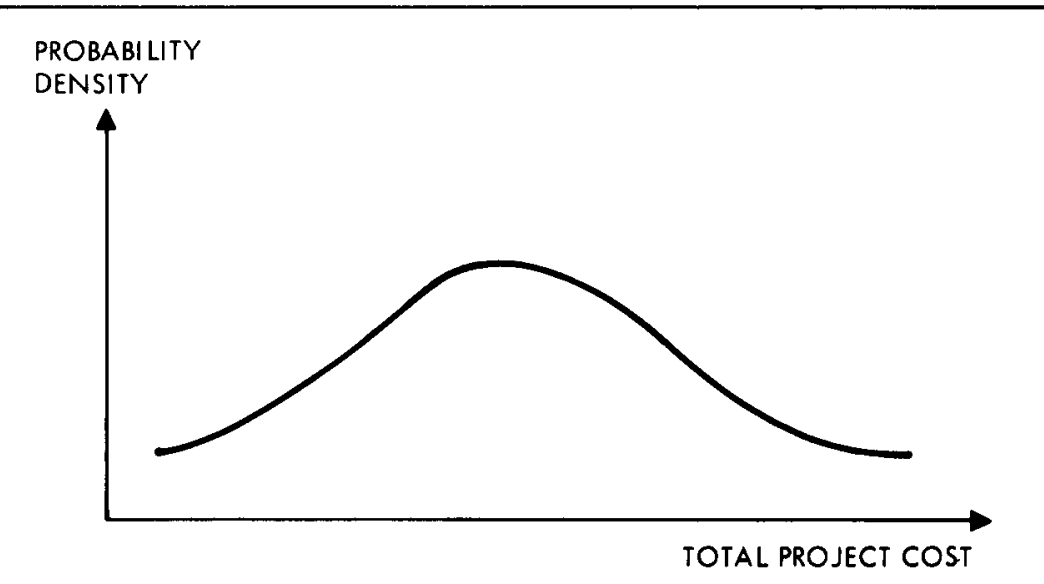

Figure 3-13b

Discrete Approximation of Continuous Events 
3.4.2 Formal Model

In section 3.2 .1 , four stages were identified for the Reference

Scenario of a geothermal resource development. These stages are:

(1) Stage 1: Proving the resource.

(2) Stage 2: Development permits application, review and approval.

(3) Stage 3: Reservoir development.

(4) Stage 4: Operation of the facility until the field is depleted of an economically valuable geothermal resource.

These four stages have been used to model the Reference Scenario

here. Although any number of stages is possible, to maintain a manageable number of stages and to prevent the number of alternative scenarios from being too large, six stages should be set as the upper limit. To illustrate the problem, let there be two alternatives in each stage. With 5 stages, there are 64 scenarios. If the number of alternatives is three, there is a total of 729 scenarios! Thus, the users of this model are urged to economize on the choice of stages and physical parameters under consideration while disaggregating the problem to capture some major elements of uncertainty.

\subsubsection{The Methodology: An Overview}

To incorporate the uncertainty arising from stage length times and uncertain variables into the analysis of project cost, the model considers individually in succession all different possible permutations of values for those uncertain variables. From each such permutation of values and times, $z$ "scenario" is constructed and then analyzed.

A scenario thus represents one possible path through a decision tree. Specifically, a scenario is defined by four attributes:

(1) a set of durations specifying the length of each of the stages;

(2) a set of values for the uncertain physical parameters (e.g., wellhead temperature, flow rate); 
(3) the probabilities that each stage and each physical parameter takes the value specified for it in (1) and (2); and

(4) the dollar value costs for all cost accounts in all stages. To avoid the enormous information costs of deriving the cost accounts ( 4 above) for each possible scenario, the model uses a baseline case, or Reference Scenario. The Reference Scenario is defined as the most likely path through the decision tree. In the computer program, the cost accounts are input to the program only for this Reference Scenario. (These along with Reference stage times and Reference physical parameter values completely specify the Reference Scenario.) For all other scenarios, only their stage times, physical parameter values, and associated probabilities are input: their cost zccounts are derived within the program by modifying the Reference cost accounts for any differences in the length of each stage or for any differences in the values of the physical parameters. Thus, as described below, the Reference Scenario is really a baseline case from which all other scenarios are derived. If this were not so, based on the previous description, the required amount of information would be enormous. Dollar costs for every cost account for each scenario would be required. Because a Reference Scenario is used, the lengthy and difficult task of providing detailed cost accounts for the site under study has to be performed only once (for the Reference Scenario).

To illustrate this procedure, if in the Reference Scenario, Stage J is assumed to take 10 years, then a Cost Account $i$ in Stage $J$ is estimated based upon the 10 year figure. If, however, Stage $J$ is later assumed in another scenario to last 20 years, then Cost Account 1 in Stage $J$ for that scenario would be doubled to reflect the now longer stage time. Additionally, if a particular cost account is affected by an uncertain physical variable, 
the model would make an adjustment through the use of appropriately defined scaling functions. These adjustments are done in subroutine GSCALE.

In a like manner, the cost-accounts for each of the other scenarios are derived. Because the lengths of the stages are different from scenario to scenario, the occurrence of the cost-account expenditures in each scenario will be staggered. The model accounts for the staggered time frames by appropriately accounting for time differences when the financial analysis is performed. The financial subroutine in the model calculates levelized energy cost, life-cycle cost, and profit for each scenario. With the probability of occurrence for each scenario (and thus of their outputs) having been input ${ }^{6}$ as part of the scenario description, a complete set of values and their probabilities are obtained for levelized energy cost, life-cycle cost, and for profit. From these, separate probability functions for both of the cost categories and for profit can be constructed.

\subsubsection{The Computer Program}

a. Stages. In the model the stages are designated by the variable $J X$, with $J X$ ranging in value from 1 to $J$. The operational stage, the last stage, is the Jth stage.

b. Stage Duration. Corresponding to each stage JX there is a time lapse for completing all activities in that stage. In order to reflect the uncertainty for the completion time of any given stage, the stage time is treated as a random variable and assumed to have a discrete set of outcomes. In the Reference Scenario, the length of Stage JX is denoted by TPR(JX); in any other scenario, the length of Stage JX is denoted by $\operatorname{TP}(J X, M M)$, where MM

6 Actually, only the conditional probabilities for each stage length time and physical parameter values are input. Their product calculated in the program, yields the probability of occurrence for each scenario and its output. 
is the number of that scenario. Likewise, the length of the final stage (Stage $J$ ) in the Reference Scenario is $\operatorname{TPR}(J)$, and the length of Stage $J$ in any other scenario is $\operatorname{TP}(J, M M)$ where again MM identifies that scenario. c. Stage Intervals. Each stage is divided into intervals. The number of intervals into which a specific Stage JX will be subdivided is denoted by $M(J X)$. The $M(J X)$ remain fixed for all scenarios. All intervals in a given stage are the same length, and thus are found by the quotient $\operatorname{TP}(J X, M M) / M(J X)$. The $M(J X)$ are judiciously chosen to correspond generally to the number of times costs will recur within a stage. By dividing long stages into intervals, it is possible to specify costs for periods on the order of one year which enables the modeling of non-uniform cash flows throughout the stage.

d. Cost Accounts. There are two kinds of costs: time-dependent and time-independent. Time-dependent costs, as their name implies, vary as the length of a stage (and hence as the length of the stage's intervals) varies. (Stage times vary from scenario to scenario; the number of the stages and the number of intervals in each stage are specified at the outset and remain fixed for all scenarios.) Time-independent costs are assumed to remain constant regardless of the length of the interval in which they occur.

An example of a time-dependent cost could be the legal fees paid during the permitting process. The longer the process, the longer legal services are required, and the greater will be the cost. An example of a time-independent cost could be a bulldozer purchased for the development of the field. Once purchased, the cost will not change if the development of the field takes an additional length of time. (Although strictly speaking, operations and maintenance costs might change.)

As mentioned before, detailed cost accounts are input for the Reference Scenario only. For each time-dependent cost account, expenditures 
are input for each interval of the specific stage in which that dependent cost account occurs. This expenditure, or dependent cost for the Reference Scenario, is denoted by $\operatorname{CDR}(\mathrm{JX}, \mathrm{NX}, \mathrm{MX}, \mathrm{KDX})$. The index $\mathrm{JX}$ denotes the stage in which the cost account occurs; NX signifies the accounting lifetime of the expenditure; MX denotes the interval in which the cost occurs; and KDX designates which cost account is being described. Thus, $\operatorname{CDR}(2,1,4,3)$ signifies the time-dependent expenditure of the first accounting lifetime for the third cost account in the fourth interval of Stage 2 of the Reference Scenario.

A typical cost account for a time-dependent activitv is shown below. It is the Exploration and Well Logging account for Stage $l$ of the Reference Scenario. Note that the expenditure rate is not necessarily uniform for the duration of Stage 1. This is indicated by different dollar costs (in thousands of 1980 dollars) for each of the six intervals into which Stage 1 is divided.

$$
\begin{array}{llllll}
240.0 & 240.0 & 800.0 & 800.0 & 800.00 & 800.0
\end{array}
$$

The entire "matrix" of time-dependent cost accounts for Stage I would appear then as follows:

$\begin{array}{rrrccc}68.75 & 68.75 & 68.75 & 68.75 & 68.75 & 68.75 \\ 0.0 & 25.0 & 0.0 & 0.0 & 0.0 & 0.0 \\ 240.0 & 240.0 & 800.0 & 800.0 & 800.0 & 800.0 \\ 91.67 & 91.67 & 91.67 & 91.67 & 91.67 & 91.67 \\ 79.0 & 43.0 & 96.0 & 96.0 & 96.0 & 96.0\end{array}$

An individual entry has the label $\operatorname{CDR}(\mathrm{JX}, \mathrm{NX}, \mathrm{MX}, \mathrm{KDX})$ where $\mathrm{JX}, \mathrm{NX}, \mathrm{MX}$ and $\mathrm{KDX}$ are defined as before. All costs given in this report and used by the model are in 1980 dollars; if occurring any number of years after 1980, these costs 
are escalated appropriately by the model to account for inflation and real increases in price at rates specified by the user.

e. Subroutine GSCALE The aforementioned adjustments to the Reference Scenario Costs Accounts are performed for each scenario in the GSCALE subroutine. Time-dependent costs are assumed to be proportional to the length of Reference Scenario stages. Thus, if another scenario has a stage length (and hence stage interval length) twice that of the Reference Scenario, all of its time-dependent cost accounts would be twice that of the Reference Scenario. This effect is captured by the TP(JX,MM)/TPR(JX) term in ADMOD .

The cost accounts are also escalated in GSCALE. The cost accounts are multiplied by their cost escalation factors, $A D(J X, N X, K D X)$, raised to the exponent PWR, where PWR is the number of years up until the cost actually occurs. PWR is composed of two parts: $\operatorname{PSUM}(J X, M M)$, the number of years up to the JX stage; and $M X \cdot(T P(J X, M M) / R M J X)$, the number of years into the stage that the cost occurs.

Once the cost accounts have been adjusted for time differences, GSCALE then calls subroutines that make adjustments for differences in the levels of physical variables. These subroutines are OPT I through OPT N. These are user specified and their forms are dependent on the specific site.

f. OPT Function Subroutines. The "OPTn" function subroutines are called by the FCTMOD subroutine in GSCALE to modify the cost accounts for any differences between the Reference Scenario levels for the physical parameters and the levels of those parameters in the scenario being examined. The three physical parameters considered in this study are wellhead fluid temperature, flow rate, and well depth. The OPT functions are physical relationships that must be supplied by the user for the project being studied. The following OPT functions are used for the Heber Reservoir. 
OPT 1: Effect of Temperature. The references equation for OPTI is $\Phi_{\mathrm{W}}(\$ / \mathrm{kW})=\frac{51.107 \mathrm{Z} \exp \left[3.8884 \times 10^{-4} \mathrm{z}\right]}{\dot{\mathrm{m}}_{\mathrm{W}}\left[\mathrm{T}_{\mathrm{gf}}-\mathrm{T}_{\mathrm{o}}-\left(\mathrm{T}_{\mathrm{o}}+273.15\right) \ln \left(\frac{\mathrm{T}_{\mathrm{gf}}+273.15}{\mathrm{~T}_{\mathrm{o}}+273.15}\right)\right]}$

from Reference 5. When the equation is used to evaluate the effect of resource temperature on well cost, the well depth, $Z$, and flow rate, $\dot{m}_{W}$, are held constant to define the temperature ratio only. The cost relationship then becomes

$$
\text { Cost }(\text { scenario })=\text { Cost }(\text { reference }) * \frac{\text { Temperature equation }(\text { scenario })}{\text { Temperature equation }(\text { reference })}
$$

or

$$
\begin{aligned}
\text { OPTI }= & \text { RVAL * }\{\mathrm{P} 2-\operatorname{CON}(1)-(\operatorname{CON}(1)+273 .) *[\operatorname{ALOG}(P 2+273 .) / \\
& (\operatorname{CON}(1)+273 .)]\} / \mid \mathrm{P} 1-\operatorname{CON}(1)-(\operatorname{CON}(1)+273 .) * \\
& \left.\operatorname{ALOG}\left[\left(\operatorname{P} 1 \& 273_{\bullet}\right) /(\operatorname{CON}(1)+273 .)\right]\right\}
\end{aligned}
$$

where

$$
\begin{aligned}
\text { OPTI = } & \text { adjusted cost returned to FCTMOD } \\
\text { RVAL = } & \text { cost account data input to OPTl } \\
\mathrm{P} 2 \quad & \text { reference fluid temperature }(\mathrm{Tgf}),{ }^{\circ} \mathrm{C} \\
\mathrm{Pl}= & \text { scenario fluid temperature, }{ }^{\circ} \mathrm{C} \\
\mathrm{CON}(1)= & \text { ambient temperature, } \mathrm{T}^{\circ} \text { input for each site, }{ }^{\circ} \mathrm{C} \\
& \text { Note that the constant } 3.8884 \times 10^{-4} \text { is used when } \mathrm{Z} \text { is } \\
& \text { input in meters. If well depth is in feet, the constant } \\
& \text { must be adjusted. }
\end{aligned}
$$

OPT 2: Effect of Flow Rate. The same equation from Reference 5 can be used to define a flow rate relationship with

$$
\text { Cost }_{\text {well }}(\text { scenario })=\text { Cost }_{\text {well }}(\text { reference }) * \frac{\text { Flow rate equation }(\text { scenario) }}{\text { Flow rate equation }(\text { reference })}
$$


If the well depth, $\mathrm{Z}$, and temperature $\mathrm{T}_{\mathrm{gf}}$, are held constant, this relationship gives

$$
\mathrm{OPT} 2=\underset{\mathrm{WVAL}}{\mathrm{w}} * \frac{1 / \dot{\mathrm{m}}_{\mathrm{W}} \text { scenario }}{1 / \dot{\mathrm{m}}_{\mathrm{w}} \text { reference }}=\mathrm{RVAL} * \frac{\mathrm{P} 2}{\mathrm{P} 1}
$$

where

$$
\begin{aligned}
& \text { OPT2 = adjusted cost returned to FCTMOD } \\
& \text { P2 = reference flow rate } \\
& \text { P1 = scenario flow rate } \\
& \text { RVAL = cost account data input to OPT2. } \\
& \text { OPT 3: Effect of Well Depth. Again, in the same reference }
\end{aligned}
$$

equation, temperature and flow rate can be held constant to look at the effect of well depth on well cost. This gives:

$$
\Phi_{W}(\$ / \mathrm{kW})(\text { scenario })=\Phi_{W}(\$ / \mathrm{kW})(\text { reference) }) \frac{\mathrm{Z}_{s} \exp \left[3.8884 \times 10^{-4} \mathrm{Z}_{\mathrm{s}}\right]}{\mathrm{Z}_{\mathrm{R}} \exp \left[3.8884 \times 10^{-4} \mathrm{Z}_{\mathrm{R}}\right]}
$$

or

$$
\text { OPT3 }=\operatorname{RVAL} *(\mathrm{P} 1 / \mathrm{P} 2) * \operatorname{ExP}[(\operatorname{CON}(6) *(\mathrm{P} 1-\mathrm{P} 2))]
$$

where

$$
\begin{aligned}
\text { OPT3 = } & \text { adjusted cost returned to FCTMOD } \\
\text { RVAL = } & \text { cost account data input to OPT } 4 \\
\mathrm{P} 2 \quad= & \text { reference well depth } \\
\mathrm{P} 1 \quad & \text { scenario well depth } \\
\mathrm{CON}(6)= & \text { constant } 3.8884 \times 10^{-4} \text { from Reference } 5 . \\
& \text { Note that the constant } 3.8884 \times 10^{-4} \text { is used when } \\
& \mathrm{Z} \text { is input in meters. If well depth is in feet, the } \\
& \text { constant must be adjusted. }
\end{aligned}
$$

With these equations, we can incorporate any uncertainty in the resource characteristics into the derivation of the probability density function for resource development costs. 
g. Subroutine RCOST. After the modifications by GSCALE to each scenario, RCOST discounts all cost accounts in all the stages to present dollars as of the beginning of Stage 1. This is performed one stage at a time. For each stage in succession the entries for each cost account (i.e., the costs in all the time intervals) are discounted to the beginning of that stage and summed together. This yields a single figure for all the costs in that stage. This number (CDT in the program) is expressed in dollars as of the beginning of that stage; it is then discounted back to the beginning of Stage 1 and summed into the variable CD. Referring to Figure 3-14, the costs in a given interval are added together into variable CDTT, and then discounted to the beginning of the stage as $\operatorname{CDTT}^{*} \mathrm{~d}^{*}[\mathrm{MX} * \mathrm{TPR}(\mathrm{JX}) / \mathrm{MLIM}]$. This is summed into variable CDT. CDT is then discounted to the beginning of the project by $\operatorname{CDT}^{*} D^{*} \operatorname{PSUMR}(J X)$, where $\operatorname{PSUMR}(J X)$ is the number of years prior to the beginning of Stage $\mathrm{JX}$ in the scenario being considered. This is done for all stages, $\mathrm{JX}=1$ to $\mathrm{J}$.

The present value cost figures thus obtained are then operated upon in RCOST to find levelized cost and life cycle cost for the scenario under consideration. Because cost accounts with different accounting lifetimes are treated differently for tax purposes, the cost accounts of differing accounting lifetimes must be segregated by accounting type. This is accomplished by the first Do Loop in RCOST. It first performs the above discounting for accounts with a 1-year life; then does so for the second accounting type; then for the third, and so on. Thus, costs will be indexed by accounting type, NX, e.g., $\operatorname{CAPR}(N X), C R(N X)$.

RCOST also computes "upfront capital cost" or the costs of the stages prior to the final or operating stage. To do this the cost of the upfront stages must initially be kept separate from the cost of the final stage. This separation is achieved by the second Do Loop which considers all stages except 


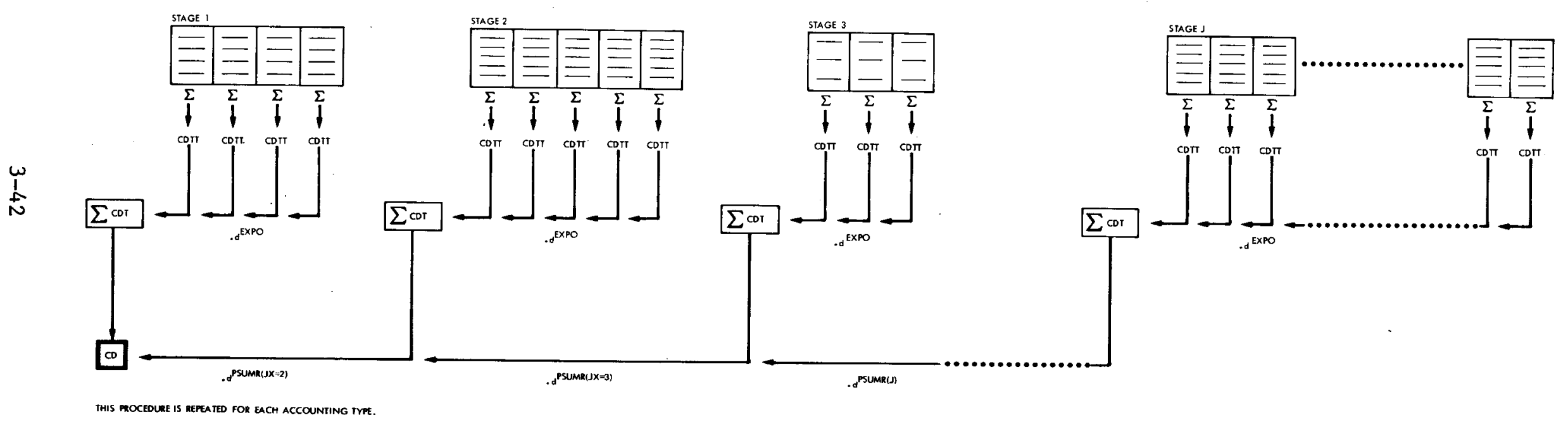

THIS ROCCEDUR IS AEFEA JFE FOR EACH ACCOUNIING IYTE. 
the last. After that Loop, the cost accounts for the final stage are discounted. CAPR(NX) designates the upfront capital costs for accounting type $N X$, and $C R(N X)$ the total project capital costs for that accounting type. Thus, the total project cost of the second accounting type, CR(2), consists of the upfront capital costs of the second accounting type, $\operatorname{CAPR}(2)$, plus the discounted time-dependent and time-independent cost accounts of the second accounting type for the final stage, Stage J.

After the present value cost is obtained for each accounting type with a lifetime longer than one year, ${ }^{7}$ the effects of taxes, depreciation, and investment tax credits are accounted for through the use of the fixed charge rate (FCR). Because the FCR is a function of the accounting lifetime, It can now be seen why, up to this point, the costs have been segregated by accounting lifetime. Multiplying $\mathrm{CR}(\mathrm{NX})$ by the FCR yields the constant annual amount that exactly pays back this capital investment with interest over the Iifetime of the project, after taxes (which have been adjusted for the effect of depreciation and any investment tax credit) have been paid. Dividing this constant annual payment by the capital recovery factor (CRF) gives the present value sum of those payments. The present value sums for each accounting type can then be added together. In the program, this aggregate sum is denoted by CDUM, an Intermediate "dummy" variable for cost.

Thus far, this sum does not include the effects of depletion allowance and royalties. To account for these, the final sum, CDUM, obtained above is multiplied by $\frac{1-t}{1-t+a t-R O Y+t R O Y}$, where ROY is the royalty rate, $t$ the tax rate, and a the depletion allowance rate. The quotient is simply the ratio: $\frac{1-t}{1-t+a t-R O Y+t R O Y}=\frac{P V[\text { all costs with depletion allowance and royalties] }}{\mathrm{PV}[\text { all costs without depletion allowance and royalties] }}$

7 Costs with a lifetime of one year are expensed; no taxes are paid on the income required to cover them, and no depreciation or tax credits are applied. 
When multiplied by the amount necessary to cover all costs without a depletion allowance and royalty payments, which is what is thus far obtained above, the amount necessary to cover all costs with depletion allowance and royalty payments is obtained. If the depletion allowance is calculated on gross revenues net of rents and royalties, the life cycle cost of the project can be expressed as

$$
\text { LCC }=[E I * \text { CDUM }]+\left[\frac{a t}{\operatorname{ESCAL}} *(\text { RENROY })\right],
$$

where $E I=\frac{1-t}{1-t+a t-R O Y+t R O Y}$ and RENROY is the sum of rents and royalties. This is for the regulated case. (Note that in order for the program to handle them correctly, rents and leases for each stage, except the last, must be inputted into the program as the first time-dependent cost account for those stages.)

Profit, in the non-regulated case, is obtained by Revenue minus Life Cycle Cost. As the effects of taxes, depletion allowance, and royalties have been factored in on only the cost side, and not the revenue side, the difference REV - LCC must be multiplied by ( $1-t+a t-R O Y+t R O Y)$ to appropriately reduce the revenue retained by the firm as profit to reflect the effects of depletion and royalty payments. This leads to an expression for LCC as $([\mathrm{EL} *$ CDUM $]+$ $\left[\frac{\text { at }}{\text { ESCAL }} *\right.$ RENROY $\left.]\right)$ ESCAL + [(1-ESCAL $) *$ REV $]$, where ESCAL is $(1-t+a t-R O Y+R O Y)$. To find Levelized Energy Cost, calculating the Life Cycle Cost alone is not sufficient. The economically recoverable part of the resource and the life of the resource must be known to determine the energy cost. Over time, the temperature of the resource and possibly the flow rate from the wells will degrade. While this degradation is not modeled explicitly by this studv, a redrilling program is assumed to take place and new wells are scheduled to keep the heat content, E, from the wells constant for the life of the geothermal field. The costs of this program are included in the cost accounts for Stage IV and are reflected in the final cost figures. 
With a given $E$, we can calculate the generalized energy cost $^{8}$ as

$$
C E L=\frac{1000 \cdot C C L}{G G \cdot E}
$$

This follows directly from Equation D-12, in Reference 13, when both numerator and denominator are multiplied by annual energy output. The constant 1000 is a conversion factor to yield $\$ / \mathrm{kWh}$ from mills $/ \mathrm{kWh}$.

h. Probabilistic Analysis. The probability associated with the energy cost for a scenario is simply the product of the conditional probabilities specified for stage times and physical variables in that scenario. These are input as $\mathrm{P}(J \mathrm{X}, \mathrm{I})$. If the stage times and/or the physical variables are assumed to be independent, then the probability of a specific value occurring for a variable remains the same regardless of what the preceding variables might turn out to be. If any of the variables are correlated, the inputted probabilities would have to reflect this correlation.

As discussed in the introduction to the formal model, it is likely that the number of scenarios for a specific project under evaluation may be

8 Generalized energy cost is defined as that price per unit of energy which, if held constant in real terms throughout the project life would provide the required revenue to finance the life cycle cost of the project, assuming that all cash flow interim requirements or excesses are borrowed or invested at the utility's internal rate of return. Levelized energy cost is defined as that price per unit of energy which, if held constant in nominal terms throughout the project life would provide the required revenue to finance the life cycle cost of the project, assuming that $a l 1$ cash flow interim requirements or excesses are borrowed or invested at the utility's internal rate of return. We caution that the concept of levelized energy cost as an energy cost index is defective. It can be used to rank order different energy projects only if they have the same project life. Clearly, the optimal project life design should depend on the physical characteristics and economic trade-offs thereof, and should not be arbitrarily standardized. If projects have different lifetimes, choices based on levelized energy costs may bias towards short life projects, even though they have the same fixed costs and proportionate variable costs. Generalized energy cost will not have this problem. Thus, we suggest using the latter as an output from the computer model. In the computer program, a generalized energy cost is used. Uniform energy cost is a special case of the latter with nominal energy cost escalation factor being one. 
very large. In that event, the costs of calculating all these scenario costs may be prohibitively large. Fortunately, we have a well-known statistical theory, the Kolmogorov-Smirnov Theorem, which shows that we can randomly select 150 scenarios as a sample to approximate the required probability distribution The likelihood of selecting a scenario should be weighted by its probability, and the approximate distribution will be good within $90 \%$ confidence. (However, we caution the users of this model that even though the computational cost is cut to a minimum, the data collection costs may still be prohibitive.) The Kilmogorov-Smirnov Theorem is: Let $F(x)$ be the underlying continuous cost distribution, and $x_{1}, \ldots, x_{n}$ be a sample from $F(x)$. Define $F_{n}(x)$ as the proportion of observed values in the sample which are less than or equal to $\mathrm{X}$. Let

$$
D_{n}=\sup _{-\infty<X<\infty}\left|F_{n}(x)-F(x)\right|
$$

The Kilmogorov-Smirnov Theorem states that

$$
\lim _{n \rightarrow \infty} \operatorname{Pr}\left(D_{n}<\frac{t}{n^{1 / 2}}\right)=1-2 \sum_{i=1}^{\infty}(-1)^{i-1} e^{-2 t^{2}{ }^{2}}
$$

Let $H(t)$ be the value on the right hand side of the equation. A table of $\mathrm{H}(t)$ is given in Table 3-5. As an example, consider $90 \%$ confidence, i.e., $\left(H(t)=0.90\right.$. The corresponding $t$ is 1.22. Suppose we want $D_{n}-0.1$. The required sample size, $n$, will then be calculated as:

$$
\begin{aligned}
n & =\frac{1.22^{2}}{0.1} \\
& \cong 150
\end{aligned}
$$


Table 3-5

Probability Limit for the Kolmogorov-Smirnov Theorem

\begin{tabular}{l|l|l|l}
\hline$t$ & $H(t)$ & & \\
& & $t$ & $H(t)$ \\
\hline & & & \\
0.30 & 0.0000 & 1.20 & 0.8878 \\
0.35 & 0.0003 & 1.25 & 9.9121 \\
0.40 & 0.0028 & 1.30 & 0.9319 \\
0.45 & 0.0126 & 1.35 & 0.9478 \\
0.50 & 0.0361 & 1.40 & 0.9603 \\
0.55 & 0.0772 & 1.45 & 0.9702 \\
0.60 & 0.1357 & 1.50 & 0.9778 \\
0.65 & 0.2080 & 1.60 & 0.9880 \\
0.70 & 0.2888 & 1.70 & 0.9938 \\
0.75 & 0.3728 & 1.80 & 0.9969 \\
0.80 & 0.4559 & 1.90 & 0.9985 \\
0.85 & 0.5347 & 2.00 & 0.9993 \\
0.90 & 0.6073 & 2.10 & 0.9997 \\
0.95 & 0.6725 & 2.20 & 0.9999 \\
1.00 & 0.7300 & 2.30 & 0.9999 \\
1.05 & 0.7798 & 2.40 & 1.0000 \\
1.10 & 0.8223 & 2.50 & 1.0000 \\
1.15 & 0.8580 & &
\end{tabular}


REFERENCES

1. Bowers, H. I.; Reynolds, L. D.; Delozier, R. C.; Strite, B. F.; Concept--Computerized Conceptual Cost Estimation for SteamElectric Power Plants. Phase II User's Manual ORNL-4809, Oak Ridge National Laboratory, April 2973.

2. U. S. Energy Research and Development Administration, Users Manual for GEOCOST: A Computer Model for Geothermal Cost Analysis, Volume 1, Steam Cycle Version, prepared by Battelle Pacific Northwest Laboratories, BNWL-1972, VI, November 1978.

3. Dan, F. J.; Hersam, D. E.; Kho, S. K.; Krumland, L. R.; "Development of a Typical Generating Unit at the Geyser Geothermal Program--A Case Study." Presented at the Second United Nations Symposium on the Development and the Use of Geothermal Resources, May 1975, pp. 1949-1958.

4. U. S. Department of Energy and California Energy Resources Conservation and Development Commission, Analysis of Requirements for Accelerating the Development of Geothermal Energy Resources in California.

5. Milora, S. L. and Testor, J. W., Geothermal Energy as a Source of Electric Power, MIT Press, 1976.

6. Goldsmith, K., "Economic Aspects of Geothermal Development," U.N. Report, pp. 2301-2303.

7. Bloomster, C. H., "Economic Analysis of Geothermal Energy," Chemical Engineering Progress, July 1976, pp. 89-95.

8. Kruger, Paul and Otte, Carel, Editors, Geothermal Energy: Resources, Production, Stimulation, Stanford University Press, 1973.

9. Swanberg, C. A., "The Mesa Geothermal Anomaly, Imperial Valley, California: A Comparison and Evaluation of Results Obtained from Surface Geophysics and Deep Drilling," see Reference 1, pp. 1217-1229.

10. Electric Power Research Institute, Preliminary Design Manual for a Geothermal Demonstration Plant at Heber, Ca, prepared by Holt/PROCON, EPRI ER-670, February 1978.

11. Juul-Dan, T., and Dunlap, H. F., "Economic Analysis of a Geothermal Exploration and Production Venture, "Sec. V, Reference l, pp. 2315-2324.

12. Larsen, Tod, "The Cost of Geothermal Energy Development," in Geothermal World Directory 1977-78 (Geothermal World Publications), pp. 314-336.

13. Doane, J.W., et al, The Cost of Energy From Utility-Owned Solar Electric Systems, JPL 5040-29, Jet Propulsion Laboratory, Pasadena, CA, June 1976. 


\section{BIBLIOGRAPHY}

Barr, Ronald C., "Geothermal Exploration: Strategy and Budgeting," Proceedings of the United Nations Symposium on the Development and Use of Geothermal Resources (2nd), held at San Francisco, CA, on May 20-29, 1975, Vol. II, pp. 2269 to 2271. All references to the U.S. Report are to this volume.

Bloomster, C. H., "Economic Analysis of Geothermal Energy," Chemical Engineering Progress, July 1976, pp. 89-95.

Bowers, H. I.; Reynolds, L. D.; DeLozier, R. C.; Strite, B. F.; Concept-Computerized Conceptual Cost Estimation for Steam-Electric Power Plants. Phase II User's Manual ORNL-4809, Oak Ridge National Laboratory, April 1973.

Chevron Resources Company, Heber Geothermal Power Project, Public Relations Brochure.

Combs, J. and Muffler, L. J. P., "Exploration for Geothermal Resources" in Geothermal Energy: Resources, Productions, Stimulation, edited by Paul Kruger and Carel Otte, Stanford University Press: 1973, pp. 95-128.

Dan, F. J.; Hersam, D. E.; Kho, S. K.; Krumland, L. R.; "Development of a Typical Generating Unit at the Geyser Geothermal Program--A Case Study. Presented at the Second United Nations Symposium on the Development and the Use of Geothermal Resources, May 1975, pp. 1949-1958.

DeGroot, M. H., Probabllity and Statistics, Chapter 9, Addison-Wesley Publishing Co., (Reading, MA), 1975.

Doane, J. W.; O'Toole, R. P.; Chamberlain, R. G.; Bos, P. B.; Maycook, P. D.; The Cost of Energy from Utility-Owned Solar Electric Systems, JPL 5040-29, ERDA/JPL-1012-76/3, Jet Propulsion Laboratory, California Institute of Technology, June 1976.

Eisenstat, S. M., "Geothermal Exploration and Development in the United States: A Tax Analysis Under the Internal Revenue Code," U.N. Report 2924, pp. 2369-2372.

Electric Power Research Institute, Geothermal Energy Conversion and Economics-Case Studies, prepared by Holt/PROCON, EPRI-ER-301, November 1976.

Electric Power Research Institute, Preliminary Design Manual for a Geothermal Demonstration Plant at Heber, CA, prepared by Holt/PROCON, EPRI ER-670, February 1978.

Finn, D. F. X., "Federal Geothermal Tax Policies, Geothermal World Directory 1977-78," pp. 241-243. 
Goldsmith, K., "Economic Aspects of Geothermal Development," U.N. Report, pp. 2301-2303.

Greide, B., "Status of Economics and Financing of Geothermal Energy Power Production," U.N. Report, pp. 2305-2314.

Hankin, J. W.; Beaulaurier, L. 0.; Comprelli, F. 0.; "Conceptual Design and Cost Estimate for a 10-MWe (Net) Generating Unit and Experimental Facility Using Geothermal Brine Resources," U.N. Report, pp. 1985-1996.

Juul-Dan, T., and Dunlap, H. F., "Economic Analysis of a Geothermal Exploration and Production Venture," Sec. V, Reference 1, pp. 2315-2324.

Kruger, Paul and Otte, Carel, Editors, Geothermal Energy: Resources, Production, Stimulation, Stanford University Press, 1973.

Larsen, Tod, "The Cost of Geothermal Energy Development," in Geothermal World Directory 1977-78 (Geothermal World Publications), pp. 314-336.

MacDonald, W. J. P., "Useful Heat, Broadlands Geothermal Field, New Zealand," U.N. Report, pp. 1118-1119.

Milora, S. L. and Testor, J. W., Geothermal Energy as a Source of Electric Power, MIT Press, 1976.

Pacific Gas and Electric Company, Environmental Data Statement, Geysers Unit 17.

Schulte, S. C., Capital Cost Models for Geothermal Power Plants and Fluid Transmission Systems, Battelle Pacific Northwest Labs, PNL-2307, September 1977.

Swanberg, C. A., "The Mesa Geothermal Anomaly, Imperial Valley, California: A Comparison and Evaluation of Results Obtained from Surface Geophysics and Deep Drilling," see Reference 1, pp. 1217-1229.

Terasawa, K.; 0'Toole, R. P.; Goldsmith, M., Methodology for the Estimation of Cost of Underground Nuclear Power Plants, 5030-89, prepared by Jet Propulsion Laboratory, May 1977.

U. S. Department of Energy, Site Specific Analysis of Geothermal Development --Data Files of Prospective Sites, Volume II, prepared by Trehon, R.; Cohen, A.; Gupta, J.; Jacobsen, W.; Leigh, J.; and True, S., of Mitrel Metick, August 1978.

U. S. Energy Research and Development Administration, Users Manual for GEOCOST: A Computer Model for Geothermal Cost Analysis, Volume 1, Steam Cycle Version, prepared by Battelle Pacific Northwest Laboratories, BNWL-1972, VI, November 1978. 
U. S. Department of Energy and California Energy Resources Conservation and Development Commission, Analysis of Requirements for Accelerating the Development of Geothermal Energy Resources in California.

Wahl, E. F., "Geothermal Energy Utilization," John Waley and Sons, New York, 1971 .

Williams, F.; Cohen, A.; Pfundstein, R.; Pond, S.; Site Specific Analysis of Geothermal Development--Data Files of Prospective Sites, Vol. III, prepared by Mitre Corporation, Metrek Division for DOE, February 1978. 
PART THREE

INSTITUTIONAL ASPECTS OF GEOTHERMAL DEVELOPMENT 
CHAPTER 4

INSTITUTIONAL ASPECTS OF GEOTHERMAL DEVELOPMENT

Leasing, Contracting, Insurance

\section{$4.1 \quad$ INTRODUCTION}

Electric power is usually produced by a generator that is coupled mechanically to a turbine. One way to make the turbine rotate is to bombard its vanes with expanding steam. This steam is produced either by heating water with fossil or nuclear fuels, or by obtaining it directly from the ground in a form called geothermal water or steam. Although its role in generating electricity is very much like that of coal, oil or nuclear fuel, the institutional structure upon which a geothermal power plant operates is quite different from that of plants using other fuels. These differences and the reason why they exist are discussed in Section 4.2 .

Three kinds of institutional arrangements are common to geothermal developments. First, rights to land with geothermal potential must be obtained and its development potential assessed. This component hereafter is referred to as "Leasing". The developer then makes an agreement with a utility that seeks to use the produced geothermal resource in the production of electricity. The geothermal resource could also be used in direct applications, such as space heating, etc. This stage will be discussed under the heading "Contracting". Finally, the utility and the developer operate in an uncertain environment. Earthquakes, cold water breakthroughs, vapor flow cessations, natural calamities, and underground pressure leaks are some natural causes of uncertainty in the quantity and quality of geothermal water or steam and hence in the quantity of power generated. Both the developer and the utility need protection against this uncertainty. In the case of fossil fuels, such natural causes of uncertainties are not as threatening to 
utilities because of the availability of alternative sources of fuel. Geothermal resources cannot be sold over long distances because the reduction in the pressure and temperature of the steam during transportation is too great and the piping cost runs too high. A discussion of the methods for coping with this uncertainty appears under the heading "Insurance".

Section 4-2 spells out the general aspects of leasing of land in the case of coal, and oil resources, and provides a description of the leasing of land of geothermal resources.

Section 4.3 analyzes the leasing, contracting and insurance problems, and highlights their interrelations.

Section 4.4 summarizes this report. The appendix has a brief survey of the relevant literature on insurance and an overview of the literature on single and multiple object auctions. 
4.2 LEASING

4.2.1 Characteristics of Leasing

Leasing is the process by which potential developers of a resource acquire the rights to it. The details of the leasing arrangement are important because they affect the incentives of the developer in selecting among alternative strategies for exploring and exploiting the resource. Three aspects of the leasing process are significant: (1) the amount of competition for the lease and the institutional rules for awarding the lease; (2) the method for determining the financial compensation to be paid to the owner of the land; and (3) the duration of the lease, including the nature of the performance requirements for keeping it active.

The extent of competition for a lease depends in part on the method by which it is awarded. In some cases, leases are awarded by some sort of auction process which is announced in advance and which transpires at a specific place and time. Although unattractive lands may attract little interest and therefore produce few competing bids, normally auctions produce spirited competition among several bidders. A less common method of awarding rights to land is a lottery, whereby a lease is given to one of the applicants by drawing applications at random. The source of revenue from such a process is some combination of an application fee and a predetermined payment or payment formula. Although this process may produce numerous applicants, it is not a competition in the economic sense because the expression of willingness to pay through bidding is absent. Finally, in some cases leases are awarded on a first-come, first-served basis, perhaps requiring a filing fee and/or another financial commitment.

Whereas literally infinite variation is possible in the methods for compensating owners of land, all such methods are a combination of at most 
five elements: (1) an application or filing fee (e.g., a payment for the right to request a lease); (2) a royalty, or a payment expressed as a fraction of the revenues or profits from exploiting the resource; (3) an extraction fee, which is a payment based up on the physical quantity of the resource that is extracted, regardless of its value; (4) a rent, or an annualized payment for the right to use the land, regardless of the amount of production that takes place; and (5) a bonus bid or initial, up-front payment to secure the lease, regardless of its duration or the future productivity of the land. Normally, if a lease is awarded in a competitive process, the owner of the land will predetermine all but one of the preceding elements (perhaps at zero), and award the lease to the party that submits the highest bid in the bid variable, e.g., the remaining free dimension.

The selection of a bid variable is important for two reasons. (1) It allocates the risk about the size and development expense of the resource between the lessee and lessor. (2) It affects the development incentives facing the winning bidder. As a general rule, the allocation of risk depends up on the closeness of the relationship between the ultimate profitability of exploiting the resource and the formula for determining the payments to the owner of the land. Thus, systems emphasizing fixed fees and bonus bids put more risk on the developer, whereas formulas emphasizing profit-sharing between the developer and the land owner spread the risk most evenly. In the middle are extraction fees and royalties on sales. This relationship can be represented as follows:

\section{Risk Allocation}

More risk

More Risk to Land Owner to Developer

$\begin{array}{cccccc}\text { Royalty on } & \text { Royalty on } & \text { Extraction } & \text { Annual } & \text { Bonus } & \text { Filing } \\ \text { Profits } & \text { Sales } & \text { Fee } & \text { Rent } & \text { Bid } & \text { Fee }\end{array}$


The incentives of a compensation formula on development activities depend on the extent to which payments to the land owner are related to development. The holder of a lease will find development less attractive if payments are dependent on direct development activities, such as is the case if royalties depend on the quantity of production (regardless of sales or profitability). At the other extreme, high fixed financial obligations (and little or no dependence of payments on development) are most conducive to exploitation of a resource.

The duration of the lease, and its dependence on performance, can affect development incentives. One common practice is to set either expenditure requirements or production targets that must be satisfied for a lease to remain in force.

In selecting a combination of lease characteristics, a rational landlord will be cognizant of risk differences between buyer and seller. Although in discounted present value terms a land owner will reap higher returns if the leasing arrangements minimize the risk of the leaseholder, such arrangements are not optimal if the land owner is more risk-averse than the leasing entity. Thus, private individuals might well adopt strategies for leasing land that allocate more risk to leaseholders than the strategies adopted by large corporations or the government because the former are likely to be more risk averse than either of the latter. Nevertheless, the Federal Government has elected to organize most of its leasing activities in a manner that allocates most of the risk to the developer. The following summarizes federal leasing activities of lands for energy development.

a. Coal mining and on shore drilling of oil. Generally, the procedure for obtaining a lease on a piece of land for coal development is as follows. An interested party applies for an 
"exploration license". Upon receipt of such an application for a permit an officer of Bureau of Land Management (BLM) conducts an environmental analysis of the area to be affected. Following the completion of this analysis, a report is submitted describing what parts of the land should be excluded from exploration activities and whatever other requirements should be included in the permit. Exploration licenses are never granted for lands in national parks or monuments, or in Naval oil shale reserves.

Once a valuable coal deposit is discovered and is reported to the BLM, the discoverers can nominate the particular tract for lease. The lease is then obtained through a competitive bidding process. A competitive bidding process involves submitting bids which carry a fixed percent royalty (usually $162 / 3$ ), with a cash bonus as the bid variable. The lease conveys the rights to obtain the coal and to use only as much of the surface as is necessary for mining coal. Leases are usually subject to readjustment every 20 years.

b. Off-shore drilling. Lands located in the outer continental shelf (OCS) are not public lands. That is, once the land has been leased, the BLM cannot oversee or interfere in any way with the way the land is being used until the termination of the lease period.

Tracts selected by the government are leased through a process of competitive bidding. The lease carries a fixed (usually $162 / 3 \%$ ) royalty, with a cash bonus as the bid variable. Such a bidding procedure creates entry barriers for 
small firms which are either not able to meet the usually large capital requirements up front or unable to diversify their risks. To offset this effect, most leases are sold in auctions in which there is no prohibition on the rendering of bids by a consortium. This reduces the entry barriers to some extent. Recently, DOE has adopted a proposal from the Council of Wage and Price Stability to experiment with a net profit-share leasing system as an alternative to the conventional bidding system on outer continental shelf (OCS) tracts. One experimental system lets profit-shares or royalties be the bid variable. The advantage of this system is that it reduces entry barriers, shifts some of the risk about the value of the land to the government, and encourages more efficient development of leases.

c. Geothermals. The types of land which can be leased for geothermal exploration are either federal, state, or private lands. Federal lands include two types of geothermal resource areas. The Known Geothermal Resource Areas (KGRA) are leased through a competitive bidding process. Lands not within a KGRA are leased to the first qualified applicant. There are proposals pending before the Congress to alter the definitions of KGRA and to change the competitive bidding methods. The actual leasing of federal land is governed by the Geothermal Steam Act of 1970, and which excludes several broad categories of land: national parks, wildlife ranges, game ranges, wildlife management areas, fish hatcheries, wildlife refuges, national recreation areas, Indian trust land and other or restricted lands. 
Federal lands are divided into four categories: (1) those controlled by the U.S. Department of Interior; (2) those controlled by the U.S. Department of Agriculture; (3) those controlled by the U.S. Department of Defense; and (4) land for which the Federal Government owns mineral rights, but not surface rights. Because most geothermal resources within federal lands are controlled by the U.S. Department of Interior, the discussion of this section will pertain to this specific category of federal land only. 4.2.2 Competitive and Noncompetitive Federal Geothermal Resources Leasing Procedures

According to the Code of Federal Regulations (CFR), geothermal resources mean geothermal steam and associated geothermal resources such as hot water and mineral by products. A geothermal lease is one issued under the authority of the Geothermal Steam Act of 1970 (P.L. 91-581). There are two forms of federal geothermal resource leasing: competitive and noncompetitive. They are reviewed in that order. Two agencies of the U.S. Department of the Interior are involved in the federal leasing of geothermal resources: the Bureau of Land Management (BLM) and the U.S. Geological Survey (USGS). Competitive leasing is one covering federal lands within a Known Geothermal Resource Area (KGRA). A KGRA means an area in which the geology, nearby discoveries, competitive interests, or other indicia would lead to belief that the prospects for extraction of geothermal resources are good enough to warrant investment for that purpose. 1 The most controversial item is that of the term of "competitive interest". Competitive interest is inferred to exist if at least one-half of the lands covered by an application

I In contrast, the concept of KGRA differs from that of Known Geologic Structure (KGS) in oil and gas leasing in that the designation of a field as a KGS requires a producing well. 
for noncompetitive leasing is also covered by another application which is filed during the same application filing period. ${ }^{2,3}$ A notable case is that a company inadvertently created a KGRA through erroneously filing twice on some of the same land in the same application filing period. 4 However, current regulations prohibit an applicant which overlaps any of the land covered by his first application. 5

The BLM can accept nominations for competitive leasing of federal lands within a KGRA or may on its own nominate one. ${ }^{6}$ The role of the USGS enters at this point of the leasing procedures by being responsible for determining the appropriate parcelling of tracts and for establishing rentals and royalties. The USGS also reports to the BLM on needed lease terms and conditions, including environmental and surface rehabilitation stipulations, relating to resource exploration and development. More important at this stage is that the USGS makes all geologic, engineering, and economic value determinations including a resource evaluation on each tract to be offered and a post sale recommendation to the BLM regarding acceptance or rejection of the highest bonus bid on a given tract. That is to say that the BLM with the cooperation of the GS sets a reservation bid on all geothermal resource tracts offered for competitive leasing.

2 An application filing period begins on the first working day of each calendar month and ends at the close of business on the last working day of that month. (CFR 3210.2-2.)

3 Forty-seven of the 108 existing KGRA's were designated as such entirely on the basis of "competitive interest". See Appendix I, page 13 of the Report by the Comptroller General of the United States, "How to speed development of geothermal energy on federal lands", EMD-80-13, October 26, 1979.

4 Ibid, Appendix I, page 14.

5 Code of Federal Regulations 3210.2-2.

6 Code of Federal Regulations 3220.1. 
Separate identified sealed bids are submitted by interested parties for each resource tract offered. All sealed bids are opened at the same time, and the highest bonus bid will be accepted if it exceeds the reservation bid; otherwise, it is rejected. If the bid is accepted, the bonus bid will be paid either in a single payment upon the award of the lease or in two equal annual installments due and payable within 2 years. ${ }^{7}$ Standards for diligent operation of the lease are then set by the Secretary of Energy. This completes the description of the process of competitive leasing of federally owned geothermal resource lands.

Lands not within any KGRA are avilable for noncompetitive leasing. When an application is filed without the BLM, the date of filing is stamped on the envelope. The envelope containing the application remains sealed until the end of the application filing period during which the application is filed. On the first working day following the end of the application filing period all applications are opened, and it is determined which applications are for lands included in a KGRA, especially those newly created KGRA through the concept of a show of "competitive interest." Applications for land determined to be KGRA are rejected. If any application covers both land within a KGRA and land outside a KGRA, the applicant will be granted the opportunity to amend his application to exclude the portion included in a KGRA. ${ }^{8}$ This completes the description of the process of noncompetitive leasing of federally owned geothermal resource lands.

All leases, be they competitive or noncompetitive, are for a primary term of 10 years. If the lessee commences actual drilling before the end of the primary term and is being diligently prosecuted at that time, a lease can

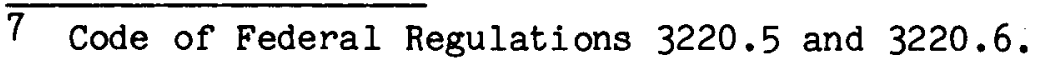

8 Code of Federal Regulations 3210.1 and 3210.2-2. 
be extended for an additional 5 years. If geothermal steam is produced or used in commercial quantities within the primary term of a lease that lease will be extended up to 40 years. And at the end of these 40 years extension on the lease, the lessee will have a preferential right to a renewal of the lease for a second 40-year term upon such terms and conditions as deemed appropriate by the BLM. Note that production or use of geothermal steam in commercial quantities is defined as the presence of one or more wells producing or capable of producing geothermal steam in commercial quantities and a bona fide sale of geothermal steam for delivery to or use by a facility or facilities not yet installed, but scheduled for installation not later than 15 years from the date of commencement of the primary term of the lease (CFR $32031-2,32031-3,32031-4)$. 
4.3 THE LEASING, CONTRACTING AND INSURANCE PROBLEMS

This section summarizes specific institutional aspects of geothermal development and their effects in the production, distribution, and use of geothermal energy. It addresses two questions: (1) What is unique about geothermal energy as compared to conventional sources? (2) What are the problems specific to it that need further analysis?

4.3.1 The Leasing Problem

The very fact that geothermal resources differ from conventional ones creates considerable confusion as to the application of the pre-existing regulatory schemes that were designed to deal with other kinds of resources. For example, in most jurisdictions there are separate bodies of law governing tract ownership and extraction of minerals, water, and oil and gas. Unfortunately, some geothermal resource consists of mineral laden water that must be drilled to be produced. Thus; there is some uncertainty as to the ownership of the resource and the body of the law that governs its exploitation. (The courts usually decide on a case-by-case basis.) As pointed out later, it is important to determine who the owner is, for this will affect the leasing procedures and related incentives to the lessee.

As another example, in states where there is already pre-existing regulation of drilling for oil and gas, the question arises whether such requirements and benefits are equally applicable to the drilling of geothermal wells. (Tax incentives enjoyed by oil and gas developers are a case in point.) In fact, today there are increasing instances of litigation to seek resolution of conflicts in law.

There are usually several problems facing a firm that wants to enter a market in which substitutes for its goods are available; but, in addition, because of the complexities of the institutional environment, the geothermal 
developer must face strict performance standards. From its beginning, geothermal development has been subject to extensive supervision and to constant evaluation of its proposed actions for their potential environmental impact.

Geothermal developments face one institutional factor for allocating risk that is not common for other rsources. On federally owned lands, if the tract is a KGRA, the lease is allotted by a competitive bidding process. If it is not a KGRA, the BLM leases the land to the first qualified applicant. Thus, a potential applicant should be reluctant to explore a tract before obtaining a lease for it lest discoveries by the potential applicant lead it to be reclassified as KGRA. On the other hand, an applicant who obtains the lease before exploring faces the risk that the tract is dry.

This kind of a problem does not arise in the case of state or privately owned lands, where a prospecting permit gives the prospector the first shot at bidding, and only if the bid is unreasonable is the tract opened for competitive bidding.

\subsubsection{Revenues from Leasing of Federally Owned Geothermal Resource Lands}

Revenues are generated through the leasing of federally owned geothermal resource lands. These revenues come from three major sources in addition to the usual corporate income tax on profitable ventures. Land rentals and royalty from commercial sale of geothermal resources are generated from both competitively and noncompetitively leased federal lands:

(1) rentals, (2) royalty, and (3) bonus bid. The third source, bonus bid, is generated only from the competitive lease sales.

(1) There is an annual rental charge of $\$ 1$ per acre on all leases and beginning with the sixth year of a lease and for each year thereafter until commercial production of geothermal resources 
begins, the annual rental will be increased by $\$ 1$ per acre per year. 9

(2) A royalty rate, as part of the lease terms proposed by the U.S. Geological Survey, lies between 10 to $15 \%$ of the value of steam, or any other form of heat or energy derived from production under the lease and sold or utilized by the lessee or reasonably susceptible to sale or utilization by the lessee. For byproducts, a royalty rate of no more than $5 \%$ will be set. ${ }^{10}$

(3) From January 1974 through May 1979, there were 59 competitive public lease bids, about $\$ 73.6$ million in total bonus bids, and about $\$ 36$ million in total winning bonus bids. The Geysers KGRA alone accounted for over $\$ 24$ million in total accepted bonus bids. 11

The escalated rental charges are designed to encourage orderly and timely exploration and development of geothermal resources. Unfortunately, the time span from obtaining a lease to commercial production is not completely under the control of the lessee.. Three time factors enter the picture. First, there is the time lag for negotiating a contract with a final user, for example, a utility company. Time is definitely consumed in the process of convincing a final user that the geothermal resource can sustain throughout the operating life of the production facilities of the final user. Careful negotiation of the price of the delivered geothermal resources over time is necessary. Finally, there must be careful consideration of how the risk will be shared. All these negotiations are time consuming.

\footnotetext{
9 Code of Federal Regulations 3205.3-1, and 3205.3-3.

10 Code of Federal Regulations 3205.3-5.
}

11 Report by the Comptroller General, op. cit., Appendix I, page 5. 
Second, even when a contract is negotiated, there are regulatory delays for the utility company to obtain a certificate of public convenience and necessity (at least for the case of California utilities). In the table below, the actual experience of Pacific Gas and Electric (PG\&E) of California is documented. It is clear that the time required to obtain a certificate has increased in leaps and bounds. For units 1 through 6 , the time required ranges from 1 to 5 months with a general decline in the time required as the regulatory agency (the California Public Utility Commission) learned to streamline the regulatory procedures for a new energy source. For units 7 to 11, there was a jump in regulatory delays. Antitrust issues were raised. The time lag ranges from 6 to 12 months. For units 12 to 15, environmental issues were raised. There was another' jump in regulatory delays. The time lag increased to a range of 26 to 41 months. Again there was a general decline in the regulatory delay as the regulatory agency learned to deal with the intervening issues.

Third, after a certificate is issued, the lessee still has to allow lead time for the utility company to construct its generating plant

facilities. For capacity size less than $50 \mathrm{MW}$, the time lag ranges from $171 / 2$ to 31 months. For capacity size ranging from 50 to $100 \mathrm{MW}$. the time lag ranges from 21 to 38 months. For capacity size over $100 \mathrm{MW}$, the time lag ranges from 38 to 53 months.

It can be concluded that there is supporting evidence that developers face time lags for the commencement of commercial production of geothermal resources that are not fully under their control. Moreoever, these time lags can easily own more than 5 years without including the time needed for exploration and identification of a commercially exploitable geothermal resource. As the escalated rental rates is likely to be invoked, it is 
Table 4-1 Time to Obtain CPUC Certificate

Time to Complete the Construction of Electricity Generating Facilities: The Experience of PG\&E

\begin{tabular}{|c|c|c|c|c|c|c|}
\hline Unit & $\begin{array}{l}\text { Size, } \\
\text { MW }\end{array}$ & $\begin{array}{c}\text { Application } \\
\text { Date }\end{array}$ & $\begin{array}{c}\text { Certificate } \\
\text { Date }\end{array}$ & $\begin{array}{c}\text { Time Required } \\
\text { to obtain } \\
\text { Certificate, } \\
\text { months }\end{array}$ & $\begin{array}{l}\text { Date of } \\
\text { Commercial } \\
\text { Operation }\end{array}$ & $\begin{array}{l}\text { Time Required } \\
\text { to Complete the } \\
\text { Construction of } \\
\text { Electricity } \\
\text { Generating } \\
\text { Facilities, } \\
\text { Months }\end{array}$ \\
\hline 1 & 11 & $12 / 5 / 58$ & $4 / 7 / 59$ & 5 & $9 / 25 / 60$ & $17-1 / 2$ \\
\hline 2 & 13 & $4 / 19 / 61$ & $7 / 11 / 61$ & 3 & $3 / 19 / 63$ & 20 \\
\hline 3 & 27 & $7 / 15 / 64$ & $9 / 22 / 64$ & 2 & $4 / 28 / 67$ & 31 \\
\hline 4 & 27 & $5 / 6 / 66$ & $7 / 12 / 66$ & 2 & $3 / 2 / 68$ & 19 \\
\hline 5 & 53 & $12 / 11 / 67$ & $1 / 23 / 68$ & 1 & $12 / 15 / 71$ & 35 \\
\hline 6 & 53 & $9 / 18 / 68$ & $11 / 12 / 68$ & 2 & $12 / 15 / 71$ & 25 \\
\hline 7 & 53 & $5 / 11 / 70$ & $11 / 10 / 70$ & 6 & $8 / 18 / 72$ & 21 \\
\hline 8 & 53 & $5 / 11 / 70$ & $11 / 10 / 70$ & 6 & $11 / 23 / 72$ & 24 \\
\hline 9 & 53 & $11 / 24 / 70$ & $11 / 23 / 71$ & 12 & $10 / 25 / 73$ & 23 \\
\hline 10 & 53 & $11 / 24 / 70$ & $11 / 23 / 71$ & 12 & $11 / 30 / 73$ & 24 \\
\hline 11 & 106 & $2 / 4 / 72$ & $9 / 12 / 72$ & 7 & $11 / 20 / 75$ & 38 \\
\hline 12 & 106 & $7 / 19 / 72$ & $12 / 30 / 75$ & 41 & $3 / 1 / 79$ & 38 \\
\hline 13 & 135 & $3 / 22 / 74$ & $11 / 23 / 76$ & 32 & $5 / 15 / 80$ & 42 \\
\hline 14 & 110 & $7 / 24 / 73$ & $4 / 20 / 76$ & 33 & $9 / 12 / 80$ & 53 \\
\hline 15 & 55 & $3 / 1 / 74$ & $4 / 20 / 76$ & 26 & $6 / 17 / 79$ & 38 \\
\hline
\end{tabular}

Source: Pacific Gas and Electric Company 
reasonable to conclude that the starting date for escalating rental rates should be readjusted to allow for a larger lead time even though there is current provision that the Bureau of Land Management may, upon a showing of sufficient justification by the lessee, waive the payment of all or any portion of the additional rental (CFR 3205.3-3).

The discussion of royalty is a bit premature because, as of October 26, 1979, the Comptroller General reported to Congress that there was no commercial geothermal production from a federal lease. ${ }^{12}$ Nevertheless, there are several interesting points deserving a short discussion. Setting up a royalty rate provides a form of risk sharing. Because royalty payment is due only if there is commercial sale of geothermal resources, lessees face no additional penalty if their leases turn out to be of no economic value. However, the Federal Government receives its share of the payoff if commercial sale occurs. Moreover, imposing a royalty rate lowers the expected net return. Thus, competitively bidding will lead to a smaller bonus bid. This, in turn, lessens the upfront cash requirement and attracts more bidders especially the relatively lower running capital geothermal developer encouraging more competition in the competitive leasing process. The unwarranted affect of royalty is that a higher royalty rate will shift the pattern of resource extraction to the future.

Although the Geothermal Steam Act of 1970 calls for the Secretary of Interior to unilaterally readjust the terms of a geothermal lease, the current regulations state that rentals and royalties readjustment of any geothermal lease "may be readjusted at not less than 20-year intervals beginning 35 years after the date geothermal steam is produced." (CFR 2305.3-9) As geothermal power plants are usually designed for a 30-year life, there seems to be no

$\overline{12}$ Ibid, page 2 of the main text. 
additional restraint on developers or on utilities to exploit geothermal potential.

The presence of a competitive bonus bid essentially allows the Federal Government to capture the pure economic rent from economically valuable geothermal resources. It is interesting to note that a bonus bid in the absence of a reservation bid by a seller will lead to no distortion of the path of resource extraction. However, as bonus bidding redistributes economic rent from developers to the federal governemnt, it is obvious that, ceterus paribus, developers prefer noncompetitive than competitive leases. The evidence given in Table 4-2 does not seem to contradict this statement. As of June 1, 1979, data on leasing activities under the two forms of leasing are available.

Table 4-2. Leasing Activities

Number of Leases

Type of Lease Issued Active Ended

Noncompetitive $1,320 \quad 988 \quad 332$

Competitive Total

$$
\frac{296}{1,616} \quad \frac{265}{1,253} \quad \frac{31}{363}
$$

Total Acreage under active leases
Total Acreage relinquished or terminated

Source: Report by the Comptroller General, op. cit, Appendix I, page 5

Noncompetitive leasing is far more active than its competitive counterpart. This is borne out by the number of leases issued as well as the number of acreage leased. It is also not surprising that far more numbers of leases obtained through noncompetitive leases are relinquished or terminated. This is true also on an acreage basis (absolute or relative). The reason is that it only costs $\$ 50$ service charge to file a noncompetitive lease application. As noncompetitive leasing is allowed only for non KGRA lands, especially 
lands without a show of competitive interest, it is clear that many leases turn out to be of no economic value. This empirical observation coupled with the fact that there was no commercial geothermal production from a federal lease indicates that the form of leasing procedure is not an impediment to geothermal resource exploitation. The key is that more promising geothermal resources have not been identified. Public policy should be addressed towards the enchancement of discovering economically valuable geothermal resource in order to foster the tapping of geothermal resources.

It is now apparent that there is a need to study the role of information in fostering the development of geothermal resources. In particular, the role of information is studied under two contexts--pre-leasing and post-leasing situations.

4.3.1.2 Information in a Pre-leasing Context: The Nash Equilibrium Case ${ }^{13}$

To exposit the importance of information, the simplest case is examined. Specifically, it is assumed that a geothermal resource tract offered for lease can be one of two economic values, designated by $\mathrm{V}_{\mathrm{H}}$ for a high value tract and $V_{L}$ for a low value tract. The likelihood of the tract to take on the high value is given by the probability $p$ and the low value by the probability 1-p. Let there be two bidders interested in this particular tract. The probability values are public knowledge to them. Suppose that at a cost $K>0$, any one of the bidders can acquire a piece of perfect information telling him which is the true value of the tract. The interest here is to identify and study the Nash equilibrium (or equilibria) for this rivalry situation.

13 A Nash equilibrium for two bidders using strategy $\sigma_{i}, i=1,2$ is defined as a strategy pair $\left(\sigma_{1}^{*}, \sigma_{2}^{*}\right)$, such that:

$$
\text { and } \left.\pi_{1}\left(\sigma_{1}\left(\sigma_{1 *}, \sigma_{2}^{*}\right) \geq \sigma_{2}\right) \geq \pi_{2}\left(\sigma_{1}, \sigma_{2}^{*}\right) \text { for all } \sigma_{1}, \sigma_{2}\right) \text { for all } \sigma_{2} \text {. }
$$


The strategy of bidder $i=1,2$ is given by a triplet $\sigma_{i}=\left(k_{i} ; b_{i}^{H}, b_{i}^{L}\right)$ where

$$
\begin{aligned}
& \mathrm{K}_{i}= \begin{cases}\mathrm{K} & \text { if purchase information } \\
0 & \text { otherwise }\end{cases} \\
& \mathrm{b}_{\mathrm{i}}^{\mathrm{H}}=\text { bid on tract if information indicates high value } \\
& \mathrm{b}_{i}^{\mathrm{L}}=\text { bid on tract if information indicates low value }
\end{aligned}
$$

The adopted convention for the case of no information acquisition is that $b_{i}^{H}=b_{i}^{L}=b_{i}$. The strategy of the seller is assumed passive and pessimistic; namely, the reservation bid of the seller is set equal to $V_{L}$. Last of all, it is assumed that the following inequality holds true:

$$
(1-p)\left(V_{H}-V_{L}\right)>\frac{K}{p}
$$

The inequality says that condition on the true value of the tract offered for lease is low, the benefit of knowing that as measured by $(1-p)\left(V_{H}-V_{L}\right)$ should be greater than the adjusted cost condition on the true value of the tract offered for lease is high anyway, $\mathrm{K} / \mathrm{p}$. This is a reasonable assumption on the seller side.

Three cases are considered. These cases are discussed below.

a. Case 1. Both bidders acquire the information, i.e., $K_{i}=K, i=1,2$. Since bidding is competitive, if the true value of the tract is revealed to be high, each bidder will bid $\mathrm{V}_{\mathrm{H}}$. If one bidder bids less than that, the other bidder can win the lease by bidding a small amount above that. It is obvious that none of them will bid more than $\mathrm{V}_{\mathrm{H}}$. Thus, the claim is proved. The same line of argument will lead to the conclusion that if the true value of the tract is revealed to be low, each bidder will bid $V_{L}$. Thus, the strategy is $o_{i}=\left(K ; V_{H}, V_{L}\right) i=1,2$. But then the expected profit for each bidder will be $\pi_{i}=-K<0$. Each bidder will sustain a loss equal to the cost of information. Moreover, there is a 
duplication of information acquisition effort. Define $V_{e}=p_{H}+(l-p)$

$V_{L}$. It is clear that the expected profit to the seller is $\pi_{s}=V_{e}$.

b. Case 2. In this case, only one bidder acquires the information. Without

loss of generality, let bidder one acquire the information. Suppose

bidder two's strategy is

$$
\sigma_{2}=\left(0 ; V_{L}, V_{L}\right)
$$

Then bidder one's strategy ought to take the form

$$
\sigma_{1}=\left(\mathrm{K} ; \mathrm{V}_{\mathrm{L}}+\varepsilon, \mathrm{V}_{\mathrm{L}}\right)
$$

where $\varepsilon$ is a very small positive number that allows bidder one to win the bid if the true value of the tract is high. However, bidder two's strategy will then be $\sigma_{2}=\left(0, \mathrm{~V}_{\mathrm{L}}+\varepsilon+\delta, \mathrm{V}_{\mathrm{L}}+\varepsilon+\delta\right)$. But bidder one will have incentive to raise his bid if the tract is of high value. Bidder two will in turn either raise his bid and the process continues or will return to the strategy $\sigma_{2}=\left(0, \mathrm{v}_{\mathrm{L}}, \mathrm{V}_{2}\right)$. Thus, there is no pure strategy Nash equilibrium for the bidding part of the two stage game. If mixed strategy is introduced, a Nash equilibrium exists and is given by a paid of bid distributions. Bidder two's bid distribution is

$$
G(b)=\frac{(1-p)\left(V_{H}-V_{L}\right)}{V_{H}-b}
$$

If the tract is informed to be of high value, bidder one's bid distribution is

$$
F(b)=\frac{(1-p)\left(b-V_{L}\right)}{p\left(V_{H}-b\right)}
$$

where $b \varepsilon\left[\mathrm{V}_{\mathrm{L}}, \mathrm{V}_{\mathrm{e}}\right]$. Note that $\mathrm{F}$ stochastically dominates $\mathrm{G}$. Thus, it is expected that the informed bidder will, on the average, bid higher than the uninformed bidder if the tract is of high value. For low-value tract, 
the uninformed bidder will, on the average, bid higher than the informed bidder. The expected profit of the uninformed bidder is zero, and that of the informed bidder is $p(I-0)\left(V_{H}-V_{L}\right)-K$. The equilibrium mixed strategies are, therefore, given by

$$
\begin{aligned}
& \sigma_{2}=(0 ;(b), G(b)) \\
& \sigma_{1}=\left(k ; F(b), V_{L}\right) .
\end{aligned}
$$

c. Case 3. Suppose both bidders do not acquire the information. They will have identical bids. If not, the higher bidder can lower his bid by a small amount and still win the bid. Moreover, the bid should be equal to $\mathrm{V}_{\mathrm{e}}$. If the identical bid is greater than $\mathrm{v}_{e}$, both bidders have a negative expected profit and it pays for one of the bidders to bid less losing the bid and making zero expected profit, a definite improvement. If the identical bid is less than $\mathrm{V}_{e}$, then both bidders have a positive expected profit and it pays for one of the bidders to break the tie by bidding a small amount higher, winning the bid and making higher expected profit. Thus, it can be concuded that the strategy of the two bidders is given by

$$
\sigma_{i}=\left(0 ; v_{e}, v_{e}\right), \quad i=1,2
$$

The expected profits of the bidders are given by

$$
\pi_{i}=0 ; \quad i=1,2
$$

The seller's expected profit is

$$
\pi_{s}=v_{e}
$$

Three points must be noted. First, if a bidder decides to acquire information given the other does not and if the informed bidder decides to use a mixed strategy, it pays the first bidder to inform the other bidder that he has adopted such a strategy. If not, the uninformed bidder (say bidder 2) will maintain his strategy at

$$
\sigma_{2}=\left(0 ; v_{e}, v_{e}\right)
$$


Table 4-3. Payoff Matrix

Bidder 2

Acquires information Does not acquire information

Bidder 1

$(-K,-K)$

$\left(p(l-p)\left(V_{H}-V_{L}\right)-K, 0\right)$

Does not acquire

information $\quad\left(0, p(1-p)\left(V_{H}-V_{L}\right)-K \quad(0,0)\right.$

Bidder two's profit will then be zero. The informed bidder using his mixed strategy will not win the lease because

$$
F(b) \geq 0 \text { for } b \varepsilon\left[V_{L}, V_{e}\right] \text {. }
$$

His expected profit is $-K$, which is less than that which he can get if he has

informed his opponent of his information acquisition decision.

Second, the results can be summarized in a payoff matrix (assuming information acquisition decision is announced: see Table 4-3).

The Nash equilibria are asymmetrical and not interchangeable. It is

this fact that the Nash equilibria may not be stable. Without coordination, over or under investment in information acquisition may be the case. Thus, noncompetitive leasing may be preferable. However, this conclusion could be dubious for two reasons: (1) The seller is assumed to be pessimistic. If the seller is not pessimistic, he may set a different reservation bid and the conclusion may be different. (2) The seller is assumed to be passive. If the seller is not passive, he may provide the information to the two bidders free of charge. In that event, the strategy of the bidders is given by

$$
\sigma_{i}=\left(0 ; V_{H}, V_{L}\right), \quad i=I, 2
$$

and their profits

$$
\pi_{i}=0 ; i=1,2
$$

The expected profits of the seller are 


$$
\begin{aligned}
\pi_{\mathrm{x}} & =\mathrm{p} \mathrm{V}_{\mathrm{H}}+(\mathrm{I}-\mathrm{p}) \mathrm{V}_{\mathrm{L}}-\mathrm{K} \\
& =\mathrm{V}_{\mathrm{e}}-\mathrm{K}
\end{aligned}
$$

which could be greater than his expected profit under one of the asymmetrical Nash equilibria. Thus, one concludes that if reservation bid is set at the lower value, it is possible that it pays the seller to provide the kind of information described.

Third, if the asymmetrical Nash equilibrium is the final solution, two interesting properties of this solution emerge. The prediction of this form of asymmetrical equilibrium is that one bidder will bid high on some tracts and low on others while the other bidder will bid low on the first set of tracts and high on the others (depending on which set of tracts is informed to be good or bad) a commonly observed result of resource leasing. This is consistent with empirical observations below.

In the January 22, 1974, geothermal lease sale held in Sacramento, California, there were eight Geysers KGRA tracts, both for which Signal Oil Co. and Union Dil Co. of California submitted bids. The data on submitted bids are recorded as listed in Table $4-4$.

In a similar type of runoff between Union 011 Co. and Phillips in the July 30, 1974, Roosevelt Hot Springs (Utah) geothermal lease sale, the following data on submitted bids again reconfirmed the predictions of the model: see Table 4-5.

\subsubsection{Information in a Pre-leasing context: The "Stackelberg" Case}

The assumptions will not be changed for the rest of the discussion with the exception that only one bidder is considered. It should be noted that the result in this section can be easily generalized for a two-bidder case. For ease of exposition, a one bidder case is considered. Specifically, 
Table 4-4. Data on Submitted Bids: Signal Oil Co. and Union Oil Co. of California

\begin{tabular}{|c|c|c|c|}
\hline Tract & Acreage & Name of Bidder & Amount \\
\hline 1 & 2,340 & $\begin{array}{l}\text { Signal Oil and Gas Co., et al. } \\
\text { Union Oil Co. of Calif. }\end{array}$ & $\begin{array}{l}\$ 1,516,660.00 \\
\$ 774,867.60\end{array}$ \\
\hline 4 & 101 & $\frac{\text { Union Oil Co. of Calif. }}{\text { Signal Oil and Gas Co. }}$ & $\frac{\$ 48,314 \cdot 36}{\$ 28,381.00}$ \\
\hline 7 & 626 & $\begin{array}{l}\text { Union Oil Co. of Calif. } \\
\text { Signal Oil Co. }\end{array}$ & $\begin{array}{l}\$ 318,120.68 \\
\$ 180,288.00\end{array}$ \\
\hline 8 & 250 & $\frac{\text { Signal Oil Co. }}{\text { Union Oil Co. of Calif. }}$ & $\frac{\$ 75,600.00}{\$ 57,045.00}$ \\
\hline 9 & 160 & $\begin{array}{l}\text { Union Oil Co. of Calif. } \\
\text { Signal Oil and Gas Co. }\end{array}$ & $\begin{array}{l}\$ 129,161.00 \\
\$ 32,480.00\end{array}$ \\
\hline 10 & 222 & $\begin{array}{l}\text { Signal Oil and Gas Co. } \\
\text { Union Oil of Calif. }\end{array}$ & $\begin{array}{l}\$ 78,588.00 \\
\$ 67,634.52\end{array}$ \\
\hline 11 & 45 & $\frac{\text { Union Oil Co. of Calif. }}{\text { Signal Oil and Gas Co. }}$ & $\frac{\$ 22,868 \cdot 10}{\$ 4,770 \cdot 00}$ \\
\hline 12 & 737 & $\frac{\text { Signal Oil and Gas Co. }}{\text { Union Oil Co. of Calif. }}$ & $\frac{\$ 56,666.00}{\$ 18,631.36}$ \\
\hline
\end{tabular}

a Bids underlined are accepted winning bids.

Table 4-5. Data on Submitted Bids: Union Oil Co. and Phillips

\begin{tabular}{cccc}
\hline Tract & Acreage & Name of Bidder & Amount \\
\hline 1 & 2,560 & $\frac{\text { Union Oil }}{\text { Phillips }}$ & $\frac{\$ 51,993.60}{13,081.60}$ \\
2 & 1,640 & $\frac{\text { Phillips }}{\text { Union Oil }}$ & $\frac{\$ 87,543.20}{62,090.40}$ \\
4 & $2,453.5$ & $\frac{\text { Phillips }}{\text { Union Oil }}$ & $\$ \frac{\$ 14,199.05}{93,234.14}$ \\
6 & 1,940 & $\frac{\text { Phillips }}{\text { Union Oil }}$ & $\$ \frac{\$ 24,391.58}{46,672.30}$ \\
\hline
\end{tabular}

Source: Montgomery, W. David, "The Structure of the Geothermal Industry Through 1974" Environmental Quality Laboratory, Report No. 11, July 1975. California Institute of Technology, Pasadena, California 91125. 
it is assumed that the seller is active and knows what strategy is adopted by the bidder.

a. Suppose the bidder does not acquire the information. Then the strategy for the bidder is given by

$$
\sigma_{1}=\left(0 ; v_{e}, v_{e}\right)
$$

given that the seller's reservation bid is $V_{e}$. The expected profit of the bidder is

$$
\pi_{1}=0
$$

The expected profit of the seller is

$$
\pi_{s}=V_{e}
$$

b. Suppose the bidder acquires the information. Then the strategy for the bidder is

$$
\sigma_{1}=\left(\mathrm{K} ; \mathrm{V}_{\mathrm{H}}-\frac{\mathrm{K}}{\mathrm{p}}, \mathrm{V}_{\mathrm{L}}\right)
$$

given that the seller's reservation bid is $V_{H}-\frac{K}{p}$. The expected profit of the bidder is zero, and that of the seller is

$$
\pi_{S}=p\left(v_{H}-\frac{K}{p}\right)
$$

It is noted that the seller's expected profit is higher under Case 1 than under Case 2. If not,

$$
p\left(v_{H}-\frac{K}{p}\right) \geq V_{e}=p V_{H}+(1-p) V_{L}
$$

or $-\mathrm{K} \geq(1-\mathrm{p}) \mathrm{V}_{\mathrm{L}}$ contradiction.

Hence, one concludes that if the seller sets reservation bid appropriately, the seller has no incentive to encourage bidders to gather information.

If the seller provides free information, his expected profit is

$$
\pi_{s}=v_{e}-K
$$

less than the case of no information. 
Thus, one concludes that, if the seller sets reservation bid

appropriately, the seller has no incentive to provide free information of the type described.

4.3.1.4 Information in a Post-leasing context

In a post-leasing context, the developer has obtained a lease. He has to decide and actually carry out exploratory and/or development activities. There are two major informational problems in this context. The first problem is externality, which can be easily disposed of. This subject is discussed first. The second problem is provision of public information.

a. Externality. There are two forms of informational externality. First, if a developer finds an economically valuable geothermal resource, there will be one less resource remaining to be discovered. If the finding is not revealed to other developers, there may be over investment in resource exploration. This is known as the Easter egg problem. For lands located within a KGRA, this problem can be disposed of, as all major resource findings are publicized. For lands outside of any KGRA, there is definitely an incentive not to disclose a discovery lest valuable lands around the discovery will be classified as KGRA and have to be competitively leased. However, two reasons seem to counteract this incentive. For one, it is difficult to cover up. Moreover, the lessor (THE BLM) may revoke any lease so obtained if a coverup is unraveled.

Second, if there are tracts close together belonging to the same geologic structure, the failure or success in finding a geothermal resource will signal to other lessees in the neighborhood whether development is worthwhile or not. This information spillover leads to a free-rider problem because every lessee in the neighborhood will wait for someone else to do the exploration. If every lessee behaves alike, there will be no exploration or 
at most, up to the point of minimally satisfying the diligent exploration regulation. This problem can be disposed of by the formation of unit agreement. The remaining question is how to split the costs and benefits among members of a unitized field. Rules of thumb such as proration according to the number of lessees or according to the number of acreage are common. b. Public Information. To study the role of public information, there is a need of clarifying how to estimate the benefits of information. There are two concepts generally used. The first is called the gain in information. To explain this concept, it is best to consider an example. Suppose a decision-maker's preference is represented by a utility function $U(a, w)$ where $a$ is the decision variable a $A$, the set of all decision variables. Let there be four states of the world $w_{1}, w_{2}, w_{3}, w_{4}$ stating the net payoffs to the decision making. The decision maker's probability assessment of the likelihood of occurrence of these four states of the world is $p_{1}, p_{2}, p_{3}, p_{4}$, respectively, with $p_{1}+p_{2}+p_{e}+p_{4}=1$. Suppose a piece of information is available which will inform for such whether the true state is either $\left\{w_{1}, w_{2}\right\}$ or $\left\{w_{3}, w_{4}\right\}$. If $\left\{w_{1}, w_{2}\right\}$ is the revealed information, the decision maker's problem is

$$
\max _{a \in A}\left[\frac{p_{1}}{p_{1}+p_{2}} U\left(a, w_{1}\right)+\frac{p_{2}}{p_{1}+p_{2}} U\left(a, w_{2}\right)\right] \equiv \phi_{1}\left(w_{1}, w_{2}\right)
$$

If $\left\{w_{3}, w_{4}\right\}$ is the revealed information, the decision-maker's problem is

$$
\max _{a \in A}\left[\frac{p_{3}}{p_{3}+p_{4}} U\left(a, w_{3}\right)+\frac{p_{4}}{p_{3}+p_{4}} U\left(a, w_{4}\right)\right] \equiv \phi_{2}\left(w_{3}, w_{4}\right)
$$

But before the information is revealed, the expected utility is $v_{I}=\left(p_{1}+p_{2}\right) \phi_{1}\left(w_{1}, w_{2}\right)+\left(p_{3}+p_{4}\right) \phi_{2}\left(w_{3}, w_{4}\right)$ given there is information to be revealed. The expected utility of the decision maker in the absence of the information is 


$$
\mathrm{V}_{E}=\max _{a \in A}\left[p_{1} \mathrm{U}\left(\mathrm{a}, \mathrm{w}_{1}\right)+\mathrm{p}_{2} \mathrm{U}\left(\mathrm{a}, \mathrm{w}_{2}\right)+\mathrm{p}_{3} \mathrm{U}\left(\mathrm{a}, \mathrm{w}_{3}\right)+\mathrm{p}_{4} \mathrm{U}\left(\mathrm{a}, \mathrm{w}_{4}\right)\right]
$$

The gain in information is defined as

$$
\mathrm{V}_{\mathrm{G}} \equiv \mathrm{V}_{\mathrm{I}}-\mathrm{V}_{\mathrm{E}}
$$

The second concept is called the value of information. To explain this concept, the same example will be used with the only modification being that the utility function is now given by

$$
U(a, w, M)
$$

where $M$ is the amount of wealth of the decision maker. To find the value of information is to seek a payment $\mathrm{K}$ such that the decision-maker will be indifferent between having the information or without it, i.e., to find $\mathrm{K}$ such that

$$
\begin{aligned}
& \left(P_{1}+P_{2}\right) \max _{a \varepsilon A}\left[\frac{p_{i}}{p_{1}+p_{2}} U\left(a, w_{1}, M-K\right)+\frac{p_{2}}{p_{1}+p_{2}} U\left(a, w_{2}, M-k\right)\right] \\
& +\left(p_{3}+p_{4}\right) \max _{a \varepsilon A}\left[\frac{p_{3}}{p_{3}+p_{4}} U\left(a, w_{3}, M-K\right)+\frac{p_{4}}{p_{3}+p_{4}} U\left(a, w_{4}, M-K\right)\right]= \\
& \quad \max _{\operatorname{a\varepsilon A}}\left[p_{1} U\left(a, w_{1}, M\right)+p_{2} U\left(a, w_{2}, M\right)+p_{3} U\left(a, w_{3}, M\right)+p_{4} U\left(a, w_{4}, M\right)\right]
\end{aligned}
$$

In general, these two concepts are not the same. The latter provides a practical measure of the benefit of information. However, for the case of linear utility functions, the two concepts coincide and can be used interchangeably. For the rest of the section, it is assumed that this is indeed the case. An example of this case is when the decision-maker's objective is simply to maximize expected profits. A simple illustration is useful.

Suppose a geothermal resource lease can take on a high value $\mathrm{V}_{\mathrm{H}}$ or a low value $V_{L}$. The probability assessment of the likelihood of these 
two events is $p$ and $1-p)$, respectively. Let $V_{e}=p V_{H}+(1-p) V_{L}$, the expected value of the tract. Suppose the cost of development is $F$ such that

$$
\mathrm{V}_{\mathrm{L}}<\mathrm{F}<\mathrm{V}_{\mathrm{e}}<\mathrm{V}_{\mathrm{H}}
$$

Now, at a cost of $\mathrm{K}$, a piece of information can be purchased that can tell for sure which value the geothermal tract will take. Then it pays to be an informed developer if the following inequality holds:

$$
\mathrm{p}\left(\mathrm{V}_{\mathrm{H}}-\mathrm{F}\right)-\mathrm{K}>\mathrm{V}_{\mathrm{e}}-\mathrm{F}
$$

or

$$
F-V_{L}>\frac{k}{l-p}
$$

that is, conditioning on a bad outcome, the savings in development cost is greater than the conditional information cost.

It is now time to consider two types of information concatenation, namely substitutable information and complementary information. In the substitution information case, a piece of information is worth purchasing on its, own but the public availability of another piece of information will render the first piece of information unworthwhile. To see this, consider the following example. Suppose there are four states of the world for the value of a geothermal tract, say $\{10,6,4,1\}$ measured in monetary units. Let the probability assessment be $\{1 / 4,1 / 4,1 / 4,1 / 4\}$, respectively. The cost of development is five monetary units. There is a piece of information which can tell for sure whether the tract is of value $\{10,4\}$ or $\{6,1\}$. The cost of this piece of information is $1 / 2$. The value of this piece of information is therefore

$$
\begin{aligned}
& \quad \frac{1}{2} \max \left[\frac{1}{2}(10)+\frac{1}{2}(4)-5,0\right]+\frac{1}{2} \max \left[\frac{1}{2}(6)+\frac{1}{2}(1)-5,0\right] \\
& -\max \left[\frac{1}{4}(10)+\frac{1}{4}(16)+\frac{1}{4}(4)+\frac{1}{4}(1)-5,0\right]=\frac{3}{4}
\end{aligned}
$$


Since this is greater than the cost of information, on its own, this piece of information will be purchased.

Now, suppose a piece of public information is provided at no cost to the developer. This piece of public information can tell for sure whether the value of the tract is $\{10,6\}$ or $\{4,1\}$. With this piece of public information, the developer's payoff is

$$
\frac{1}{2} \max \left[\frac{1}{2}(10)+\frac{1}{2}(6)-5,0\right]+\frac{1}{2} \max \left[\frac{1}{2}(4)+\frac{1}{2}(1)-5,0\right]=1 \frac{1}{2}
$$

If the developer further acquires the private information, he can tell for sure whether the value of the tract is $10,6,4$ or 1 . The developer's payoff under the concatenated information is

$$
\frac{1}{4} \max [10-5,0]+\frac{1}{4} \max [6-5,0]+\frac{1}{4} \max [4-5,0]+\frac{1}{4} \max [1-5,0]=1 \frac{1}{2}
$$

The additional value of the private information given that the public information is made available at no charge is zero. Thus, this piece of private information will not be purchased under the circumstances. This is an example of one piece of information substituting for another.

The question that needs to be answered is under what condition will the provision of one piece of information displace the acquisition of another piece of information. The following proposition helps to answer the question. Proposition: If $\mathrm{b}$ is the more valuable information in the sense that $\mathrm{v}_{\mathrm{a}}$ $\mathrm{K}_{\mathrm{a}}<\mathrm{V}_{\mathrm{b}}-\mathrm{K}_{\mathrm{b}}$, and if $\mathrm{b}$ will not be privately acquired whenever $a$ is publicly provided i.e., $v_{a, b}-v_{a}<K_{b}$, then $a$ will not be privately acquired whenever $b$ is publicly provided i.e., $v_{a, b}-v_{b} \geq k_{a}$.

Proof: If not, $\mathrm{v}_{\mathrm{a}, \mathrm{b}}-\mathrm{v}_{\mathrm{b}}<\mathrm{K}_{\mathrm{a}}$, but $\mathrm{v}_{\mathrm{a}, \mathrm{b}}-\mathrm{v}_{\mathrm{a}}<\mathrm{K}_{\mathrm{b}}$; therefore $\mathrm{V}_{\mathrm{a}}-\mathrm{K}_{\mathrm{a}}>\mathrm{V}_{\mathrm{b}}-\mathrm{K}_{\mathrm{b}}$, contradiction. 
The next question is under what condition a piece of information should not be publicly provided. The following proposition helps to answer it. Proposition: If $b$ will not be privately acquired whenever $a$ is publicly provided, i.e., $\mathrm{V}_{\mathrm{a}, \mathrm{b}}-\mathrm{V}_{\mathrm{a}}<\mathrm{K}_{\mathrm{b}}$ and if a is not privately acquired on its own i.e., $\mathrm{V}_{a}-\mathrm{V}_{e}<\mathrm{K}_{a}$, then if $b$ has already been privately acquired, a should not be publicly provided i.e., $\mathrm{V}_{\mathrm{a}, \mathrm{b}}-\mathrm{V}_{\mathrm{b}} \leq \mathrm{K}_{\mathrm{a}}$.

Proof If not $v_{a, b}-v_{b}>K_{a}$

$$
\text { or } \begin{aligned}
V_{a, b}-v_{a}>V_{b} & -V_{a}+K_{a} \\
= & \left(V_{b}-K_{b}\right)-\left(v_{a}-K_{a}\right)+K_{b} \\
& K_{b} \text {, contradiction. }
\end{aligned}
$$

In the complementary information case, a price of information that is not worth private acquisition on its own may become worthwhile if another piece of information is publicly provided. To see this, consider the following example. Suppose there are four states of the world for the value of a geothermal tract, say $\{10,8,4,3\}$ measured in monetary units. Let the probability assessment of the likelihood of each state of the world be $1 / 4,1 / 4,1 / 4,1 / 4$ respectively. The cost of development is 5 monetary units. There is a piece of information which can tell for sure whether the tract is of value $\{10,4\}$ or $\{8,3\}$. The cost of this piece of information is $1 / 2$. The value of this piece of information is

$$
\begin{aligned}
& \frac{1}{2} \max \left[\frac{1}{2}(10)+\frac{1}{2}(4)-5,0\right]+\frac{1}{2} \max \left[\frac{1}{2}(8)+\frac{1}{2}(3)-5,0\right] \\
& -\max \left[\frac{1}{4}(10)+\frac{1}{4}(8)+\frac{1}{4}(3)-5,0\right]=0
\end{aligned}
$$

As this is less than the cost of information, on its own this piece of information will not be acquired. Now, suppose a piece of public information is provided at no cost to the developer. This piece of public information can 
tell for sure whether the value of the tract is $\{10,3\}$ or $\{8,4\}$. With this piece of public information, the developer's payoff is

$$
\frac{1}{2} \max \left[\frac{1}{2}(10)+\frac{1}{2}(3)-5,0\right]+\frac{1}{2} \max \left[\frac{1}{2}(8)+\frac{1}{2}(4)-5,0=1 \frac{1}{4}\right]
$$

If the developer further acquires the private information, he can tell for sure whether the value of the tract is $\{10\},\{8\},\{4\}$ or $\{3\}$. The developer's payoff under the concatenated information is $1 / 4 \max \{10-5,0\}+1 / 4 \max \{8-5,0\}$ $+1 / 4 \max \{4-5,0\}+\max \{3-5,0\}=2$.

Thus, the addition value of the private information, given that the public information is made available at no charge, is $3 / 4$. Thus, the private information will now be privately acquired. This is an example of one piece of information complementing another.

Corollary: If $b$ is the more valuable information, i.e., $v_{b}-V_{e}-K_{b}>$ $\mathrm{V}_{\mathrm{a}}-\mathrm{V}_{\mathrm{e}}-\mathrm{K}_{\mathrm{a}}$ and $\mathrm{a}$ is privately acquired whenever $\mathrm{b}$ is publicly provided, i.e., $\mathrm{V}_{\mathrm{a}, \mathrm{b}}-\mathrm{V}_{\mathrm{b}}>\mathrm{K}_{\mathrm{a}}$, then $\mathrm{b}$ is privately acquired whenever $a$ is publicly provided, i.e., $v_{a, b}-V_{a}>K_{b}$. The question that needs to be answered is under what circumstances will the complementary private acquisition of information lead a net positive surplus.

Proposition: If $a$ is privately acquired whenever $b$ is publicly provided, i.e. $v_{a, b}-v_{b} \geq K_{a}$, and if $b$ has positive value, i.e., $v_{b}-v_{e}>K_{b}$, then if $b$ is publicly provided the net surplus is positive, i.e., $\mathrm{V}_{\mathrm{a}, \mathrm{b}}-\mathrm{V}_{\mathrm{e}}-\mathrm{K}_{\mathrm{a}}-\mathrm{K}_{\mathrm{b}}>0$.

Proof Adding the first two inequalities will yield the third. 4.3.2 The Contracting Problem

Economic and technological features that are unique to geothermal energy cause some bilateral bargaining problems between the field developer and the utility that buys steam. First, minimization of heat loss during 
transportation of steam and of pipeline costs requires that the generating station be located centrally at the geothermal field. This makes it unlikely that a steam user can switch from one steam supplier to another. Also, steam suppliers find changing customers an equally difficult task. If power wheeling is required by law, once the distribution system is set up, the suppliers have more alternatives (though the users bear the costs and risks). Futhermore, the cost structure of geothermal development and power generation increases the mutual dependence of utilities and developers. The developer has large fixed costs and very small variable costs. If only one utility were prepared to purchase steam, and if the field were developed before the steam price is set, the developer could be forced to accept a price that paid only a small return on invested capital. Similarly, a power plant has large fixed costs and small variable costs. Consequently, a utility that builds a plant before contracting for steam could be forced to pay a price for steam that pays a small return on capital investment. Thus, theoretically, it would seem unlikely that, given the developer and the utility are different firms, any development would take place prior to their contracting.

Next, there are also some general uncertainties and disadvantages associated with geothermal energy. First, uncertainty regarding the depth and boundaries of reservoirs and about the location of fractures in the rock result in uncertainty about the cost and operating characteristics of every well over time and in the possibility that a new well may be dry. Second, the commodity is not just underground water, but is underground water under pressure. And this decreases as one drills new wells, even if one does not deplete the amount of water. The magnitude of this decline is uncertain until experience is gained by exploiting the field. Third, geothermal steam does not have as high pressure and temperature as the artificially heated steam 
that is used in conventional power plants. This causes lower thermodynamic efficiency than in normal power plants, thereby increasing the capital cost per kilowatt of energy. Lastly, contaminants in geothermal steam can cause damage to turbine blades.

All these uncertainties characteristic of electricity production through geothermal steam would seem to create significant contracting problems between the firm producing steam and the electric utility. Incentives would seem to exist for vertical integration to solve this problem.

The leasing and the contracting problems are related to each other in that the rules regarding leasing arrangements affect the bargaining position of the developer and the utility in reaching terms on the contract for steam. The expected contracting arrangements also determine how much one wishes to bid on a lease and how many prospectors will be interested in the lease. It is useful to analyze the contracting process as a two-person, cooperative game. The outcome of such a game is influenced by the initial position--the "status quo"--of the players, which determines their "threat points" or relative bargaining strength. Consider, for example, the developer who is considering development on federally owned land. As argued before, a developer wants to lease the land before any exploratory work is begun. But once the developer obtains a lease, the developer is in a disadvantageous bargaining position with the utility because the lease requires diligent development and because the developer would like to agree on a price for the steam before beginning to spend on development. Notice that the bargaining position of the developer is stronger for leases on state or privately owned lands since he gets the first shot at a bid. Then he could first explore, and if the tract turns out to be a promising geothermal source, he can make a reasonable bid and be sure to obtain the lease. Of course, after this stage, 
although most of the risk associated with uncertainty in the potency of the tract is shifted away from the developer, he would like to negotiate the contract before he fully develops the field.

To induce the developer to sign a contract, the utility must offer at least a price that recovers variable costs. If development need not begin until after the contract is negotiated, the contract must return total costs. Moreover, in the first case the developer runs the risk of a dry field, but in the latter case the contract can provide for sharing the risk. Note that the two cases put the developer in a different "status quo" position at the beginning of the bargaining between the developer and the utility. Differences in the "status quo" among the players in a game change their threat possibilities, and hence their bargaining strategies, and hence the outcome of the bargain. The following example illustrates how differences in the status quo or threat point affect the outcome of the contracting game.

Although it is true that the developer could well be a monopsonist and the utility an oligopolist (because in the end only one developer gets the lease on the land but more than one utility could want to buy steam from the developer), we assume that every negotiation is between the developer and one of the utilities only. Hence we look at a two-person game. Strictly competitive games are those games in which the players have strictly opposing preference. For example, player 1 could prefer $\mathrm{x}$ over $\mathrm{y}$. Then player 2 would prefer $y$ over $x$ and if 1 is indifferent between $x$ and $y, 2$ is indifferent too. Such players are called strict adversaries. In games like the one we are looking at, the players are not strict adversaries. Threat strategies are an assignment of probabilities to the possible threats each player can make. In other words, it is a mixed strategy over threats.

A bargaining problem is characterized by a region $\mathrm{R}$ of the Euclidean plane where the axes represent the utility levels of players 1 and 2 . Point 


\section{PLAYER 2's UTILITY}

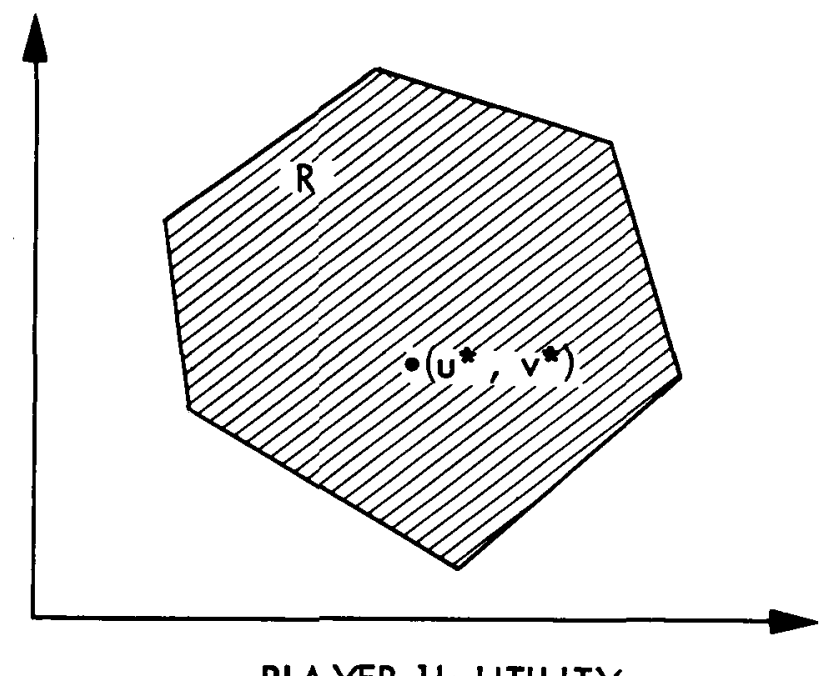

PLAYER I's UTILITY

Figure 4-1

Typical Bargaining Region

$\left(u^{*}, v^{*}\right)$ is the payoff to the players if no agreement occurs. An agreement takes place if and only if both players agree upon a unique point of $R$, which then constitutes the payoff. $R$ is the set of all feasible outcomes. It is assumed to be closed, convex and bounded. Naturally, 1 desires a trade represented by a point as far to the right as possible, and 2 wishes to obtain a point as high in $R$ as possible. An attempt at making agreements will be made as long as there are points both to the right and above $\left(u^{*}, v^{*}\right)$. The existence of such a point is assumed. Nash's "formula" to arrive at a solution is the following:

(1) Transform the coordinates so that $\left(u^{*}, v^{*}\right)$ is $(0,0)$. The new region of feasible outcomes is $R^{\prime}$.

(2) In $R^{\prime}$ find $\left(u_{0}, v_{0}\right)$ such that $u_{0} v_{0}$ is the maximum of all products $u$ v where $(u, v)$ is in $R$. 
The details of why this scheme and not any other was chosen to arrive at the solution will not be discussed here, for it digresses from the purpose of this report.

Now consider the following game. The payoff matrix is:

$$
\text { Player 2's possible action }
$$

$\begin{array}{lccc} & & \mathrm{B}_{1} & \mathrm{~B}_{2} \\ \text { Player l's } & \mathrm{A}_{1} & (1,4) & (-1,-4) \\ \text { possible } & \mathrm{A}_{2} & (-4,-1) & (4,1) \\ \text { actions } & & & \end{array}$

The bargaining region $\mathrm{R}$ is shown in Figure 2. (The region is convex because the players are allowed to use joint randomization strategies, such as deciding the payoffs to both players by a toss of a coin.) The security levels (the amount each can guarantee himself, when no threats are allowed) are $(0,0)$. The maximin strategies are $\left(4 / 5 \mathrm{~A}_{1} ; 1 / 5 \mathrm{~A}_{2}\right)$ and $\left(1 / 2 \mathrm{~B}_{1}\right.$, $\left.11 / 2 \mathrm{~B}_{2}\right)$. It is easy to see that the Nash solution is $(5 / 2,5 / 2)$, the midpoint of the line segment from $(1,4)$ to $(4,1)$.

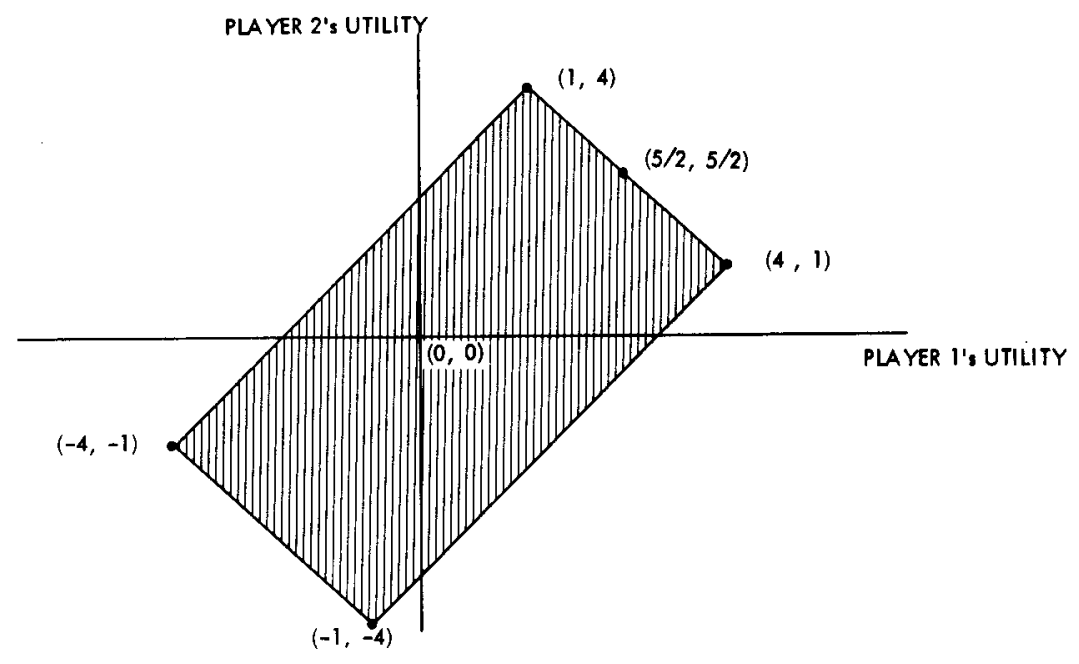

Figure 4-2

Bargaining Region for the Game 
However, from the payoff matrix, it is clear that player 2 has a slight disadvantage. For suppose 2 threatens to play $B_{1}$, then what alternatives has 1 ? If he plays $A_{1}$ then the payoff is $(1,4)$ - the best possible for 2. Therefore, l's realistic counter threat is $A_{2}$, leading to the payoff $(-4,-1)$. Hence, when there are threats, the "status quo" of the game is not $(0,0)$ but is $(-4,-1)$. With this as the "status quo", we transform the coordinates so that $(-4,-1)$ becomes $(0,0)$. The Nash solution now is seen to be $(1,4)$.

Thus, if threats are allowed, the outcome of the game is different from the case with no threats. Although, in our case, it is not the existence of threats that causes shifts in the status quo (it is the difference in the leasing arrangements).

The example given illustrates how such a shift in the status quo, whatever the cause, changes the outcome of the bargain. We could presume, in our case, threats will exist as long as either party views itself in a position capable of making a threat. Thus, leasing arrangements cause shifts in the allocation of risks between the developer and the utility. These, in turn, cause differences in the relative payoffs.

It has, therefore, been shown how mere differences in the leasing arrangements can cause changes in the status quo payoffs. This alone could change the outcome of the developer-utility contract. Over and above this, differences in the leasing types could place one of the parties at a relative bargaining advantage and hence in a position capable of making a threat. This too could change the outcome of the developer-utility contract. The question to be asked next is: How does the outcome of the developer-utility contract affect the insurance problem? 


\subsubsection{The Insurance Problem}

In geothermal development as elsewhere, insurance arises as a means for spreading risks. Geothermal contracts normally call for a penalty to be paid by the developer if the quantity of steam that is delivered to the power plant falls below some specified amount. The penalty, in essence, a preagreed liquidation damage for a breach of the development contract, is a means of reallocating the risk that the geothermal resource will prove to be less valuable than was otherwise expected.

If a geothermal development delivers less steam than was anticipated, the developer's investment in the system for delivering steam and the utility's investment in the power plant and transmission connection are reduced in value, perhaps even to scrap value if the geothermal resource diminishes to the point that it is no longer a viable steam source for a power generation facility. The penalty in the contract for insufficient performance causes the developer to bear part of the risk to the utility as well as the risk that the developer's investment will suffer a loss.

Typically, the magnitude of the penalty for insufficient performance is quite large. For example, the contract between Union Oil Company and Pacific Gas and Electric for steam at The Geysers geothermal development in northern California relieves PG\&E from the obligation to pay for steam if the steam delivered to the plant is not sufficient to operate the plant at fifty percent of rated capacity. If Union does not attempt to provide adequate steam to the facility, PG\&E may charge Union for the cost of drilling and equipping its own wells. And, for 12 months after a new unit is installed, Union agrees to pay the capital charges on any excess capacity that results 
from Union's failure to deliver the full capacity of steam for 30 consecutive days. 14

The effect of penalty features such as these is to transfer most of the risk that the geothermal resource will fail from the utility to the developer. Obviously, such contract provisions reveal that utilities are highly risk averse in their attitudes about geothermal. The reason is the status of the utilities as regulated, franchised monopoly suppliers of electricity. Only capital that is of value to rate payers, either as reserve capacity or as a regular source of power, is likely to be included in the calculation of the allowable costs that a utility can recover from the rate payers. Moreover, utility regulators are averse to risks of power shortages, and transmit this to utilities by encouraging high reliability and relatively large capacity reserves.

In the case of many power sources, the primary source of risk is in costs of power, not its availability. Utilities are less averse to cost risks because, with some lag (except for fuel cost adjustment mechanisms), regulators will enable the utility to pass through unanticipated costs to ratepayers (see Burness, Montgomery and Quirk). But in the case of geothermal developments, there is also uncertainty about the ultimate quantity of geothermal steam that can be supplied to the utility on a long term basis. Hence, there is a risk that part of the capacity that the utility builds to use geothermal steam will be unused because of inadequate steam supplies. The utility can be expected to pass on to the developer as much as possible of the risk that regulators will not permit utilities to recoup the investment in this excess capacity.

14 Union Oil was willing to bear most of the risk because the Geyers is an exceptionally good geothermal resource, namely clean dry steam. Development in hot water goethermal resources could definitely call for different risk-sharing schemes. Thus, the Union-PG\&E contract terms are exceptions rather than typical for hot water geothermal contracts. 
Once the developer has agreed to compensate the utility in case the geothermal resource proves to be inadequate, there is still another possibility for further spreading of the risk. The developer can seek to purchase insurance against the eventuality that the penalty clause of the geothermal delivery contract will be invoked. Here the insurance company accepts the risks of inadequate steam supply, in return for a premium from the developer. In the past, concern was expressed that geothermal development would be inhibited because insurers would be unwilling to insure against a failure of the resource. As it turns out, one insurance company (INA) has entered the business, selling insurance for up to 50 million dollars in damages arising from unexpectedly low steam production for the first 7 years of exploitation of the reservoir. A requirement of the insurance company is that insurance be purchased for some minimum period of time (the "minimum earned premium"). Thus, the pertinent policy issue today would appear to be whether the Federal Government should subsidize or directly provide insurance for more than 50 million dollars and for reservoirs that have been in use for more than 7 years. Because resource uncertainties are important over a long time period, policy on insurance must be activated before the contract becomes effective, otherwise risk cannot be appropriately allocated.

In order to understand and evaluate the role of the government in assuming some of this risk, some further development of how insurance works is necessary. (A brief discussion is presented here; for more details see Appendix C.) The basis for insurance is that a person buying insurance wishes to substitute a certain, well defined cost (the insurance premium) for exposure to an event that is unpredictable except in a statistical sense. Two elements enter into the calculation of an insurance premium that is acceptable to both sides. One is the expected value of the costs to which the insuring 
Jarty is exposed: in the simplest case of a single event, E, that occurs with probability, $p$, and that causes costs $C(E)$, the expected loss is $p C(E)$. The second element is the practically important variability of the cost, that is, the extent to which a wide range of potential outcomes is relatively likely before the fact. To illustrate this point, compare the following two games: (1) A coin is to be flipped once for 1 dollar, and (2) a coin is going to be flipped 100 times for 1 cent per flip. If the coin is "fair," that is, heads and tails are equally likely, the expected value of both games is zero (neither side in advance expects to win or lose). But the likely variation in outcome is much larger in the first case. In game (1), someone is certain to lose 1 dollar, and someone else is certain to make an equal gain. In the second game, the likelihood of losing or winning 1 dollar (e.g., of winning 100 hundred consecutive coin tosses) is extremely small; winning or losing more than 10 cents occurs only about $5 \%$ of the time.

The preceding discussion provides one explanation for the presence of insurance. If someone accepts a large number of independent risks, the range of their financial losses comes very close to the expected value, becoming more and more certain to be the expected loss as the number of independent risky events gets larger. Hence, an insurance company with numerous clients that charges premiums equal to the expected value will not only expect to break even, but will in fact become increasingly likely to break even as the number of its policy holders grows.

Of course, insurance companies seek profits, not break-even operations. Hence, they set premiums somewhat above the expected loss, just as gambling casinos set payoffs to gambling games that are somewhat worse than the amount that would be necessary for a fair bet. People are nevertheless willing to buy insurance because they are risk averse--that is, given the 
choice, they would prefer a certain payment equal to the expected value of a risk over actually bearing the risk, and this preference is strong enough that they would pay enough more than the expected value to make it worthwhile for an insurance company to bear the risk for them.

The preceding discussion provides a basis for analyzing why an insurance market may fail to develop. First, as a basis for setting premiums, the insurance company and the client must be able to estimate the expected 10ss. This means estimating the probability of costly events as well as knowing the costs that these events will impose. Second, the insurer must sell a large enough number of policies over independent risks so that the variability in expected outcome can be narrowed to a small range around the expected value.

Early in the development of any risky activity, like geothermal, neither of these conditions may be true. Prior to the development and operation of a reservoir through the life cycle of a power facility, the probability of maintaining steam of adequate pressure, temperature and quantity was not very well known, especially by insurers who possessed less knowledge about the technical aspects of the resource than did the developers and users. In addition, the contaminants in the steam during the lifetime of a development were also subject to uncertainty, affecting the probability that a geothermal development could operate at full capacity for a long period of time. Hence, it is not surprising to observe that insurers placed limits on both the duration and maximum exposure of insurance against a failure of a geothermal development.

Part of the uncertainty associated with geothermal development is lack of knowledge about the productivity of a reservoir over a long period of time, which in turn derives from lack of operating experience. Thus, the 
operating experience in the first few developments will alter expectations about failure rates at other developments. This means that the element of insurance that relates to narrowing the range of outcomes owing to the acceptance of a large number of risks is in part missing in the early stages of geothermal development. The problem is similar to that of selling earthquake insurance in a particular city. If the earthquake occurs, all policy holders are damaged. (Earthquakes do not occur independently for each insured building.) Hence, the annual variation in exposure to damages per policy holder cannot be narrowed by writing more policies in the same location. The preceding argument is the basis for some sort of federal intervention in the insurance market during the transition to a situation in which experience with geothermal developments is sufficient to sustain a more fully developed insurance market. The transition can be long, as the expected life of a development is measured in decades. Hence, to regard federal intervention as "temporary" is somewhat misleading though technically correct.

An element of the issue that opens possibilities for alternative policy interventions besides insurance subsidies is the risk-averseness of utilities with respect to the usability of power plants that are constructed to use geothermal steam. This risk averseness is a creature of public utility regulation; regulation prevents some of the risk of failure of a geothermal development from being carried by the utility. An alternative to subsidizing the developer's insurance against this risk is to permit the utility to bear it, such as by allowing the utility to recover part of the capital costs of the excess capacity that would result from a fall-off in geothermal steam production, especially the kinds of costs that insurers are reluctant to cover (e.g., more than $\$ 50$ million, after 7 years). To some degree, the risk-averse character of utilities is a creature of public policy, so that an alternative 
to subsidizing the costs that this risk averseness creates for developers and insurers.

A final issue is the choice of governmental intervention into the insurance market, assuming that some federal role is decided upon. Here, three possibilities are possible:

(1) Subsidization of private insurance.

(2) Direct federal provision of insurance, either as regular insurance for developers or coinsurance for insurance companies.

(3) Disaster relief to geothermal resources that prove to be less valuable than contemplated before development.

The first and third alternatives are inefficient because they will induce some geothermal development that is really too $\mathrm{risky}$ to be worthwhile. The crucial point is to distinguish between solving a market imperfection in the insurance business that arises because of an inadequate basis for developing adequate premiums, and subsidizing the development of geothermal energy. Whereas society might well elect to subsidize geothermal development because, for example, it is not vulnerable to foreign interruptions and is underpriced relative to its social value, the most effective means for providing such a subsidy is to pay part of the costs of geothermal development, either directly or through tax incentives. The first alternative, subsidizing insurance, opens up a differential between the premiums paid by the developer and the receipts of the insurance company. Assuming that the insurance is written in a competitive environment, this means that insurers are receiving a premium that appropriately matches their exposure; therefore, the purchaser of the insurance is paying less than the economic value of the risk inhering in the development. Thus, insurance subsidies of this form will encourage development on tracts that are too risky to warrant development, at least at the present time. 
The third alternative, compensation for a shortfall of geothermal output when it occurs without a formal insurance arrangement, is similar to disaster relief. In a sense, it is an extreme form of insurance subsidy--here, the subsidy is equal to a continuing premium that would represent a competitive insurance market outcome. And like insurance subsidies, it represents an inefficient solution to the problem of an inadequately developed insurance market because it encourages excessively risky developments.

The second alternative is preferred because it represents an attempt by government to correct for a market failure. If the government sells insurance (or coinsurance) at a best estimate of the fair premium price, it is substituting for private insurance in the most effective manner. Moreover, if the premiums are calculated as accurately as possible to reflect actual risks, over time the premiums will converge to the charges that would be levied by the private market, and indeed private insurers can be expected gradually to replace federal underwriting. Direct federal insurance, in particular, has the most attractive features, because if geothermal risks are eventually fully insurable, private insurers will have an incentive to develop sufficient information to get the government out of the business. This may not be true for coinsurance, for insurers may always find it worthwhile to lay off some risks to federal insurers even if the direct insurance market becomes fully developed. However, this distinction relates more to the political aspects of the issue than the economic aspects; as a purely economc matter, either form of option (2) can be efficient. 
4.4 SUMMARY

Briefly, this report provides answers to the following questions:

Q: What characteristics make geothermal resources different from other energy sources?

A : Confusion about the status of geothermal property rights and regulatory requirements.

- Is geothermal a mineral or water

- If mineral, then federal government owns geothermal resources in federally owned lands.

- If water, who owns geothermal resources?

- Preliminary court decisions indicate that ownership is federal.

- Environmental standards are far stricter than for other energy sources when they were in their development stage. - Steam is not transportable, so that on-site use is required.

Q: What are the different leasing arrangements for leasing land for geothermal development?

A: There are three kinds of land:

(1) Federally owned Known Geothermal Resource Areas;

(2) Federally owned "unknown" land;

(3) Lands owned by states or private parties.

- For (1), lease is made through a competitive bidding process.

- For (2), the first qualified applicant gets the lease if the bid is reasonable.

- For (3), prospector gets to bid first and only if his bid is unreasonable and the tract opened for competitive bidding. 
Q: What are the significant differences in the nature of the leasing contract among the types of lands?

A: Federal leases are for 10 years and are extended further if commercial production of steam occurs. For state and private, extension is granted as long as the developer keeps looking for a new well with "due diligence".

Q: What is the position of the developer at the time he makes a contract with the utility?

A: On federal KGRA lands, the developer has already sunk some fixed costs into developing the field and so is at a bargaining disadvantage; for other lands the developer will begin exploring after price of steam is agreed upon, in which case the developer bears a large portion of the risk. The leasing status of the land is important because the leasing arrangement can affect the bargaining position of the two parties, and hence the outcome of any contract between them.

Q: Who should provide the insurance? Should the government subsidize private insurers?

A: Public provision of this insurance could be socially better than private provision depending on the cause of an unwillingness to provide insurance by the private sector.

Three major sources of revenues from the leasing of federal lands are identified: rentals, royalty and bonus bid. It is found that the escalated rental charges do not allow for enough lead time for the lessee. Royalty rate is identified as a form of risk sharing between lessee and the federal government. Royalty could lessen the upfront cost of a bonus bid and thus encourages more competition in a lease sale. The unwarranted effect in the 
presence of energy supply constraint is that a higher royalty rate will shift the pattern of resource extraction to the future. Readjustment clauses on rentals and royalties are found not to be an impediment to geothermal development given the lead time before readjustment can be authorized. Bonus bidding on its own is essentially a redistribution of economic rent from lessee to the lease owner. When risk is taken into account, bonus bidding shifts most of the risk to the lessees. Empirically it is confirmed that lessees prefer noncompetitive leasing than competitive leasing both on the number of leases issued and on the acreage leased under the two forms of leasing. Of course the redistribution of economic rent is also a major reason explaining this phenomenon.

Throughout the study, it is argued that information has a definite role in fostering the development of geothermal resources. In a pre-leasing context, if the reservation bid is set at the lowest possible value, and if a bidder decides to acquire information given the other does not, it pays the first bidder to inform the other bidder that he has adopted the strategy: a common property of the battle of the sexes game. The Nash equilibria are asymmetrical and not interchangeable. Moreover, these Nash equilibria imply high-low bids, thus causing extreme difficulties for the seller to identify any collusive agreement. The result also reconciles the high-low bid phenomenon observed in actual lease sales. Furthermore, it is possible that it pays the seller to provide public information. This last conclusion is not supported by allowing for an active seller. With an active seller in a pre-leasing context, if a reservation bid is appropriately set, the seller has no incentive to encourage bidders to gather information, nor to provide public information.

In a post-leasing context, the problem of informational externality is quickly disposed. A careful dichotomy of two measures of the benefit of 
information is provided. Conditions for the two measures to be identical are also provided. Cases of informational substitutability and complementarity are identified. Conditions for informational substitutability are provided. Conditions for not providing public information are also deduced. For the case of informational complementarity it is shown that the net surplus can never be negative for the provision of public information. Clearly, the system as it stands today would make developers on federally owned lands either look for resources where it is least likely to be found or, bear a large portion of the risk by leasing the land first and then exploring at the risk of the tract turning out to be dry. The effects of uncertainties in nature on the ex ante probability of nonfulfillment of the developer utility contract are less in state-owned lands as compared to federally-owned lands. This is because the developer can lose a federal lease if commercial production of steam does not occur, while the lease on state or private owned lands is not lost as long as diligent development continues. Both of the above differences cause a difference in the bargaining positions of the developer and the utility. In general, utilities are in a stronger relative bargaining position on federal lands. This exacubates the insurance problem because utilities are especially averse to production risks. Insurance is really not a very big problem. Once the return on investment by private as well as public investors is known and the risk premium associated with private investment, the investor with a larger net return should provide the insurance. If this turns out to be the private investor, then providing a government subsidy could result in a less efficient allocation of resources. The risk premium is determined by the structure of the developer-utility contract. 
Thus we have seen how the leasing arrangements could affect the outcome of the contract which in turn could affect the decision as to who provides the insurance.

The analysis would support the following conclusions:

First, the definition of KGRA should be changed to eliminate this source of risk to the developer because of the uncertainty concerning obtaining the lease. This could be achieved, for example, by ruling that an "unknown" tract of land cannot be classified as a KGRA for some minimum grace period after a prospector finds a geothermal resource in it, after obtaining a prospecting permit.

Second, the most efficient contract mechanism if the developer is not a vertically integrated utility is one in which the developer is required to supply minimum amount of steam to the utility. Amounts in excess of the minimum quantity, if produced, must be purchased by the utility. As argued in the text, such arrangements make the bargaining positions more nearly equal, and hence do not create market structure barriers to development.

Third, utilities that produce electric power using geothermal steam, should be encouraged to be less risk averse than they are under present laws. For example, "unavoidable" supply shortages by the utility should be pardonable. This way, a more socially optimal allocation of risk could be achieved.

Fourth, a decision about who should provide insurance should be made with due regard to the argument in this report.

Lastly, should it be decided that the insurance be provided by private insuring agencies, it is better to use direct federal insurance or coinsurance than to subsidize private insurance purchases. 
Arrow, K. J., "Vertical Integration and Communication." Bell Journal of Economics, Vol. 6, No. 1, Spring 1975, pp. 173-83.

Burness, H. S., Montgomery, W. D., and Quirk, J. P., "Capital Contracting and the Regulated Firm," American Economic Review, June 1980.

Comments of the Council on Wage \& Price Stability. OCS Net Profit Share Leasing. Docket \#LPD 79-06.

Montgomery, David W., The Structure of the Geothermal Industry Through 1974, EQL Report 非1, July 1975, California Institute of Technology.

, Risk Sharing and Incentives in Geothermal Development, EQL Open File Report 非7-13, Aug. 1977. California Institute of Technology.

, Bates M. R., and Krier, J. E., Legal and Institutional Factors Geothermal Research Study in the Salton Sea Region of California. EQL, June 1975, California Institute of Technology.

Moore, Russel and Mills, Thomas, An Environmental Guide to Western Surface Mining. Part one: Federal Leaseable and Locatable Mineral Regulations. June 1977, Report \#FW5/OBS-77/20 to the Office of Biological Services.

Nimmons, J. T., "Selected Legal Aspects of Geothermal Development." Presented at the Geothermal Resources Council Special Short Course 非, San Francisco, April 1980.

Public Law, 94-579 - October 21, 1976. 
APPENDICES 


\section{APPENDIX A}

USERS GUIDE TO THE GEOTHERMAL PROBABILISTIC COST MODEL

This guide is separated into two parts: definitions of program subroutines and program variables; and a description of the inputs and instructions for inputting them.

A. 1 SUBP ROGRAM DEFINITIONS

\section{Main Program}

Used as the calling program for the subroutine.

$\underline{\text { INPUT }}$

Reads all input data and makes some preliminary calculations.

\section{$\underline{\text { SELECT }}$}

Used only if the number of scenarios to be evaluated is less than the total number input. Uses the probability of occurrence of a scenario in the process of selecting what should be evaluated.

\section{RANNUM}

Random number generator called by SELECT.

\section{RADJST}

Escalates Reference cost accounts to the year in which they occur. 


\section{GSCALE}

Scales the cost data according to time differences between scenario values and reference values. Calls FCTMOD to scale according to differences in physical parameters.

$\underline{\mathrm{RCOST}}$

Uses scaled cost data to calculate the output cost variables.

GOPT

Generates an escalation factor in evaluating levelized energy costs.

\section{PICDPF}

Calculates the depreciation factor depending on whether the depreciation method is straight line or sum of years digits.

OUT1

Prints, or calls the programs which print, the output values, tables, and histograms. OUT 1 is used only if the number of selected scenarios is less than the number of scenarios input.

Prints, or calls the programs which print, the output values, tables, and histograms. OUT2 is used only if all input scenarios are used in the calculations.

ASCEND

Arranges the output variables in ascending order. 
Prints a table consisting of the scenario numbers, the scenario probability of occurrence, and the scenario output value in ascending order.

\section{EXPEC 1}

Calculates the expected value and the standard deviation of the output if the number of scenarios selected for evaluation is less than the total number input. Called by OUT 1.

\section{$\underline{\text { EXPEC2 }}$}

Calculates the expected value and the standard deviation of the output if all scenarios are evaluated. Called by OUT2.

\section{$\underline{\text { HIST }}$}

Prints out the probability density function. Called by either HISTOG or PDF .

$\underline{\text { PDF }}$

Does some of the calculations required to print the probability density function if all scenarios are evaluated. Called by OUT1, calls HIST.

\section{$\underline{\text { HISTOG }}$}

Does some of the calculations necessary to print the probability density function if not all scenarios input are selected for evaluation. Called by OUT2, calls HIST. 


\section{FCTMOD}

Function subroutine that determines the modification to cost data required by physical parameter differences between the reference scenario and a given scenario.

OPT 1

Function subroutine to scale cost data according to differences in the scenario and reference temperatures.

$\underline{\text { OPT2 }}$

Function subroutine to scale cost data according to differences in the scenario and reference flow rate.

OPT3

Function subroutine to scale cost data according to differences in the scenario and reference well depth.

\section{A.2 VARIABLE DEFINITIONS}

Due to the intricacies of the program and the order in which certain numbers occur, a particular number may have to be referred to by more than one variable name. For example, the duration of a stage in the Reference Scenario is referred to as $\operatorname{TPR}(J X)$, where $J X$ is the number of the stage. For scenarios (other than the Reference Scenario) the duration of a stage is referred to as $\operatorname{TP}(J X, M M)$, where $J X$ is again the nunber of the stage, and $M M$ is the number of the particular scenario. $T P(J X, M M)$ is then redefined as $T R(J X)$ in GSCALE so it can be used in the CALL RCOST statement. 
This happens in a similar fashion with other variables. Generally, a

variable occurring in the Reference Scenario will have an "R" at the end (e.g. TPR, CDR, CIR, PSUMR, etc.); when it occurs in scenarios other than the Reference Scenario, the "R" will be dropped (e.g. TP, CD, CI, PSUM, etc.).

\begin{tabular}{|c|c|c|c|}
\hline $\begin{array}{c}\text { Variable } \\
\text { Name } \\
\end{array}$ & $\begin{array}{r}\text { Common } \\
\text { Block } \\
\end{array}$ & $\begin{array}{l}\text { Program } \\
\text { Usage }\end{array}$ & Definition \\
\hline A & & HISTOG & $\begin{array}{l}\text { ( } 300) \text { In HISTOG list, equivalent to } \\
\text { output variable in CALL statement. }\end{array}$ \\
\hline$A D$ & DATA2 & $\begin{array}{l}\text { MAIN, INPUT } \\
\text { GSCALE }\end{array}$ & $\begin{array}{l}(10,5,10) \text { Read in, } \mathrm{AD}(\mathrm{IX}, \mathrm{NX}, \mathrm{KDX}) \text { Cost } \\
\text { escalation factors for stage, accounting } \\
\text { type, time dependent cost account. }\end{array}$ \\
\hline ADMOD & & GSCALE & $\begin{array}{l}\text { ADMOD }=(A D(J X, N X, K D X) * * P W R) \\
\text { * (TP (JX,MM)/TPR }(J X)) \text {. Ratio of the } \\
\text { length of a stage in a scenario to the } \\
\text { length of the reference stage, adjusted } \\
\text { by the cost escalation factor, raised to } \\
\text { the cumulative difference between the } \\
\text { length of prior scenario stages and the } \\
\text { length of the corresponding reference } \\
\text { stages. }\end{array}$ \\
\hline
\end{tabular}

AI DATA2 MAIN, INPUT - $(10,5,10)$ Read in, AI (IX, NX, KIX) Cost GSCALE escalation factors for stage, accounting type, time independent cost account.

AIMOD

GSCALE

AIMOD $=A I(J X, N X, K I X) * *$ PWR. Cost escalation factors for time independent costs, raised to the power of the difference between elapsed time of prior scenario stages and the corresponding reference stages.

B1

INPUT

Read in, State tax rate

B2

IN PUT

Read in, Local tax rate

B3

INPUT

Read in, Investment tax credit 
MAIN, INPUT

$\mathrm{B} 12=\mathrm{B} 1+\mathrm{B} 2$

SELECT, GSCALE

RCOST, OUTI

OUT2, FCTMOD

C

EXPEC1, EXPEC2

CAP

DATA8

MAIN, RCOST

GSCALE, OUT1 OUT2

CAPR

RCOST

DATA8

MAIN, RCOST

GSCALE, OUTI

OUT2

$C D$

GSCALE, RCOST

CDOPT

GSCALE

DATA2 INPUT, MAIN

GSCALE, RCOST

In EXPEC1, EXPEC2 lists equivalent to the output variable in the CALL statement.

(300) Upfront capital investment.

In CALL GSCALE, ASCEND, HISTOG, PDF, EXPECT1, EXPEC2 CAP(NN) = TCAP

In RCOST list, equivalent to TCAP.

$\mathrm{CAP}=0$ if $\mathrm{Jl} 1$

$\mathrm{CAP}=\mathrm{CAP}+\mathrm{CAPR}(\mathrm{NX})$

$\mathrm{CAP}=\mathrm{CAP}+\mathrm{COSTO}$

(5) $\operatorname{CAPR}(N X)=C D+C I$. For each accounting type within a stage, the sum of the time dependent and independent costs.

(300) Life cycle costs. In CALL GSCALE, ASCEND, HISTOG, PDF, EXPEC1, EXPEC2

$\operatorname{CCL}(\mathrm{NN})=$ TCCL. In RCOST list, equivalent to TCCL.

$\mathrm{CCL}=\mathrm{E} 1 * \mathrm{CDUM}$ if $\mathrm{KOPT}=0$.

If $\mathrm{KOPT}=0, \mathrm{CCL}=\mathrm{EI} * \mathrm{CDUM}^{*} \mathrm{ESCAL}+$ $(1 .-\mathrm{ESCAL}) * \mathrm{REV}$

$(10,30,5,10)$ CD $=$ FCTMOD (CDOPT, JX, KDS, NX, MM, I). Time dependent costs, adjusted for time variations, are adjusted by FCTMOD for physical uncertainties. Then, in CALL RCOST. $C D=C D+C D T$ if $J X=1$, otherwise, $C D=$ $C D+C D T^{*} D^{* * E X P O}$

$\mathrm{CDOPT}=\mathrm{CDR}(\mathrm{JX}, \mathrm{MX}, \mathrm{NX}, \mathrm{KDS}) * \mathrm{ADMOD}$. Time dependent costs, adjusted for time differences between specific scenario and reference scenario

$(10,30,5,10)$ Read in, CDR (JX,MX, NX, KDX) Time dependent costs indexed for stage, time interval, accounting type and time dependent cost account. In RCOST list, equivalent to $C D$. 
CDT

CDTT

CDUM

CEL

DATA8

CI

CIOPT

CIR

CMAX

CM IN

DATA2
$\mathrm{RCOST}$

RCOST

RCOST

MAIN, RCOST

GSCALE, OUT1

OUT2, ASCEND

TABLE, HISTOG

EXPEC1, EXPEC2

GSCALE

RCOST

GSCALE

INPUT, MAIN

GSCALE, RCOST

OUT1, OUT2

OUT1, OUT2
$\mathrm{CDT}=\mathrm{CDT}+\mathrm{CDTT}^{*} \mathrm{D} * \mathrm{EXPO}$

$\mathrm{CDTT}=\mathrm{CDTT}+\mathrm{CDR}(\mathrm{JX}, \mathrm{MX}, \mathrm{NX}, \mathrm{KDX})$.

Sum over KDX of time dependent costs

CDUM $=\mathrm{CR}(1)+$ COSTO. Used internally. Initialize COST, then sum COST

(300) Levelized energy cost. In CALL GSCALE CEL (NN) = TCEL.

In RCOST list, equivalent to TCEL. $\mathrm{CEL}=(1000 * \mathrm{CCL}) /(\mathrm{GG} * \mathrm{E})$.

In CALL TABLE, ASCEND, HISTOG, PDF, EXPECl, EXPEC2. In ASCEND list represents all output variables. Ordered in ASCEND.

The difference between the expected value and a scenario value of the output variables.

$(10,5,10)$ Time independent costs adjusted for variations of time and physical uncertainty between the reference and scenario value.

CIOPT $=$ CIR ( JX, NX, KIX $) * A I M O D$

Time independent cost adjusted for cost escalation factors

$(10,5,10)$ Read in, CIR (JX, NX, KIX) time independent costs, indexed for stage, accounting type, and time independent cost account. In RCOST list, equivalent to $\mathrm{CI}$.

Calculated in ASCEND as maximum value of appropriate output variable. Used in printing, plotting output in $\mathrm{PDF}$. In CALL ASCEND, HISTOG.

Calculated in ASCEND as minimum value of appropriate output variable. Used in printing, plotting output in PDF. In CALL ASCEND, HISTOG. 


\begin{tabular}{|c|c|c|c|}
\hline CON & DATA5 & $\begin{array}{l}\text { INPUT, MAIN } \\
\text { GSCALE, RCOST } \\
\text { FCTMOD, OPT1 } \\
\text { OPT2, OPT3, } \\
\text { OPT } 4\end{array}$ & (6) Read in, Scaling parameters \\
\hline $\operatorname{cosT}$ & & $\mathrm{RCOST}$ & $\begin{array}{l}\mathrm{COST}=((\mathrm{OMB} 3-\mathrm{TAU} * \mathrm{DPF}) * O M T A U I * C R F+B 12) \\
* \mathrm{CR}(\mathrm{NX}) / \mathrm{CRF} \text {. Life cycle cost, per } \\
\text { accounting type, to be summed. (Ref. } 1 \text {, } \\
\text { p. B-7). }\end{array}$ \\
\hline COSTO & & $\mathrm{RCOST}$ & $\begin{array}{l}\text { COSTO }=0 \text { if DELAY }=0 \text {. Otherwise, } \\
\text { COSTO }=\text { PPRICE* } E^{*}\left(G C^{*} \text { PSUMR }(J)\right) *\left(1 .-G D^{*}\right. \\
(D E L A Y+1 .)) /((1 .-G D) * 1000000 .) \\
\text { Penalty cost for delay of delivery of } \\
\text { fuel. }\end{array}$ \\
\hline COSTR & DATA7 & $\begin{array}{l}\text { MAIN, OUT1 } \\
\text { OUT2 }\end{array}$ & $\begin{array}{l}\text { COSTR }=\text { RCCL. Reference life cycle, or } \\
\text { true cost. }\end{array}$ \\
\hline COSTT & DATA8 & $\begin{array}{l}\text { MAIN, OUT1 } \\
\text { OUT2 }\end{array}$ & $\begin{array}{l}\text { (300) True cost COSTT }(N X)= \\
\text { PROFIR-PROFIT }(N X)+\operatorname{CCL}(N X) \text {. Reference } \\
\text { profit minus scenario profit plus life } \\
\text { cycle cost. In CALL ASCEND, HISTOG, } \\
\text { PDF, EXPECI, EXPEC2. }\end{array}$ \\
\hline CPROB & & SELECT & $\begin{array}{l}\text { Used in subroutine as cumulative } \\
\text { probability. }\end{array}$ \\
\hline CR & & RCOST & $\begin{array}{l}\text { (5) } \mathrm{CR}(\mathrm{NX})=\mathrm{CAPR}(\mathrm{NX})+\mathrm{CDT}+\mathrm{CI} \\
\text { Total cost. }\end{array}$ \\
\hline CRF & & RCOST & $\begin{array}{l}\mathrm{CRF}=\mathrm{DMI} /(1 \cdot-\mathrm{D} *(-\mathrm{TSTAGE})) \\
\text { Capital Recovery Factor (Ref. } 1 \text {, } \\
\text { p. III-9). }\end{array}$ \\
\hline CSPSR & & IN PUT & Read in, Common and Preferred stock ratio \\
\hline CTEMP & & ASCEND & Used in ordering the output variables. \\
\hline D & DATAI & $\begin{array}{l}\text { INPUT, MAIN } \\
\text { SELECT, GSCALE } \\
\text { RCOST, GOPT } \\
\text { PICDPF, OUT1 } \\
\text { OUT2, FCTMOD }\end{array}$ & 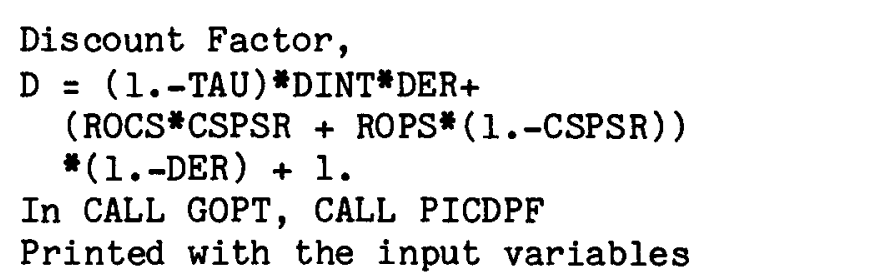 \\
\hline
\end{tabular}


DELAY

GSCALE, RCOST MAIN

DER

DINT

DMI

DPF

DPL

E

DATAI

MAIN, INPUT

SELECT, GSCALE

RCOST, OUT 1

OUT2, FCTMOD

E1

DATAI

MAIN, INPUT

SELECT, GSCALE

RCOST , OUT 1

OUT2, FCTMOD

ESCAL

RCOST
In CALL RCOST. In GSCALE,

DELAY $=\operatorname{PSUM}(J, M M)-\operatorname{PSUM}(J C O N, M M)-$

$\operatorname{PSUMR}(J)+\operatorname{PSUMR}(J C O N)$. At scenario MM, the elapsed time difference between the total scenario time at stage $\mathrm{J}$ and the total scenario time at contract effectiveness, minus the same difference for the reference scenario. In MAIN, DELAY $=0$. Used to calculate the penalty cost.

Read in, Debt Equity Ratio

Read in, Interest rate on debt

DMI $=$ D-1, In CALL PICDPF

In CALL PICDPDF, Calculated in PICDPF. If IOPT $=1, \mathrm{DPF}=\left(1,-\mathrm{D}^{* *}(-\mathrm{TNI}) /\right.$ (DMI*TNI), straight line depreciation factor. If IOPT $=2, \mathrm{DPF}=$ 2.*(TNI-(1.-D**(-TNI))/DMI)/(TNI*(1.+TNI)* DM1), sum of years digit depreciation factor.

Read in, Depletion Allowance

Read in, Annualized Energy Output

$E I=(1 .-T A U) /(1 .-T A U *(1 .-D P L)-R O Y)$

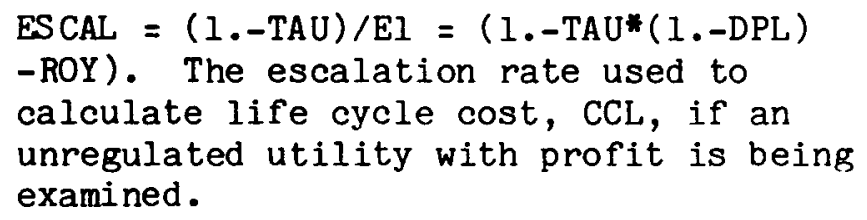


ESMOD

ESMOI

EXPECT

EXPO

FCTMOD

FMAX

FREQ

FREQM

G

DATA 1 MAIN, INPUT

GD

DATA9 INPUT, MAIN

GG SELECT, GSCALE RCOST, GOPT OUT1, OUT2 FCTMOD GSCALE, RCOST

OUT1, OUT2

EXPECl, EXPEC2

RCOST

PDE, HISTOG HIST

PDF

RCOST, GOPT
ESMOD $=A D(J X, N X, K D X) * P W R$, where $P W R$ is the time until the occurrence of account KDX.

ESMOI $=A I(J X, N X, K I X) *$ *PW, where $P W R$ is the time until the occurrence of account KIX.

Expected value of the relevant output variable. In CALL EXPECl, EXPEC2.

Used as an intermediate definition to calculate capital costs. EXPO represents the time exponential.

Function variable. Cost variable modified by stage and physical uncertainty if required.

Maximum frequency.

(20) Calculates the frequency of each interval for each output. In CALL HIST. Used in plotting output.

Used to determine scaling factor for frequency for plotting purposes.

Read in, Energy cost escalation factor. In CALL GOPT

$G D=G / D$

In CALL GOPT. If $G=D$ (energy cost escalation = discount factor), $G G=T$, time. Otherwise, $G G=$ $(G /(D-G)) *(1 .-(G / D) * * T)$. 
INPUT, PDF

Used as an index

ASCEND, HISTOG

HIST, FCTMOD

RANNUM

I1

ASCEND, RANNUM

$I I=I+1$. Used internally.

II

FCTMOD

DEVICE AII

PDF, HIST

HISTOG

PDF

INTVAL HISCOM HISTOG

IOPT

DATA I

MAIN, INPUT SELECT, GSCALE RCOST, PICDPF OUT1, OUT2

FCTMOD

IOUT

DEV ICE

All

ASCEND

ITEMP

IX

MA IN, INPUT

SELECT

HIST

FCTMOD

In FCTMOD list, identifies whether a cost variable is time dependent or independent. If II $=1$, it is time dependent. If II $=2$, it is time independent.

Input device $=5$

IN $=$ NINT +2 in CALL HIST.

Used to calculate frequency interval for plotting histogram.

$I N N=N I N T+1$

(20) Used in calculating frequency interval for plotting histogram.

Read in, IOPT $=1$ Straight line depreciation IOPT $=2$ Sum of years digit depreciation

In CALL PICDPF

Output device $=6$

Used to order the scenario numbers from smallest output value to largest.

Used as index

Used to print output frequencies.

$I X=\mathrm{J}+1$, the operating lifetime stage plus 1 . 
IXX

J

Jl

J CON

JFCT

JJ

JOUT

JP

DATAI

JX

JXI

DATAl

DATA9

DATA 1
F CTMOD

MA IN, INPUT

SELECT, GSCALE

RCOST, OUT 1

OUT2, FCTMOD

RANNUM

HIST, ASCEND

GSCALE, RCOST

INPUT, MAIN

GSCALE, RCOST

FCTMOD

MAIN, INPUT SELECT, GSCALE RCOST, OUTI OUT2, FCTMOD

HIST

MA IN, INPUT SELECT, GSCALE RCOST, OUTI OUT2, FCTMOD

HIST

INPUT, GSCALE FCTMOD, RCOST

TABLE

GSCALE
$I X X=I-J$. Counts the physical variables.

Read in, Number of stages. J-stage is the operating lifetime stage.

Used as index.

$\mathrm{J} 1=\mathrm{J}-1$. Stage before the operating stage.

Read in, Stage at which contract is effective

Identifies by MOD, MOI if cost variable must be scaled by physical uncertain variable.

$\mathrm{JJ}=\mathrm{J}+\mathrm{JP}$. Total of the number of stages and number of uncertain probabilities.

(20) Used to print output character in histogram in HIST.

Read in, Number of uncertain physical variables

Scaling factor to print histogram.

Used to index stages

Used as an index.

$J X 1=J X+1$ 
PDF, OUT1, OUT2 Used as index.

EXPEC1, EXPEC2

$\begin{array}{ll}\text { HIST } & \text { Data variable containing } \\ \text { HISTOG } & \text { Used to assign GOTO statement. }\end{array}$

$\mathrm{KD}$

DATA2 MAIN, INPUT GSCALE, RCOST

$(10,5)$ Read in, Number of time dependent cost accounts of different accounting lifetimes but in the same stage. In CALL RCOST.

KDLIM

INPUT, RCOST

Used internally. KDLIM $=\mathrm{KD}(\mathrm{JX}, \mathrm{NX})$. GSCALE Defines the number of time dependent cost accounts for each stage and accounting type.

$\mathrm{KDX}$

INPUT, RCOST GSCALE

Used to index time dependent cost accounts.

KI

DATA2

MAIN, INPUT GSCALE, RCOST

$(10,5)$ Read in, Number of time independent cost accounts of different accounting lifetimes but in the same stage. In CALL RCOST.

KILIM

INPUT, RCOST GSCALE

Used internally, KILIM - KI(JX,NX). Defines the number of time independent cost accounts for each stage and accounting type.

KIX

INPUT, RCOST GSCALE

Used to index time independent cost accounts.

$\mathrm{KK}$

TABLE

Used internally to print out ordered scenario numbers.

PDF

Used internally

KOPT DATAL INPUT, MAIN GSCALE, SELECT RCOST, OUTI OUT2, FCTMOD

Read in. If KOPT $=0$, life cycle costs are equal to revenue ( $C C L=R E V)$, to be used in the case of a utility regulated to no profit. Otherwise, KOPT $=0$, then $\mathrm{CCL}=\mathrm{REV}$.

Equivalent in FCTMOD list of KDX, KIX. 
L

M

DATA3

INPUT, MAIN

GSCALE, RCOST

FCTMOD

PDF

HI ST

INPUT, RCOST

GSCALE

MM

MOD

DATA6

MOI

DATA6

MX

$\mathrm{N}$

MTEMP
INPUT, MAIN

GSCALE, FCTMOD

PDF

GSCALE

INPUT, MAIN

GSCALE, FCTMOD

INPUT, GSCALE

MA IN, INPUT

GSCALE, SELECT

RCOST, OUT 1

OUT2, FCTMOD

HISTOG

HISTOG
Used briefly as dummy to plot probability density function.

(10) Read in, Number of time intervals, defined for each stage. In CALL RCOST

Used briefly as dummy to plot probability density function.

Used in plotting histogram.

Used internally, MLIM $=M(J X)$ Number of time intervals at stage $J X$

$M M=N S C(N N)$ where NN goes from 1 to NSELEC.

$(10,5,10,10)$ Read in. Identifies which time dependent cost variables also are dependent on physical uncertain variables.

$(10,5,10,10)$ Read in. Identifies which time independent cost variables are dependent on physical uncertain variables.

Used to temporarily store one element at a time of array NORDER.

Used to index time intervals.

Read in, Number of Different Accounting Life Times

In HISTOG list equivalent to NSELEC

$\mathrm{NI}=\mathrm{NINT}+2$ 
NINT

NN

MAIN, FCTMOD

GSCALE

NORDER

NO TH

NPOINT

NSI

NSC

DATA4

MAIN, SELECT GSCALE, OUTI OUT2

NSCEN

DATAI

MAIN, INPUT GSCALE, SELECT RCOST, OUT2 TABLE, ASCEND FCTMOD

NSCEN1

NSELE 1

OUT1

NSELEC DATAI MAIN, INPUT GSCALE, SELECT RCOST, OUTI FCTMOD
In CALL INPUT, Read in. In CALL OUTl, OUT2, HISTOG, PDF, HIST. The number of equal intervals into which the output is to be divided to plot the histogram. Note: the histogram has NINT +2 vectors.

$\mathrm{NN}=\mathrm{NSC}(\mathrm{NX})$. In FCTMOD list equivalent to $M=N S C(N N)$.

Used as an index.

(300) Used to rank order the scenarios according to appropriate output, i.e., life cycle cost, levelized energy cost, upfront capital investment, profit, true cost, etc. In CALL ASCEND, CALL TABLE.

Data variable containing black space.

Used in PDF as equivalent to NSCEN, the number of scenarios.

NSI = NSELEC -1

(300) (NSELEC) In CALL SELECT

statement

Index the number of "Selected" scenarios

Read in, Number of scenarios.

In CALL ASCEND, TABLE, PDF, EXPEC2

NSCEN1 = NSCEN - 1. In CALL ASCEND.

NSELE1 = NSELEC-1, In CALL ASCEND, equivalent to NSCENI

Read in, Number of scenarios to be selected. In CALL ASCEND, HISTOG, EXPECl. 
RANNUM

OMB3

$$
\text { DATAl }
$$

MAIN, INPUT SELECT, GSCALE RCOST, OUTl OUT2, FCTMOD

OMTAU

DATA 1

MAIN, INPUT SELECT, GSCALE RCOST, OUT 1 OUT2, FCTMOD

OMTAUI DATAI

MAIN, INPUT SELECT, GSCALE RCOST, OUT 1 OUT2, FCTMOD

OPT 1

OPT2

OPT3
FCTMOD, OPTI

FCTMOD, OPT2

FCTMOD, OPT3
Used internally in random number generator

$\mathrm{OMB} 3=1 \cdot-\mathrm{B} 3$

OMTAU $=1 .-\mathrm{TAU}$

OMTAUI $=1 . /$ OMTAU
Function variable. Scaling equation (scaled cost variable) used if the cost variable is temperature dependent, and temperature is a physical uncertainty.

Function variable. Scaling equation (scaled variable) used if the cost variable is flow rate dependent and flow rate is a physical uncertainty.

Function variable. Scaling equation (scaled variable) used if the cost variable is well depth dependent, and well depth is a physical uncertainty. 
$(20,100)$ Read in as scenario conditional probability for each stage and uncertain variable for each scenario. The scenario probability is the product of all probabilities describing the ASCEND, TABLE scenario. EXPEC2, PDF (1000) Equivalent to scenario probability, PROB. In CALL TABLE, EXPEC2

P1

P2

PPRICE DATA9

PRICE

DATA9

P RO

PROB

DATA2

MAIN, INPUT SELECT, OUT 1 OUT2

FCTMOD, OPT1

FCTMOD, OPTI

INPUT, MAIN

INPUT, MAIN

GSCALE OPT2, OPT3, OPT4 OPT2, OPT3, OPT4 GSCALE, RCOST GSCALE, RCOST

PROFIR DATA7 MAIN, OUTI OUT2

PROFIT DATA8 MAIN, GSCALE OUT1, OUT2 RCOST

PS

PSUM
GSCALE

GSCALE
Represents the scenario value of an input physical variable.

Represents the reference scenario value of an input physical variable.

Read in, Penalty price in mills per $\mathrm{kWh}$

Read in, Energy price in mills per kWh.

In CALL RCOST, equivalent to PROFIT. $\operatorname{PROFIT}(\mathrm{NN})=$ PRO.

(1000) (NSCEN) Calculated in INPUT as the product of the JJ probabilities describing each scenario. Used in SELECT as part of the criteria to select a scenario. In OUTl, OUT2 used in CALL ASCEND.

Reference value of profit.

(300) Present value of profit. In CALL GSCALE statement PROFIT = REV - CCL.

(10) $\operatorname{PS}(J X I)=\operatorname{PSUM}(J X I, M M)$. In CALL $\mathrm{RCOST}$.

$(11,300)$ Cumulative sum of scenario variables, elapsed time. 
PSUMR

PWR

R

RCAP

DATA7

$\begin{array}{lll}\text { RCCL } & \text { DATA7 } & \begin{array}{l}\text { MAIN, OUT } 1, \\ \text { OUT2 }\end{array} \\ \text { RCEL } & \text { DATA7 } & \begin{array}{l}\text { MAIN, OUT } 1, \\ \text { OUT2 }\end{array}\end{array}$

RENROY

RENSUM

RENTS

REV

RMAX

RMIN
MAIN, OUT 1, OUT2

MAIN, GSCALE

RCOST, OUT I

OUT2

RANNUM

OUT2

RCOST

RCOST

$\mathrm{R} \cos \mathrm{T}$

$\mathrm{RCOST}$

ASCEND, HISTOG

ASCEND, HISTOG
(11) In CALL GSCALE. PSUMR( JX+1) $=\operatorname{PSUMR}(J X)+\operatorname{TPR}(J X)$

Total time of time dependent stages of reference scenario. At stage $\mathrm{J}$, $\operatorname{PSUMR}(J)=$ cumulative time of prior stages. In RCOST list, equivalent to PS.

$\operatorname{PWR}=\operatorname{PSUM}(J X, M M)-\operatorname{PSUMR}(J X) \cdot$ Scenario value minus reference values.

In CALL RANNUM list. Random number generated, then ordered.

Reference upfront capital investment.

Reference life cycle cost.

Reference levelized energy cost.

The sum of TRENTS and ROYLT.

The sum of discounted rents, calculated for each stage.

$\operatorname{RENTS}(\mathrm{JX})=$ RENSUM.

Revenue REV = PRICE*E*

(GD**PSUMR $(\mathrm{J})) *(1 .-G D *(\operatorname{TPR}(\mathrm{J})+$ 1.) $) /((1 .-G D) * 1000000)$.

RMAX $=$ CEL (NSCEN)*1000. Maximum levelized energy cost. Used to represent maximum value of all output variables.

RMIN $=\operatorname{CEL}(1) * 1000$. Lowest levelized energy cost times 1000. Used to represent the minimum value of all output variables. 
ROCS

ROPS

ROY

$\begin{array}{ll}\text { DATA1 } & \text { MAIN, INPUT } \\ & \text { GSCALE, RCOST } \\ & \text { OUT1, OUT2 } \\ & \text { FCTMOD }\end{array}$

ROYLT

RTEMP

RVAL

RVECT

SELEC

STDV

$\mathrm{T}$

TAU

$\begin{array}{ll}\text { DATA1 } & \text { MAIN, INPUT } \\ & \text { SELECT, RCOST } \\ & \text { OUT1, OUT2 } \\ & \text { FCTMOD }\end{array}$

TCAP

TCCL

TCEL
INPUT

INPUT

RCOST

RANNUM

FCTMOD, OPTI OPT2, OPT3, OPT4

SELECT

MAIN

OUT1, OUT2

EXPEC1, EXPEC2

GOPT

GSCALE

GSCALE

GSCALE

HISTOG
Read in, Rate of Return on Common Stock

Read in, Rate of Return on Preferred Stock

Read in, Royalty Rate

Royalty payments, ROY*REV.

Used to order $R(I)$.

Cost variable scaled by the required physical parameter.

(300) In CALL RANNUM from SELECT. Equivalent to $R$ in RANNUM.

Logical. Decide whether to evaluate all scenarios or choose some

Standard deviation of the relevant output variable. In CALL EXPECl, EXPEC2.

In GOPT list. Equivalent to TSTAGE.

Read in, Federal Tax Rate

In CALL 'DOST, equivalent to CAP.

In CALL RCOST, equivalent to CCL.

In CALL RCOST, equivalent to CEL.

Used in calculating frequency interval for plotting histogram. 


\begin{tabular}{|c|c|c|c|}
\hline TIR & DATA2 & $\begin{array}{l}\text { INPUT, MAIN } \\
\text { RCOST }\end{array}$ & $\begin{array}{l}(10,5,10) \text { Read in, } \operatorname{TIR}(\mathrm{JX}, \mathrm{NX}, \\
\mathrm{KIX}) \text { Expenditure time, indexed for } \\
\text { stage, accounting type, and time } \\
\text { independent cost. In CALL RCOST. }\end{array}$ \\
\hline TITLE & & $\begin{array}{l}\text { INPUT, MAIN } \\
\text { OUT 1, OUT2 } \\
\text { HIST, PDF } \\
\text { HISTOG }\end{array}$ & $\begin{array}{l}\text { (20) In CALL INPUT. First data } \\
\text { card read--title--fullcard. In } \\
\text { CALL OUT1, OUT2, HIST, HISTOG, PDF. }\end{array}$ \\
\hline TN & DATA3 & $\begin{array}{l}\text { MAIN, INPUT } \\
\text { GSCALE, RCOST } \\
\text { FCTMOD }\end{array}$ & $\begin{array}{l}\text { (5) Read in, } \mathrm{N} \text { separate } \\
\text { Accounting Lifetimes. In CALL } \\
\text { RCOST. }\end{array}$ \\
\hline TNI & & $\mathrm{RCOST}, \mathrm{PICDPF}$ & $\begin{array}{l}T N I=T N(N X) \text {. In CALL PICDPF, the NXth } \\
\text { Accounting Lifetime, indexed to } N .\end{array}$ \\
\hline $\mathrm{TP}$ & DATA3 & $\begin{array}{l}\text { MAIN, INPUT } \\
\text { GSCALE, FCTMDD }\end{array}$ & $\begin{array}{l}(20,1000) \text { Read in, Scenario } \\
\text { variable of time or physical } \\
\text { characteristic. }\end{array}$ \\
\hline TPR & DATA3 & $\begin{array}{l}\text { MA IN, INPUT } \\
\text { GSCALE, RCOST } \\
\text { FCTMOD }\end{array}$ & $\begin{array}{l}\text { (20) Read in, Reference variables, } \\
\text { one per stage and uncertain } \\
\text { variable. In RCOST list, equivalent to } \\
\text { TR. }\end{array}$ \\
\hline TR & & GSCALE & $\begin{array}{l}\text { (10) } T R(J X)=T P(J X, M M) \text {. In CALL } \\
\text { RCOST, equivalent to TPR. Has a time or } \\
\text { physical characteristic definition. }\end{array}$ \\
\hline TRENTS & & RCOST & Total rents; the sum of $\operatorname{RENTS}(J X)$. \\
\hline TSTA GE & & RCOST, GOPT & $\operatorname{TSTAGE}=\operatorname{TPR}(\mathrm{J}) \cdot \quad$ In CALL GOPT \\
\hline VAR & & EXPECl, EXPEC2 & $\begin{array}{l}\text { Variance of the relevant output } \\
\text { variables. }\end{array}$ \\
\hline $\mathbf{X}$ & & $\begin{array}{l}\text { PDF } \\
\text { HIST }\end{array}$ & $\begin{array}{l}\text { Used as scaling factor for frequency. } \\
\text { Used internally }\end{array}$ \\
\hline XCEL & & $\mathrm{PDF}$ & $\begin{array}{l}X C E L=(R M I N+X I N T * X K K) * 1.0001 \text {. Used in } \\
P D F \text { to define the length of each } \\
\text { consecutive frequency interval. }\end{array}$ \\
\hline
\end{tabular}


XINT $=($ RMAX-RMIN) $/$ FLOAT(NINT). The length of the output intervals used to plot the probability density functions.

FLOAT(KK) 


\section{A.3 GEOTHERMAL PROBABILISTIC COST MODEL INPUT DESCRIPTION}

The description of the data set will follow the order of input. Much of the input data has interdependencies; that is, if one number is changed, then other numbers must also be changed, added, or omitted. For example, if the discount rate is input directly, then certain other financial parameters do not need to be input at all.

In what follows, a card set number, used only for purposes here, begins an input data subset. It is followed by the name of each variable to be listed in that section. Following each variable name is the format of that variable, and the number of columns it occupies. Then a brief explanation is given if it is necessary to expand beyond the definition given in the variable definition section of the report.

Card Set 1

$$
\text { TITLE 20A4 2-80 }
$$

The TITLE will identify the data set in any way the user wishes. Leave the first column blank.

Card Set 2
NINT
15
$1-5$

The output will be plotted in the form of histograms. The cost axis will be divided into NINT+2 intervals.

Card Set 3

ROY F20.8 $1-20$

The royalty rate is input as a decimal number.
KOPT
15
$21-25$

This is input as integer 1 in column 5 if a profit will be taken into account. Otherwise, enter 2 to indicate a regulated utility. 
Card Set 4
PPRICE
F20.6
$1-20$

The penalty price is input in mills/kWh.

$\begin{array}{lll}\text { PRICE } & \text { F20.6 } & 21-40\end{array}$

The contract price for delivered energy is input in mills $/ \mathrm{kWh}$.

$\begin{array}{lll}\text { TCON } & \text { I5 }\end{array}$

Card Set 5

$\begin{array}{lll}\text { TAU } & \text { F20.8 } & 1-20\end{array}$

The tax rate is input as a decimal (e.g., $46 \%=.46)$.

B1 F20.8 $21-40$

The state tax rate is input as a decimal.

$\begin{array}{lll}\text { B2 } & \text { F20.8 } & \text { 41-60 }\end{array}$

The local tax rate is input as a decimal.

$\begin{array}{lll}\text { B3 } & \text { F20.8 } & 61-80\end{array}$

Input as a decimal.

Card Set 6

$\begin{array}{lll}\text { E } & \text { F20.8 } & 1-20\end{array}$

The annualized energy output is input in watt hours.

$\begin{array}{lll}G & \text { F20.8 } & 2 l-40\end{array}$

The rate at which energy prices will escalate is input as 1 plus the decminal percent.

$\begin{array}{lll}\text { DPL } & \text { F20.8 } & 41-60\end{array}$

The depletion allowance rate is input as a decimal.

Card Set 7

$\begin{array}{lll}\text { NSCEN } & 15 & 1-5\end{array}$

This specifies the number of scenarios input. If NSCEN is greater than 1000, the dimensions of PROB and TP must be increased. 
NSELEC

This specifies the number of scenarios to be evaluated. If NSELEC is greater than 300, a large number of variables in several subroutines need to be re-dimensioned.
$\mathrm{N}$
15
$11-15$

This specifies the number of different accounting life times to be used. Individual cost accounts are grouped according to accounting type within each stage. There must be at least one accounting type.

IOPT $15 \quad 16-20$

If there is an integer 1 in column 20 (columns 16-19 blank), straight line depreciation is used. Otherwise, sum of years digits is used.

Card Set 8
D
F20.8
$1-20$

The discount factor can be input directly, or calculated. If it is to be calculated by the program, this card must be input as 0.0 .

Card Set 9

DINT

F20.8

$1-20$

If $D=0.0$, then DINT is input as a decimal used in the calculation of the discount factor. If $D=0.0$, then DINT, ROCS, ROPS, DER, and CSPSR are left out.
ROCS
F20.8
$21-40$

This is the return on common stock, input as a decimal. See note under DINT •
ROPS
F20.8
$41-60$

This is the return on common stock, input as a decimal. See note under DINT . 
DER

F20.8

$61-80$

This is the return on common stock, input as a decimal. See note under DINT.

Card Set 10

$\begin{array}{lll}\text { CSPSR } & \text { F20.8 } & 1-20\end{array}$

This is the return on common stock. input as a decimal. See note under DINT .

Card Set 11

$\mathrm{J}$

JP
15

15
$1-5$

$6-10$

$J$ indicates the number of stages and $J P$ the number of physically uncertain variables. Note that while JP refers to the number of physical uncertainties, it is possible to have a specific time uncertainty that is not the length of a stage, and would show a cost effect to be evaluated by a user supplied $O P T_{n}$ routine.

Card Set 12

PCHAR (JPX, JPZ) 20A4 2-80

JPX $=1, J P$. This set of cards lists the titles of the physical

characteristics which are uncertain. There is one title per card and there must be one card title per physical variable, and they must be in the same order as the physical variables are input.

Card Set 13

$M(J X) \quad 16 I 5 \quad$ Every 5 spaces

$J X=1, J$. The cost accounts are to be put in by time intervals for each stage. The number of intervals is not necessarily equal to the number of years in the reference or any other scenario. $M(J X)$ indicates into how many intervals each stage is divided. 
Card Set 14

TN (I) $\quad 4 F 20.8 \quad$ Every 20 spaces

$I=1, N$. This gives the length of each accounting lifetime. The first, TN(1), must be $I$ year, i.e., accounts that are expensed. The rest must be in the order that will be referenced later; i.e., $\operatorname{TN}(2)$ is "Accounting Type 2", and so on.

Card Set 15

$\operatorname{CON}(\mathrm{I}) \quad 4 \mathrm{~F} 20.8 \quad$ Every 20 spaces

$I=1,6$. CON is dimensioned 6 for convenience. It can be changed at the user's need. The $\mathrm{CON}(\mathrm{I})$ are site specific scaling parameters used in the OPTn function subroutines to show the effect on cost of physical uncertainties. The user can supply his own OPT equations as well as the $\operatorname{CON}(I)$ 's. In the temperature equation, $\operatorname{CON}(I)$ has been used to refer to ambient temperature in degrees Centigrade. In the well depth equation, $\operatorname{CON}(6)$ refers to a constant in the literature from which the equation was obtained.

Card Sets $16-26$

Note here that blocks of data are read in, then repeated in blocks of the same order:

For each stage:

$\mid$

$\mathrm{KD}(\mathrm{JX}, \mathrm{NX})$

For each $\mathrm{KD}(\mathrm{JX}, \mathrm{NX})=0$ of each accounting type:

$\longrightarrow\left[\begin{array}{l}\text { ADTITL } \\ \mathrm{CDR}(J \mathrm{JX}, \mathrm{MX}, \mathrm{NX}, \mathrm{KDX})\end{array}\right.$

$A D(J X, N X, K D X)$

$\mathrm{KI}(\mathrm{JX}, \mathrm{NX})$ 
For each $\mathrm{KI}(J \mathrm{X}, \mathrm{NX}) \quad 0$ of each accounting types:

$\left\{\begin{array}{l}\operatorname{CIR}(J X, N X, K I X) \\ \operatorname{TIR}(J X, N X, K I X) \\ \operatorname{AI}(J X, N X, K I X) \\ \operatorname{AITITL}\end{array}\right.$

(Please see the example card layout following the descriptions below.)

Card Set 16

$\mathrm{KD}(\mathrm{JX}, \mathrm{NX}) \quad 1615 \quad$ Every 5 spaces

$\mathrm{NX}=1, N$. This card is entered at the beginning of data for each stage. One number for each accounting type specifies how many accounts will be read in.

Card Set 17

ADTITL 20A4 2-80

A title card is required for each cost account. Leave the first column blank, and use only one card. The title is read, then the cost account, and repeated until all cost accounts of a specific accounting type and stage are read.

Card Set 18

$\mathrm{CDR}(\mathrm{JX}, \mathrm{MX}, \mathrm{NX}, \mathrm{KDX}) \quad 4 \mathrm{~F} 20.8 \quad$ Every 20 spaces

CDR are the time-dependent cost accounts. Each account consists of $M(J X)$ dollar figures, with the dollar amounts entered in thousands. A title card is read, then the cost data over and over again for all $\mathrm{KD}(\mathrm{JX}, \mathrm{NX})$ accounts. In describing the Reference Scenario via these Reference cost accounts, adjustments must be made for the case when costs are in annual amounts but the length of the interval is other than a year (i.e. the number of intervals is other than the number of years in the reference scenario stage). 
Card Set 19

$\mathrm{AD}(\mathrm{JX}, \mathrm{NX}, \mathrm{KDX}) \quad$ 4F20.8 $\quad$ Every 20 spaces

Following each complete set of cost accounts (i.e., for a given stage and

a given accounting type) and their titles, the escalation rates for each account are entered as 1 plus the escalation rate in decimal form. This is one escalation rate per account, and it remains fixed for the life of the project.

Card Set 20

$\mathrm{KI}(\mathrm{JX}, \mathrm{NX}) \quad 1615 \quad$ Every 5 spaces

$N X=1, N$. This card identifies the number of time dependent cost accounts per accounting type for the JXth stage, and follows all data referring to time dependent cost.

If $\mathrm{KI}(\mathrm{JX}, \mathrm{NX})=0$, then the cards for CIR,TIR,AI, and AITITL (Card Sets 2l, 22,23 , and 24) are skipped.

Card Set 21

$\operatorname{CIR}(J X, N X, K I X) \quad 4 F 20.8 \quad$ Every 20 spaces

CIR are the independent cost accouints. Each account consists of a single dollar amount. If $\mathrm{KI}(\mathrm{JX}, \mathrm{NX}) \quad 0$, there must be $\mathrm{KI}(\mathrm{JX}, \mathrm{NX})$ cost accounts for the given stage and accounting type.

Card Set 22

$\operatorname{TIR}(\mathrm{JX}, \mathrm{NX}, \mathrm{KIX}) \quad$ 4F20.8 $\quad$ Every 20 spaces

TIR identifies in which interval a time-independent cost occurs. There are $\mathrm{KI}(\mathrm{JX}, \mathrm{NX})$ numbers per each card set.

Card Set 23

$\mathrm{AI}(\mathrm{JX}, \mathrm{NX}, \mathrm{KIX}) \quad 4 \mathrm{~F} 20.8 \quad$ Every 20 spaces

There is one escalation rate per cost account. 
Card Set 24

AITITL 20A4 2-80

There is one separate title card per time independent accounts. All title cards for a given stage and accounting type appear together, following the rest of the time independent cost account data. They must be in the same order as the cost accounts they are identifying.

Card Set 25

$\operatorname{MOD}(J X, N X, K D X, I X X) \quad 1615 \quad$ Every 5 spaces

There is one number for each account identifying whether a time dependent account is dependent on a physical variable. The numbers entered are 0 if there is no dependency on the physical variable, or 1 through 4 depending on which OPTn, $N=1,2,3$, or 4 , equation relates that physical uncertainty to the cost account. There is one separate set of $\mathrm{MOD}(\mathrm{JX}, \mathrm{NX}, \mathrm{KDX}, \mathrm{IXX})$ cards for each physical uncertainty, each set completely read in before the set for the next physical uncertainty is read. Within each set, there is a separate card(s) for each stage and accounting type for which cost data was entered. These cards must be listed in the same order as the cost accounts. Each card contains the identifying MOD numbers for all cost accounts for that stage and accounting type.

Card Set 26

MOI (JX,NX, KIX, IXX) $1615 \quad$ Every 5 spaces

See the note on MOD (JX,NX,KIX,IXX). The MOI do exactly the same thing for all time independent cost accounts. The MOI cards for a given stage and accounting type follow the MOD cards for the same stage and accounting type. (Thus the MOI cards are "sandwiched" in between the MOD cards.) This is done for the first physical uncertainty, and then the process is repeated for the second physical uncertainty, and so on. 
Card Set 27

$\operatorname{TPR}(\mathrm{JX}) \quad$ 4F20.8 $\quad$ Every 20 spaces

$J X=I, J J$. The Reference Scenario stage length times and values for physically uncertain variables are entered.

Card Set 28

$\mathrm{TP}(\mathrm{JX}, \mathrm{I}) \quad$ 4F20.8 $\quad$ Every 20 spaces

The data for each scenario is entered with stage time data and physically uncertain variable data given in exactly the same order as the Reference Scenario data they correspond to. Each card(s) describes a complete scenario, with NSCEN scenarios read in. The program will assign an identifying number from 1 to NSCEN to each scenario, based on the order in which it is read in.

Card Set 29

$\mathrm{P}(\mathrm{JX}, \mathrm{I}) \quad$ 4F $20.8 \quad$ Every 20 spaces

The probability of occurrence of each stage and physical characteristic is entered to exactly correspond in order of entry of the values of each scenario. For a given stage the probabilities of all the possible times must sum to 1 . Likewise, for a given physical variable, the probabilities of all the possible outcome values must also sum to 1 . As with the $\operatorname{TP}(J X, I)$, the program will identify the probabilities for each scenario with a number from 1 to NSCEN. 
A.3.1 Example Card Layout

The order of cards is shown here for a fictional Stage 4. There are

3,1 , and 2 time-dependent cost accounts of the 1st, 2 nd, and 3 rd accounting type respectively. There are 2,1 , and 3 time-independent cost accounts of the 1st, 2nd, and 3rd accounting type respectively.

\section{STAGE 4}

$\mathrm{KD}(\mathrm{JX}=4, \mathrm{NX})$

$3 \quad 12$

ADTITL

$\operatorname{CDR}(\mathrm{JX}=4, \mathrm{MX}, \mathrm{NX}=1, \mathrm{KDX}=1$ )

ADTITL

$\operatorname{CDR}(\mathrm{JX}=4, \mathrm{MX}, \mathrm{NX}=1, \mathrm{KDX}=2)$

ADTITL

$\operatorname{CDR}(J X=4, M X, N X=1, K D X=3)$

$\mathrm{AD}(\mathrm{JX}=4, \mathrm{NX}=1, \mathrm{KDX})$

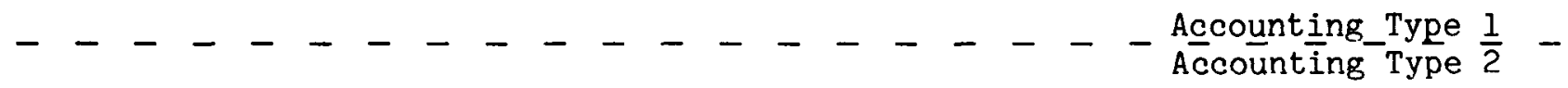
ADTITL

$\mathrm{CDR}(\mathrm{JX}=4, \mathrm{MX}, \mathrm{NX}=2, \mathrm{KDX}=1)$

$A D(J X=4, N X=2, K D X)$

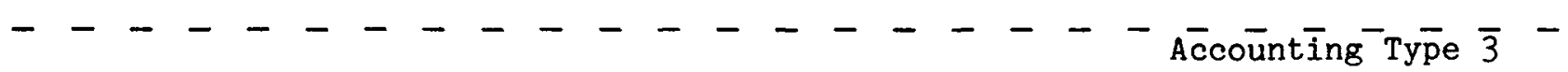

ADTITL

$\operatorname{CDR}(\mathrm{JX}=4, \mathrm{MX}, \mathrm{NX}=3, \mathrm{KDX}=1)$

ADTITL

$\mathrm{CDR}(\mathrm{JX}=4, \mathrm{MX}, \mathrm{NX}=3, \mathrm{KDX}=2)$

$\mathrm{AD}(\mathrm{JX}=4, \mathrm{NX}=3, \mathrm{KDX})$ 
$\mathrm{KI}(\mathrm{JX}=4, \mathrm{NX})$

CIR ( JX $=4, N X=1, K I X)$

$\operatorname{TIR}(J X=4, N X=1, K I X)$

AI $(J X=4, N X=1, K I X)$

AITITL

AITITL

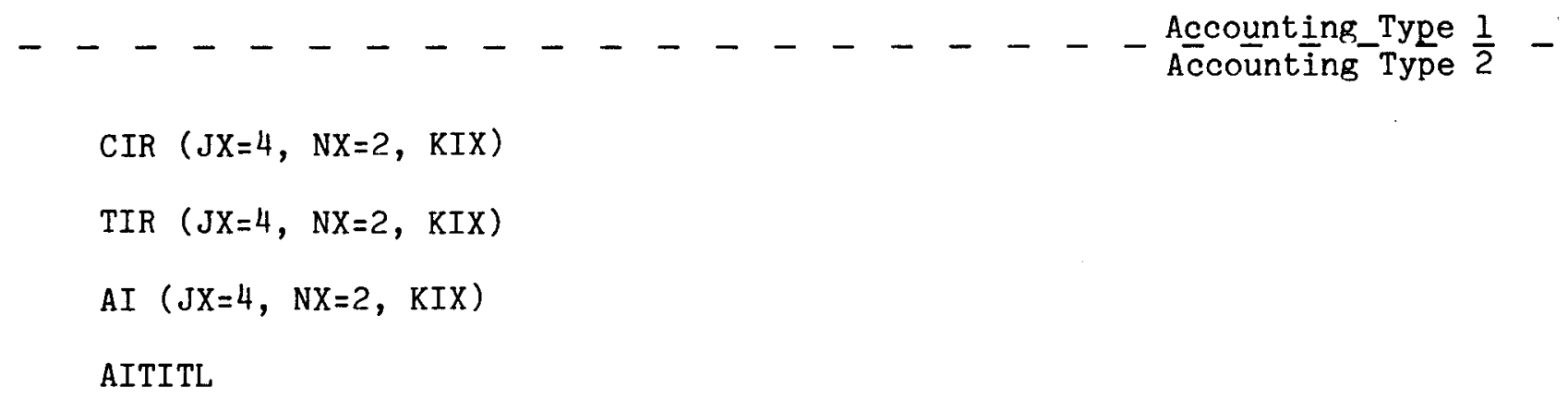

$\operatorname{CIR}(J X=4, N X=3, K I X)$

$\operatorname{TIR}(\mathrm{JX}=4, \mathrm{NX}=3, \mathrm{KIX})$

AI $(J X=4, N X=3, K I X)$

AITITL

AITITL

AITITL

The data for each stage is put in as one block complete in itself, as shown above. These blocks occur in the same order as the stages. (If $\mathrm{KD}(\mathrm{JX}, \mathrm{NX})$ or $\mathrm{KI}(\mathrm{JX}, \mathrm{NX})$ is zero for any of the accounting types, $\mathrm{NX}$, then all the cards pertaining to that accounting type would be left out. They are included in the above scheme for completeness.) 
Following the last stage the MOD/MOI cards appear. (It is assumed here that there are 4 stages, JX, and 3 accounting types, NX.)

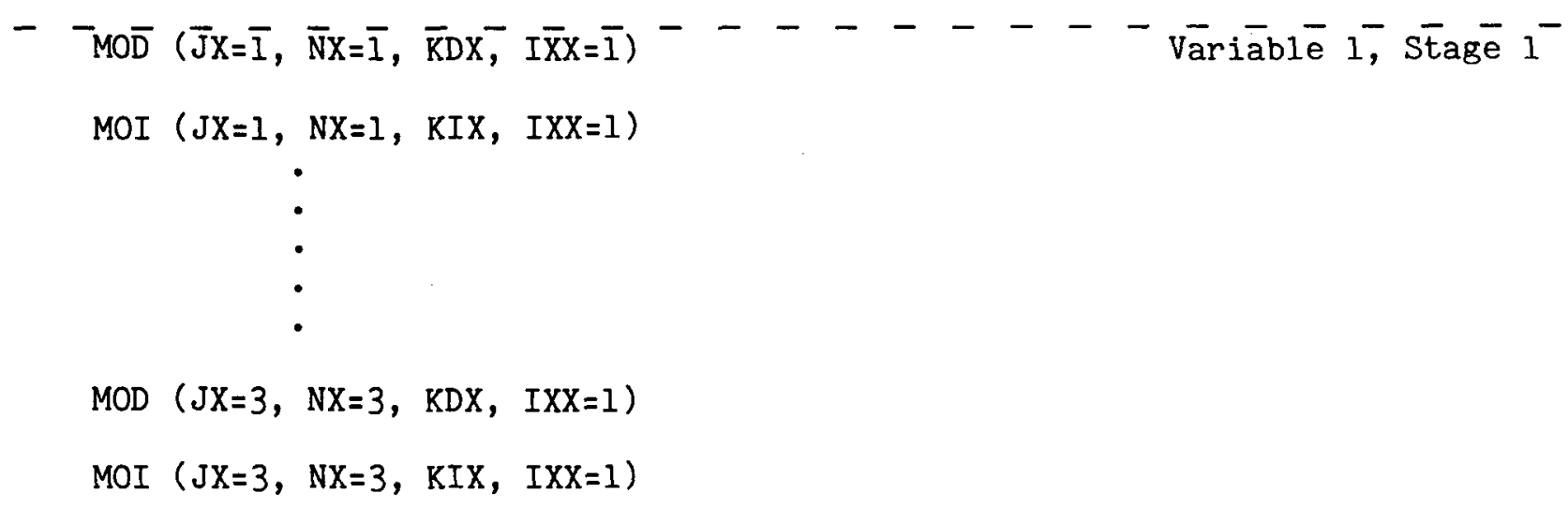


MOD $(J X=2, N X=2, K D X, I X X=2)$

MOI ( JX $=2, N X=2, K I X, I X X=2)$

The MOD/MOI cards are input in blocks for each uncertain physical variable $(\operatorname{IXX}=l, n)$. The block for the first variable occurs, and the block for the second variable, and so on. If there are no cost accounts of a particular accounting type for a stage, then the MOD/MOI cards are left out for that accounting type in that stage. 
APPENDIX B

\section{CASH FLOW LEVELIZATION}

When we levelize a stream of cash flows $\{c(t)\}$ we construct a new stream $\{B(t)\}$ with the following properties:

a) $B(t)$ is of constant value for all $t$ either in real or nominal terms, depending on the type of levelization

b) The net present value of $\{c(t)\}$ equals the net present value of $\{B(t)\}$, or

$$
\sum_{t=0}^{N} C(t)(1+K)^{-t}=\sum_{t=0}^{N} B(t)(1+K)^{-t}
$$

where $K$ is the discount rate.

If there is positive inflation, the real levelized flow will increase over time in terms of nominal dollars in order to maintain a constant purchasing power. This case is shown in Figure B-1.

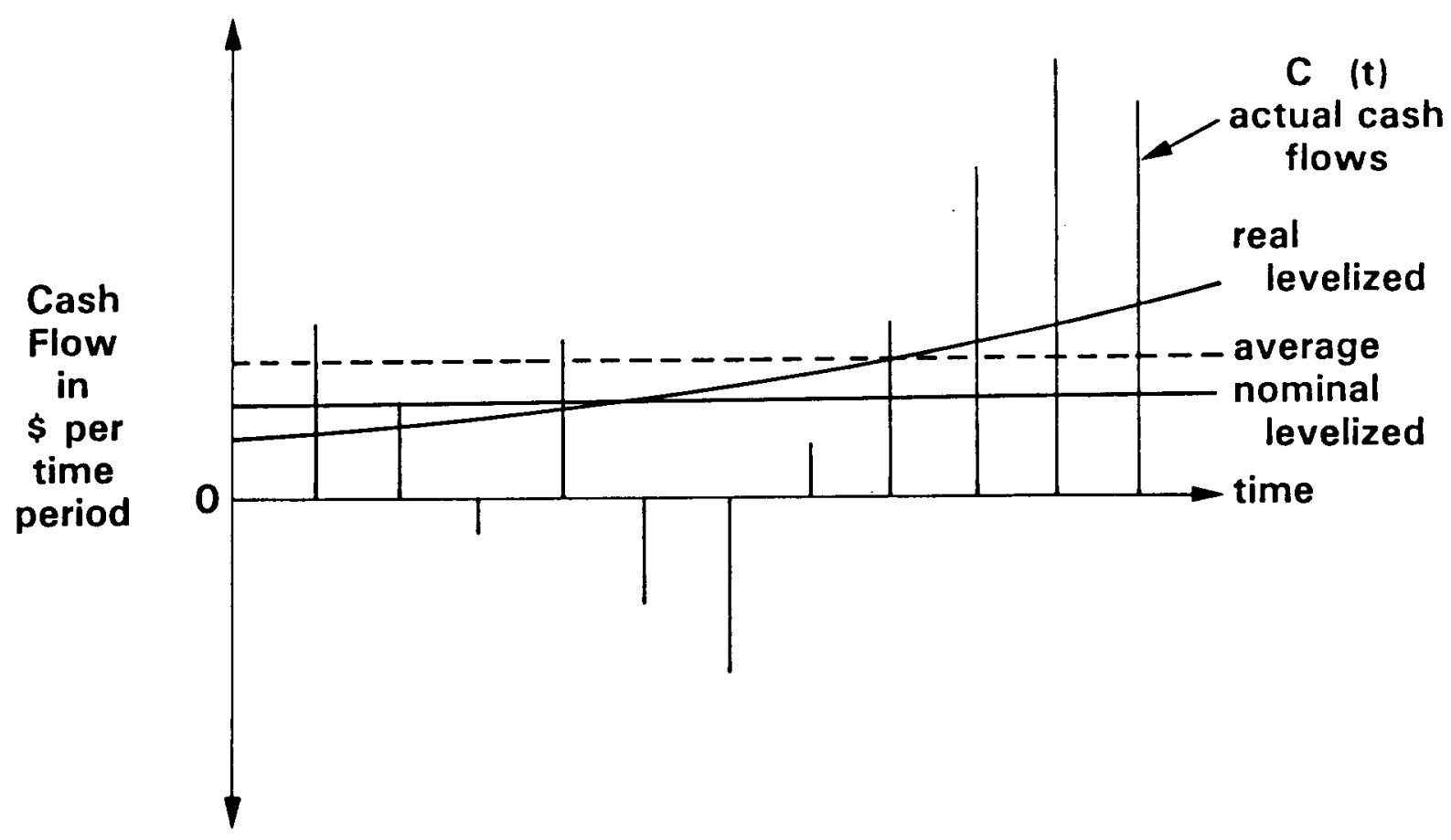

Figure B-l. Cash Flow Levelization 


\section{APPENDIX C}

\section{A BRIEF SURVEY OF THE THEORY OF INSURANCE}

Insurance and insurance type phenomena arise because some people are willing to accept the certain loss of a small sum (the premium) in preference to the small chance of a large loss and a large chance of no loss. A theoretical analysis of such phenomena should rightly begin by attempting to explain how people choose between alternatives involving risk. Although economic theorists have tried to explain such choices, such explanations had never been integrated with the theories that account for choices among riskless alternatives until the pristine effort by Friedman and Savage (Reference 19).

Such an attempt, however, led to a drastic revision of unreasonable belief in the concept of diminishing marginal utility. For they showed that such an assumption was wholely redundant in the explanation of insurance or gambling.

There they defined the expected utility of an alternative involving risk, namely $A$, that has a chance $\alpha$ of an income $I_{l}$ and the complementary probability of an income $I_{2}$, as

$$
\bar{U}(A)=\alpha U\left(I_{1}\right)+(1-\alpha) U\left(I_{2}\right)
$$

and consequently if $I^{*}$ is the certain income that has the same utility as $A$ (see Figure $C-1$ ), i.e., $U\left(I^{*}\right)=U(A)$, then the maximum amount he would be willing to pay to insure himself against the uncertainty would be:

$$
\bar{I}-I^{*} \text { where } \bar{I}=\alpha I_{1}+(1-\alpha) I_{2}
$$

Figure C-1

Expected Utility and Certain Equivalent

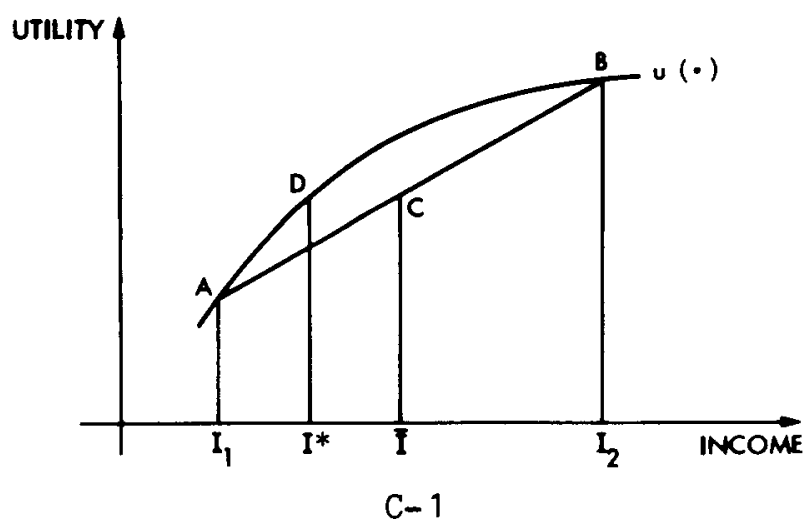


Their paper thus set the basis for an expected utility maximization analysis for insurance type phenomena--an approach buttressed by the arguments of Von Neumann and Oskar Morgenstern (Reference 16).

This was in 1948. Several years later in 1976, Benjamin Eden (Reference 5) showed the converse in a rigorously elegant paper. Assuming the expected utility hypothesis he showed that $U^{\prime \prime}<0$ is a sufficient but not a necessary condition for insurance type pheonomena. He proved that people will eliminate future risk by insurance and create the desired (if it exists) present risk by gambling. In fact, doing so makes everyone better off.

Having delved on the fundamental assumption leading to insurance theories, we shall proceed to the theories themselves. But before doing so, let us identify some features of current insurance firms so that from the firms we can continue to the theory of their functioning.

It was pointed out by Marshall (Reference 7) that it is mainly because of these features that insurance companies do not insure catastrophies. The features being:

(1) Reserves: He defines it thusly: If $\mathrm{z}$ is the ratio of reserves to total liability, $\theta$ the probability of loss $\mathrm{L}$, and if there are $n$ people, with $\mathrm{k}$ losses a year, then the firm is ruined if $\mathrm{KL}>\mathrm{n} \theta \mathrm{L}+\mathrm{nLz}$ and since by the Weak Law of Large Numbers (WLLN), for a fixed $z>0$,

$$
P \lim k / n=\theta \text {, }
$$

economies of pooling reserves exists whenever an increase in $n$ tends to concentrate $\mathrm{KL} / \mathrm{n}$ around $\theta \mathrm{L}$ as $\mathrm{n}$ increases. In other words, he showed that there is no economy in pooling resources, and hence no role for insurance if WLLN does not apply. 
(2) Mutuality: under mutuality each person's consumption depends upon other's losses through dependence on the aggregate income level. Thus, in this case, insurance companies merely act as brokerages that exchange appropriate bundles of claims between individuals.

Most insurance companies work on one of these two principles, mainly the former. Marshall adds that catastrophes involve interdependence of risk and hence rule out the WLLN rendering insurance under the reserved principle impossible.

In all of the theories to follow, therefore, interdependence of risk is assumed away, and with stochastically independent risks across individuals, we can talk of functioning insurance firms under the referred principle.

\section{THE THEORY OF INSURANCE AND OPTIMALITY UNDER INSURANCE}

Perhaps it is apt here to start by mentioning Pauly's paper (Reference 8) which, though not the first one renders a lucid discussion on the theory of insurance. Pauly, Arrow (Reference 1) and Johnson (Reference 6) have together provided sufficient literature on the theory of and optimality under insurance.

Their simplest form (Pauly's) has a 2-state model in which individuals face a possible loss of a fixed amount L, and protects himself by buying insurance, $\mathrm{X} \leq \mathrm{L}$ and engages in an activity $\mathrm{z}$ which can reduce the probability of the loss.

Thus with

$$
\frac{\partial \overline{\mathrm{U}}}{\partial \overline{\mathrm{z}}}<0
$$

and assuming

$$
\begin{gathered}
\frac{\partial z}{\partial x} \leq 0 \\
\text { we have } \frac{\partial \pi}{\partial x_{i}} \geq 0
\end{gathered}
$$


Characteristic of this model (and a truth in real life) is the fact that,

$$
\left.\frac{\partial P_{i}}{\partial z_{i}}\right|_{x_{i}}=x_{i}^{*}=0
$$

which is the essence of moral hazard, a problem well defined by both Pauly and Johnson, i.e., under moral hazard, the insurance induces the individual to alter his value of $z_{i}$ since $\pi_{i}=\pi_{i}\left(z_{i}\right)$.

$$
\begin{aligned}
& \text { And so } \frac{\partial \pi_{i} x_{i}}{\partial z_{i}} \neq 0 \\
& \text { While }\left.\frac{\partial P_{i}}{\partial z_{i}}\right|_{x_{i}}=x_{i}^{*}=0
\end{aligned}
$$

Pauly makes an attempt though to provide a theoretical solution to the problem of moral hazard. He begins by envisioning an individual to buy insurance by solving a two-stage problem.

For an initial wealth if he is indeminified $x_{i}, s_{i}^{0}$, and if expected utility can be given by:

$$
E U=\left(1-\pi\left(z_{i}\right)\right)-u\left(s_{i}^{0}-z_{i}-p_{i}\right)+\pi\left(t_{i}\right) u\left(s_{i}^{0}-z_{i}-p_{i}+x_{i}-L\right)
$$

he can be looked upon as optimizing EU with respect to $z_{i}$ first and then gets $z_{i}^{*}\left(x_{i}\right)$. Next he optimized EU with respect to $x_{i}$.

If $z_{i}$ is observable by the insurer then the insured would set $x_{i}=L$ and choose that level of $z_{i}$ such that

$$
\frac{\partial \pi}{\partial z_{i}}=1
$$

However, $z_{i}$ is unobservable. What is in fact observable is $x_{i}$. (Spence and Zeckhauser (Reference 10) go into greater detail.) Then assuming $\pi_{i}=\pi_{i}\left(x_{i}\right)$, the price of $x_{i}=p\left(x_{i}\right)$, i.e., the premium for $x_{i}$ is given by

$$
\frac{\partial p}{\partial x_{i}}=\pi+\frac{\partial x}{\partial x}
$$


At this point, Pauly shows that in the case of competitive

equilibrium, given the assumptions, the price of insurance per unit purchased $(=p)$ is a constant. Zero profit conditions demand,

$$
p=\frac{\sum \pi_{i} x_{i}}{x_{i}}=\pi
$$

Since $x_{i}$ is the same given $p$

$$
<\pi+x \frac{\partial \pi}{\partial x}
$$

and hence in competitive equilibrium there is an over production of insurance. Further, in the competitive model

$$
\frac{d p}{d x}=p=\pi
$$

which means $x=L$. Hence a person who buys any insurance at all buys full coverage.

While Pauly proves that in the presence of moral hazard, $x=L$, Arrow shows why such a state is suboptimal. Thus, Pauly concludes that for "rational" decisions, the individual's premium must vary as much as possible with his expected loss. That is to say, his recommendations to tide over moral hazard is to provide public provisions that either:

(a) require the individual to buy as much insurance as he would have under optimality or,

(b) force him to declare his total purchases $x_{i}$ to every firm from which he buys insurance.

Adverse Selection: This is another problem well formalized by Pauly (Reference 8). Under adverse selection there exists two indistinguishable risk classes $\pi^{G}$ and $\pi^{B}$ such that

$$
\pi^{\mathrm{G}}>\pi^{\mathrm{B}}
$$

If they were distinguishable, they could be charged prices under competitive equilibrium 


$$
p^{* B}=\pi^{B} \text { and } p^{* G}=\pi^{G}
$$

However, since they are supposed to be indistinguishable, let there be a price $p_{E}$ charged to all. Clearly under zero profit conditions $p_{E}$ is the lowest (an aspect well dealt by Johnson 6 ) amount that satisfied,

$$
p_{E}=\frac{\sum_{B} \pi^{B} x^{B}\left(p_{E}\right)+\sum_{G} \pi_{x} x^{G}\left(p_{E}\right)}{\sum_{B} x^{B}\left(p_{E}\right)+\sum_{G} x^{G}\left(p_{E}\right)}
$$

Determination of $\mathrm{p}_{E}$ (Reference 8 and Reference 6) is the following: "There will be an excess of payments by type-G individuals over their actuarially fair premiums and a deficiency for type-B. As $p_{E}$ increases from $p^{* G}$, the sum of excess payments by type-G individuals will increase to a point, reach an interior maximum and decline, if demand curves are negatively sloped, while the sum of deficiencies in payment by type-B individuals will increase continuously as p falls. Equilibrium will be reached at a point when the sum of excess payments equals the sum of deficiencies. (See Figure C-2)

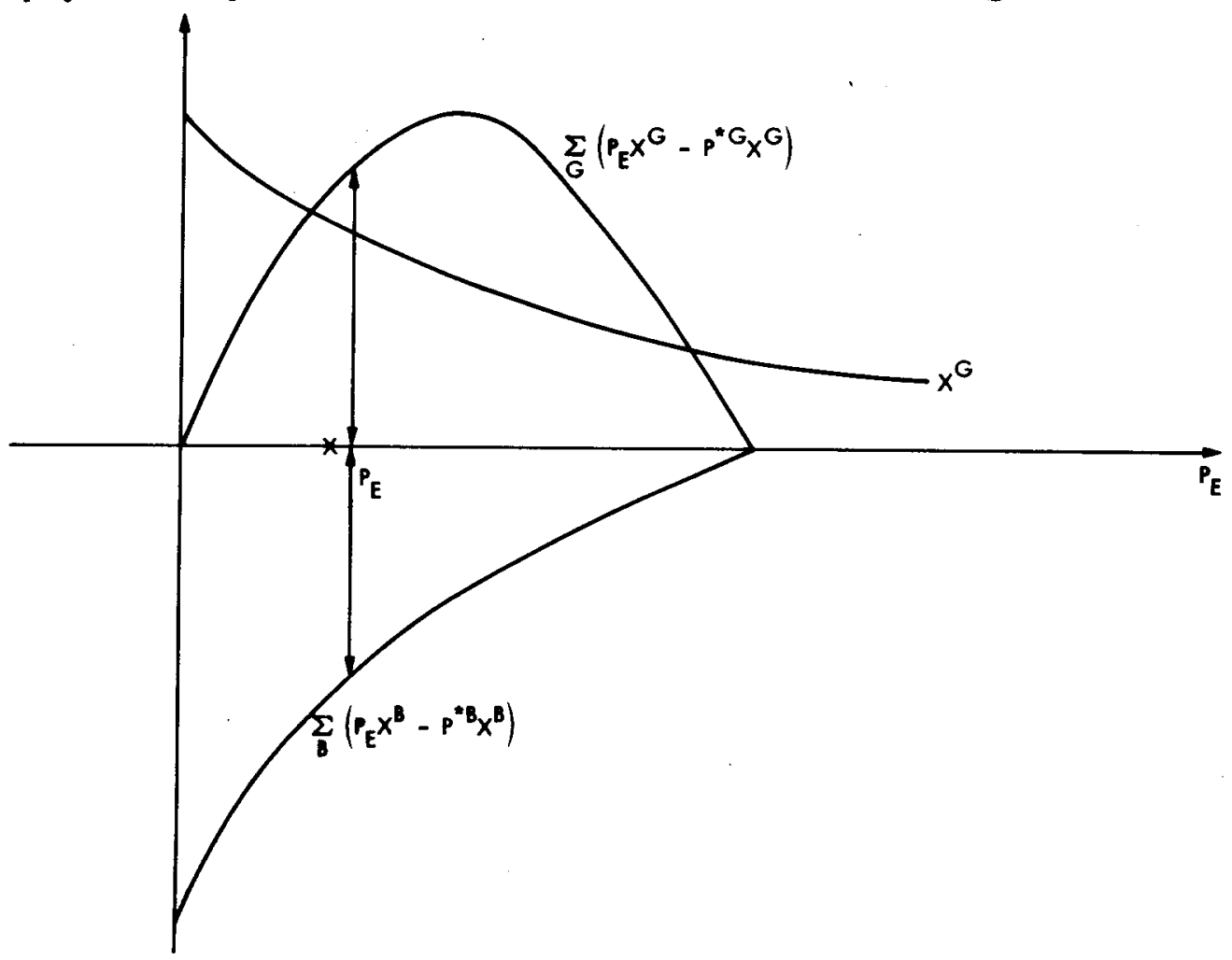

Figure C-2 
A solution to this problem of adverse selection is the following: If compulsory insurance $x_{0}$ must be purchased and if voluntary additional insurance could be bought, $P$ only shows that this will be bought only by type B people at an equilibrium price $\mathrm{p}^{\text {B }}$.

Thus here compulsory insurance laws tells the sellers that anybody who buys insurance over the mandatory quantity is a type B person and hence can be charged $p$ "B.

Compulsory insurance is useful here in contrast to the moral hazard case.

Note that the difference is mainly because in the moral hazard case $\frac{\partial \pi}{\partial x}$ is a continuously increasing function, and so information on $x$ is needed to be able to obtain $\pi(x)=P$. But in the adverse selection case, there are only 2 classes $\pi^{G}$ and $\pi^{B}$, and the problem is to be able to classify individuals. Thus, while compulsory laws could help in this classification, they provide no information on $x$.

Of several other concepts that attracted theoretical ventures, one deserving of mention is that of coinsurance, whose existence was first shown by Arrow (Reference 1). He proved that if both the insurer and the insured are risk averters, and there are only coverage costs, then,

$$
0<\frac{\mathrm{dx}(\mathrm{L})}{\mathrm{dL}}<1
$$

It has thus been acknowledged that in the operation of contingent claim markets (insurance markets are an example) it is necessary for the insurer (e.g.) to monitor actions taken by the insured that affect the probability and/or the magnitude of loss and hence the payoff function. In real world this may not be possible. A series of papers were written to view the real world functioning of these markets. Most noteworthy are those by Spence and Zeckhauser (Reference 10 and Reference 12). 
Spence and Zeckhauser show that if $u$ is the utility of wealth $w$, the act of nature is $n$, and if the individual action is $a, g(s)$ the payoff function over the information $s$ monitored, and $R-\gamma(n, a)$ is the return on individual action, $f(n)$ the distribution of $n$, then:

(a) If the insurer can monitor $\gamma$ directly the insurance scheme can operate like a traditional continent claims market. No adverse incentives, and full risk spreading is achieved.

(b) If the insurer can monitor $\mathrm{R}$, when it exists, adverse incentives problem can be warded off by stgructuring $g(r, a)$ to enforce appropriate $a=a^{*}$.

(c) However if $g()=g(a)$, then the individual alters a to increase $g(a)$, and although the insurer is aware of this adverse selection problem, he cannot overcome it leading to improper risk spreading.

Illustrating with the case of catastrophic illnesses, Zeckhauser (Reference 12) points out further problems in the establishment and efficient running of a contingent claims market for a coverage of such illnesses. His model shows how insurance, a mechanism to transfer money between states of the world to maximize expected utility, works to get efficiency. The process involves transfer of resources from states of high utility but low marginal utility to states of low utility but high marginal utility. Several variables like annuities do not satisfy this property.

Even assuming the market has been established, possible inefficiencies, other than those due to adverse selection and moral hazard, could be:

(i) Actuarial: i.e.; we ought not to consider the efficiency of the contingent claims payment solely on the context of the states in 
which they are paid. We should rather be seeing the patterns requested by individuals before his condition became known.

(ii) Ceremonial: where money is spent (as the frills in medical coverage) even though total welfare could be better off by conserving the expenditure

In general the literature dealing with real world contingent claims markets clearly show the incapacity of these markets to achieve the efficiency levels purported by related theory.

Equilibrium and Dynamics of Insurance and Reinsurance Markets:

Equilibrium in these markets have been studied just short of constructing a dynamic model that analyzes how companies would adjust their policies with changes in the market. The most illuminating work is by Arrow (Reference 19), Allais (Reference 18) which has been referred to in an exhaustive work by Borch (Reference 3). An axiomatic analyses, however, has been best done by Wilson (Reference 11).

Borch extends the Walras-Cassel model to markets where decisions are made under uncertainty, typically the reinsurance market. He posits that of the total claims to be paid by the ith insurance company is $x_{i}$, and if the treaty made by this company is $y_{i}\left(x_{i} \ldots x_{n}\right)$, then $y_{i}$ will depend only on $x_{1}+x_{2} \ldots x_{n}$, i.e.; the total amount of claims made on the industry. And hence that any pareto optimal arrangement is equivalent to a pool arrangement. Further if $F_{i}\left(x_{i}\right)$ is the risk distribution, then prices for these treaties $P=P(F)$, if they exist, do not lead to a pareto optimal arrangement under utility maximization, although to an equilibrium.

This result is in apparent contradiction to the results arrived at by Arrow and Allais. The reason is that Allais (dealing with the market for lotteries) assumes that the lotteries are indivisible and that there is only 
one kind of ticket, which has a normally distributed prize associated with it. As Borch points out "the problem will completely change if the model is generalized by the introduction of several kinds of tickets (prize is drawn from different probability distributions." The problem can then be analyzed in a way similar to Borch's if one accepts the Bernoulli hypothesis. Allais, however, emphatically rejects this hypothesis.

Arrow's model is more general. But the difference in the results noted above arises because his model has a price associated with every state of the world. The price being the same for all states that lead to the same amount of total claim payment. Instead Borch's model has one specific price of risk $P=P(F)$.

Wilson (Reference 11) studies the allocation of insurance policies in a competitive market when firms cannot distinguish between different risk classes of consumers. Unfortunately, it can be shown that in models with self selection, there can be no equilibrium if firms have static expectations. However, he later shows that it is possible to revise the expectation of firms in such a way that an equilibrium exists.

Conclusions:

In closing, it can be remarked that while existence of insurance and insurance type phenomena together with the problems entailed by their theoretical explanations, have been analyzed by scholars, removal of ineffiencies in the real world eludes formal expositions. It would also be interesting at this point to set up a dynamic model that analyses how insurance companies could alter their policies with changes in the market parameters. 
1 Arrow, K. J., "Uncertainty and Medical Care" AER Vol. 53, Dec. 1963 pp 941-73.

2 Arrow, K. J. and Lind, R. C., "Uncertainty and the Evaluation of Public Investment Decisions", AER, Vol. 60, 1970, pp 364-78.

3 Borch, Karl, "Equilibrium in a Reinsurance Market," Econometrica, V. 30 , No. 3, July 1962, 424-44.

4 Diamond, P. and McFadden, D. L., "Some Uses of the Expenditure Function in Public Finance." JPE, 3(1974), pp 3-21.

5 Eden, Benjamin, "The Role of Insurance and Gambling in Allocating Risk Over Time," JET, 16, (1976) pp 228-46.

6 Johnson, W., "Choice of Compulsory Insurance Schemes under Adverse Selection" Public Choice, 1978, pp 23-35.

7 Marshall, J. W., "Insurance Theory Reserves versus Mutuality." Economic Enquiry, V. 22, 1974, pp 476-92

8 Pauly, M. V., "Over Insurance and Public Provision of Insurance." OJE, Feb. 1974, pp 44-62.

9 Shavel, Steven, "Sharing Risks of Deferred Payment." JPE, V. 84, 1976, No. 1 , pp 161-68.

10 Spence, M. and Zeckhauser, R. J., "Insurance, Information, and Individual Action." AER, 1971, pp 380-91.

11 Wilson, Charles, "A Model of Insurance Markets with Incomplete Information JET, 16, (1977) pp 167-207.

12 Zeckhauser, R. J., "Coverage for Catastrophic Illness." Public Policy, Vol. 21, 1973, pp 149-72.

13 Zeckhauser, R. J., "Resource Allocation with PIP." AER Vol. 59 (1969), pp 546-52.

14 Arrow, K. J., Essays in the Theory of Risk Bearing. Chicago, Markham 1971.

15 Arrow, K. J., "The Role of Securities in the Optimal Allocation of Risk Bearing." RES, Apr. 1964, 31, pp 91-96.

16 Von Neumann, J. and 0. Morgenstern, Theory of Games and Economic Behavior. 2d ed., New York 1964.

17 Hirshleifer, J., "Investment Decisions under Uncertainty: Applications of State Preference Approach." QJE, May 1966, 80, pp 252-77. 
18 Allais, Maurice, "L 'Extension des Theories de l'Equilibre Economic General et ch rendement Social au Cas de rique." Econometrica, 1953, pp 269-290.

19 Friedman, M. and Savage, L. J., "The Utility Analysis of Choices Involving Risks." JPE, 56 (1948), 279-304.

20 Wilson, Robert, "Risk Measurement of Public Projects." Technical Report \#240, Jun. 1977, Institute for Math. Stud. in Soc. Sci., Stanford Univ. 